\title{
Mechanical and Microstructure Study of Nickel-Based ODS Alloys Processed by Mechano-Chemical Bonding and Ball Milling
}

\author{
Belachew N. Amare
}

Follow this and additional works at: https://researchrepository.wvu.edu/etd

\section{Recommended Citation}

Amare, Belachew N., "Mechanical and Microstructure Study of Nickel-Based ODS Alloys Processed by Mechano-Chemical Bonding and Ball Milling" (2015). Graduate Theses, Dissertations, and Problem Reports. 5094.

https://researchrepository.wvu.edu/etd/5094

This Dissertation is protected by copyright and/or related rights. It has been brought to you by the The Research Repository @ WVU with permission from the rights-holder(s). You are free to use this Dissertation in any way that is permitted by the copyright and related rights legislation that applies to your use. For other uses you must obtain permission from the rights-holder(s) directly, unless additional rights are indicated by a Creative Commons license in the record and/ or on the work itself. This Dissertation has been accepted for inclusion in WVU Graduate Theses, Dissertations, and Problem Reports collection by an authorized administrator of The Research Repository @ WVU.

For more information, please contact researchrepository@mail.wvu.edu. 


\title{
Mechanical and Microstructure Study of Nickel-Based ODS Alloys Processed by Mechano-Chemical Bonding and Ball Milling
}

\author{
Belachew N. Amare \\ Dissertation submitted \\ to the Benjamin M. Statler College of Engineering and Mineral Resources \\ at West Virginia University
}

in partial fulfillment of the requirements for the degree of

Doctor of Philosophy in

Mechanical Engineering

\author{
Bruce S.-J. Kang, Ph.D., Chair \\ Mary Anne Alvin \\ Jacky C. Prucz, Ph.D. \\ Xueyan Song, Ph.D. \\ Edward M. Sabolsky, Ph.D.
}

Department of Mechanical and Aerospace Engineering

\author{
Morgantown, West Virginia \\ 2015
}

Keywords: Ni-based ODS alloy; MCB process; Thermal cycle; Micro-channel cooling Copyright 2015 Belachew N. Amare 


\section{ABSTRACT \\ Mechanical and Microstructure Study of Nickel-Based ODS Alloys Processed by Mechano- Chemical Bonding and Ball Milling \\ Belachew N. Amare}

Due to the need to increase the efficiency of modern power plants, land-based gas turbines are designed to operate at high temperature creating harsh environments for structural materials. The elevated turbine inlet temperature directly affects the materials at the hottest sections, which includes combustion chamber, blades, and vanes. Therefore, the hottest sections should satisfy a number of material requirements such as high creep strength, ductility at low temperature, high temperature oxidation and corrosion resistance. Such requirements are nowadays satisfied by implementing superalloys coated by high temperature thermal barrier coating (TBC) systems to protect from high operating temperature required to obtain an increased efficiency. Oxide dispersive strengthened (ODS) alloys are being considered due to their high temperature creep strength, good oxidation and corrosion resistance for high temperature applications in advanced power plants. These alloys operating at high temperature are subjected to different loading systems such as thermal, mechanical, and thermo-mechanical combined loads at operation. Thus, it is critical to study the high temperature mechanical and microstructure properties of such alloys for their structural integrity.

The primary objective of this research work is to investigate the mechanical and microstructure properties of nickel-based ODS alloys produced by combined mechano-chemical bonding (MCB) and ball milling subjected to high temperature oxidation, which are expected to be applied for high temperature turbine coating with micro-channel cooling system. Stiffness response and microstructure evaluation of such alloy systems was studied along with their oxidation mechanism and structural integrity through thermal cyclic exposure. Another objective is to analyze the heat transfer of ODS alloy coatings with micro-channel cooling system using finite element analysis (FEA) to determine their feasibility as a stand-alone structural coating.

During this project it was found that stiffness response to increase and remain stable to a certain level and reduce at latter stages of thermal cyclic exposure. The predominant growth and adherent Ni-rich outer oxide scale was found on top of the alumina scale throughout the oxidation cycles. The FEA analysis revealed that ODS alloys could be potential high temperature turbine coating materials if micro-channel cooling system is implemented. 


\section{ACKNOWLEDGMENTS}

I am sincerely grateful to my advisor, Dr. Bruce Kang for his guidance, research support, and encouragement during this research project. I would like to thank my committee members, Dr. Jacky Prucz, Mary Anne Alvin, Dr. Xueyan Song, and Dr. Edward M. Sabolsky for their devoted support for my Ph.D. study. In particular, I would like to express my sincere gratitude to MAE Department and Dr. Victor Mucino for his mentorship, motivation, support, and inspiration throughout my study.

I would also like to thank all my colleagues at West Virginia University for their support. Especially Guo, Patrick, Raphael and Dumbi for their encouragement, research discussions, and valuable comments.

Finally, I would like to thank all my friends and family members for their continuous support and encouragement during my study, especially to my late father, Negash Amare for whom he has dedicated all his life working hard for his children's success. 


\section{TABLE OF CONTENTS}

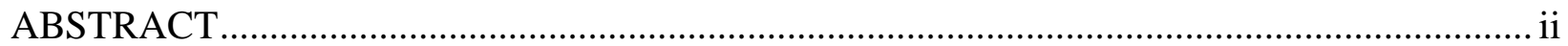

ACKNOWLEDGMENTS ...........................................................................................

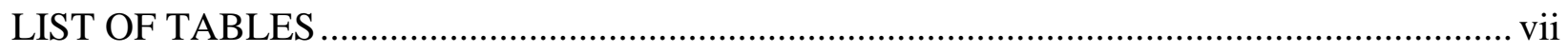

LIST OF FIGURES ….............................................................................................. vii

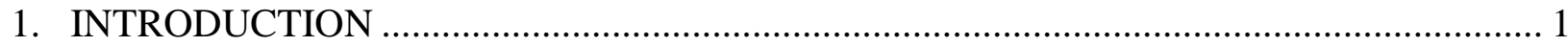

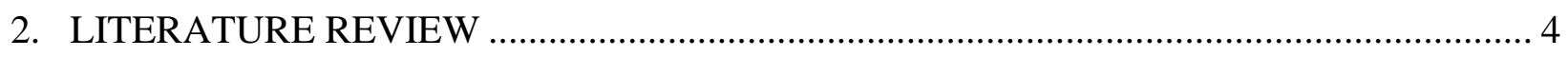

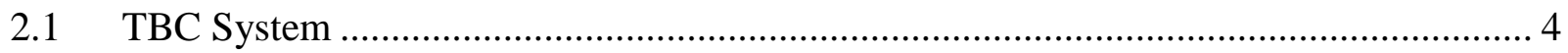

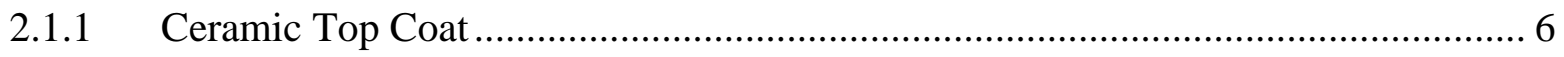

2.1.2 Metallic Bond Coat .................................................................................. 7

2.1.3 Turbine Blade Superalloy (Substrate)........................................................... 11

2.1.4 Failure Mechanisms of TBC Systems..................................................... 12

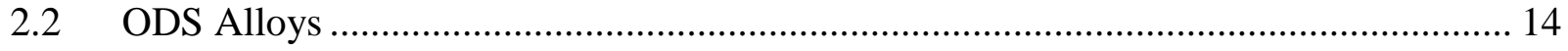

2.2.1 ODS Alloy Types................................................................................. 14

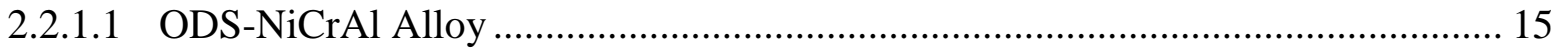

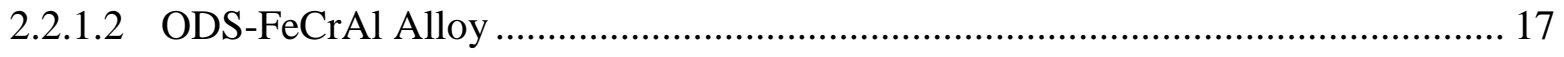

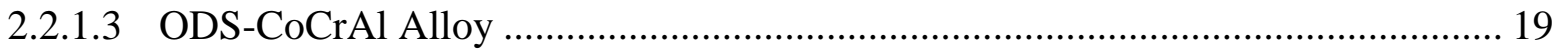

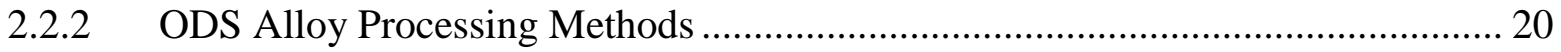

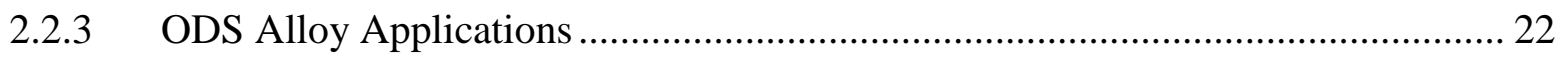

2.3 ODS Alloy Mechanical and Microstructure Characterization Methods ...................... 23

2.3.1 Oxidation Test (Cyclic Testing, Isothermal Testing) ..................................... 24

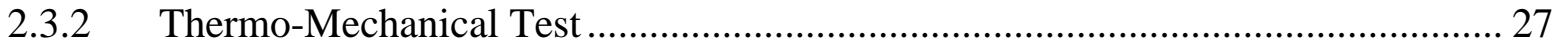

2.3.3 Indentation (Microhardness, Nanoindentation) Testing .................................. 29 


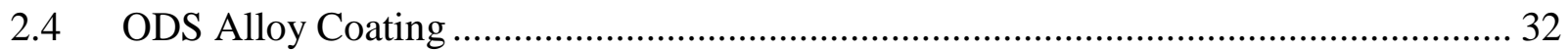

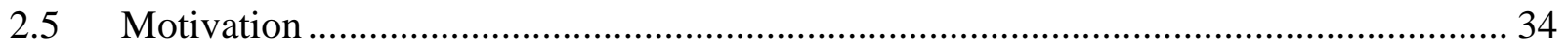

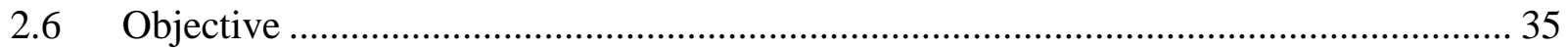

3. MATERIALS AND EXPERIMENTAL METHODS ..................................................... 36

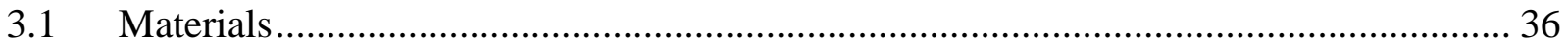

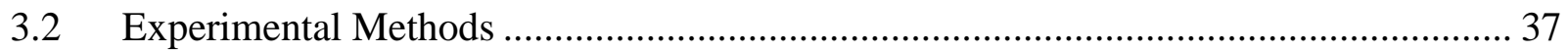

3.2.1 ODS Powder Processing by MCB and Mechanical Alloying ........................... 38

3.2.2 ODS Powder Compacting and Sintering …................................................ 39

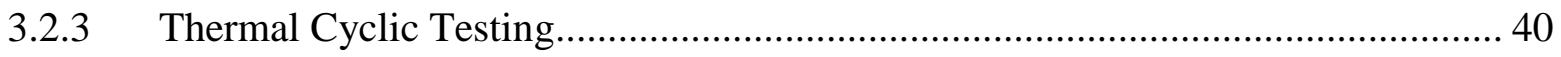

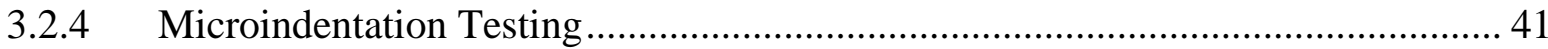

3.2.5 Microstructure Characterization ................................................................ 42

3.2.5.1 Electron Microscope (EM) Analysis ..................................................... 42

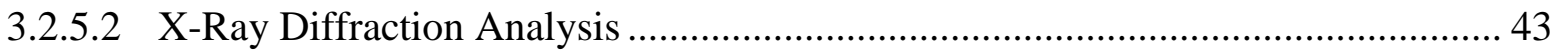

3.2.6 Heat Transfer Analysis of ODS Alloy Coating with Micro-Channel Cooling

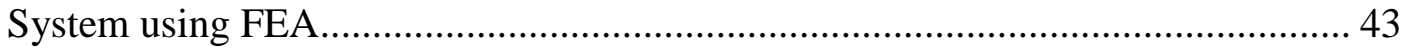

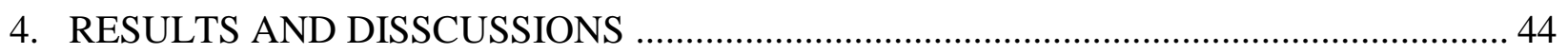

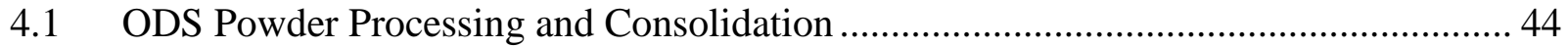

4.1.1 Mechano-Chemical Bonding (MCB) Processed Powders ................................... 44

4.1.2 Mechano-Chemical Bonding (MCB) plus Ball Milled Processed Powders .......... 49

4.1.3 Low Temperature Pre-Heat Treatment and Powder Consolidation....................... 53

4.2 ODS Alloy Thermal Cyclic Testing and Microindentation .................................... 56

4.2.1 Polished Surface Analysis of Thermal Cycled ODS Alloys................................ 56

4.2.2 Cross-Sectional Analysis of Thermal Cycled ODS Alloys .............................. 60 
4.2.3 Oxide Scale Analysis of Thermal Cycled ODS Alloy ....................................... 66

4.2.4 Elastic Modulus Determination Based on Microindentation............................... 79

4.3 Heat Transfer Analysis of ODS Alloy Coating with Micro-Channel Cooling System

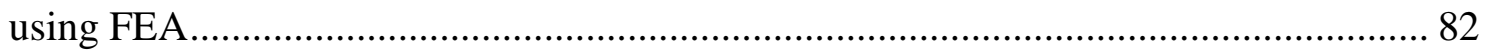

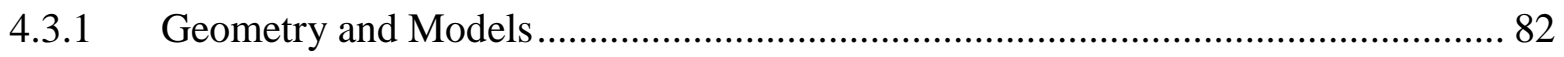

4.3.2 Temperature Distribution in the Model and Substrate....................................... 85

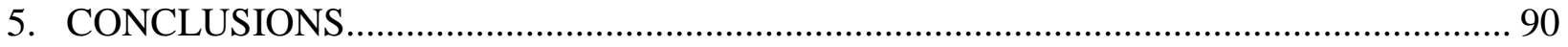

6. RECOMMENDATIONS FOR FURTHER WORK..................................................... 92

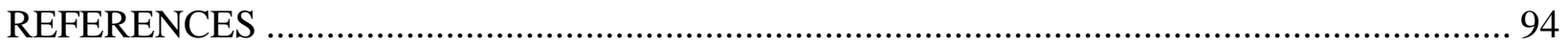




\section{LIST OF TABLES}

Table 1 Chemical composition of typical Ni-based superalloys for turbine blades and vanes [56].

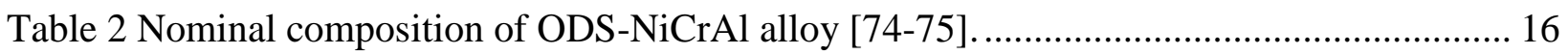

Table 3 Nominal chemical composition ODS-FeCrAl alloy [74] ....................................... 18

Table 4 Starting chemical composition of ODS powders before MCB process [125]............... 37

Table 5 Sintering conditions (pre-heated at $800{ }^{\circ} \mathrm{C}$ and sintered at $1300{ }^{\circ} \mathrm{C}$ ) .......................... 40

Table 6 Material properties of oxides and ODS matrix [140-142] ......................................... 75

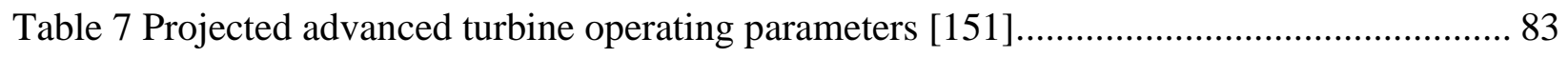

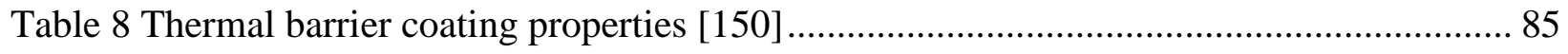

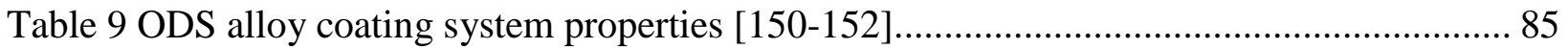




\section{LIST OF FIGURES}

Fig. 2.1 Gas turbine - SIEMENS SGT5-8000H (340MW) [1] .......................................... 4

Fig. 2.2 Cross-sectional scanning electron micrograph (SEM) of typical TBC system [31] ........ 5

Fig. 2.3 Microstructure of YSZ TBC deposited by (a) EB-PVD, (b) APS [32]........................ 7

Fig. 2.4 Cross-sections of Ni-based superalloys a) IN738 and b) CMSX-4 after exposure in air for $24 \mathrm{hrs}$ at $1050{ }^{\circ} \mathrm{C}$; c) IN738 after oxidation for $2835 \mathrm{hrs}$ in air at $1050{ }^{\circ} \mathrm{C}$ [1] ......... 8

Fig. 2.5 Relative oxidation and corrosion resistance of high temperature coating systems [50]. 10

Fig. 2.6 Schematic illustrations showing the progressive microstructural evolution and damage accumulation during cyclic oxidation leading to the spallation failure of $\mathrm{TBC}$ [62]...... 13

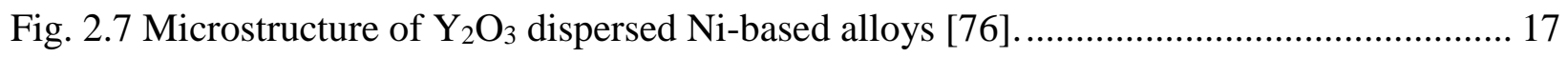

Fig. 2.8 Fracture surface of alumina scale formed on MA 956 sheet [11] ............................ 18

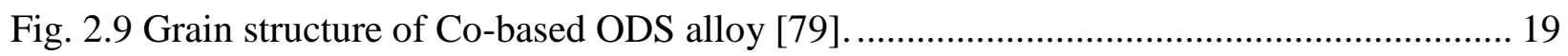

Fig 2.10 Typical processing steps of ODS powder to reach final products [86]...................... 22

Fig. 2.11 Schematic illustration showing different stages of yttrium distribution within the oxide

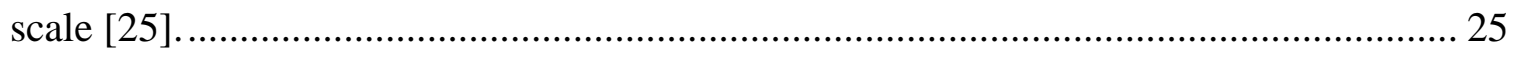

Fig. 2.12 Schematic of the scale formed on (a) ODS Ni3Al and (b) OD NiAl and ODS FeCrAl

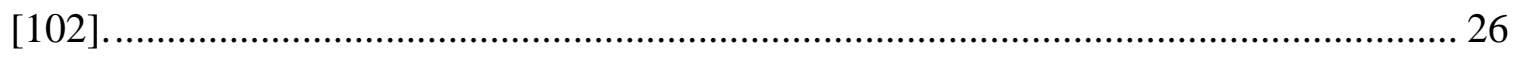

Fig. 2.13 Schematic mechanism of spallation and regrowth of the Ni-rich outer scale on ODS

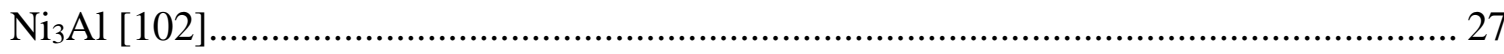

Fig. 2.14 Typical experimental load-displacement curve obtained with multiple partial unloading

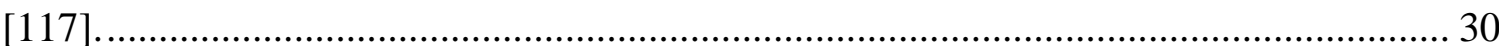

Fig. 3.1 Powder pre-heating and specimen sintering temperature profile; specimen group A and

C, B and D sintered for one and two hrs, respectively. 
Fig. 3.2 Schematic of the thermal exposure apparatus setup.

Fig. 3.3 Table top room temperature microindentation system [120]. 42

Fig. 4.1 MCB processed powders (a) XRD spectrum, (b) SEM micrograph, (c-f) EDX mapping micrographs, and (g) EDX element spectrum and wt.\%. 46

Fig. 4.2 MCB processed powders (a) TEM BF image, (b) HRTEM image, (c) STEM EDX image. 48

Fig. 4.3 SEM micrographs of milled powders for (a) $5 \mathrm{hrs,} \mathrm{(b)} 40 \mathrm{hrs,} \mathrm{(c)} 60 \mathrm{hrs,} \mathrm{and} \mathrm{(d)} 120 \mathrm{hrs,}$ and (e) XRD spectrum. 51

Fig. 4.440 hrs milled powders (a) SEM micrograph, (b-f) EDX mapping micrographs, (g) EDX spectrum and line scan across elements, and (h) TEM SAD image. 53

Fig. 4.5 Pre-heated powders (a) SEM micrograph, (b-f) EDX mapping micrographs, (g) EDX spectrum and line scan across particles with wt.\%, and (h) XRD spectrum comparisons of different hrs of milling and sintering. 55

Fig. 4.6 SEM micrographs of as sintered (a) specimen A (b) specimen B 57

Fig. 4.7 SEM micrographs after 160 cycles of specimen A (a-g), and specimen B (h-i) along with EDX spectrum, line scans, and wt.\%. 59

Fig. 4.8 SEM metallographic cross-section micrographs of specimen B after 40 cycles (a) matrix, (b) near oxide scale, (c) EDX spectrum of (a) and (b) with wt.\%. 61

Fig. 4.9 SEM metallographic cross-section micrographs of specimen A after 120 cycles (a) matrix, (b) near oxide scale, (c) EDX maps of (b), and (d) EDX spectrum of (a) and (b) with wt.\%. 62 
Fig. 4.10 SEM cross-section micrographs of specimen B after 120 cycles (a) matrix, (b) matrix EDX spectrum and its line scan with wt.\%, (c) near oxide scale, (d) near oxide scale inset picture and (e) its EDX spectra and line scan with wt.\% 65

Fig. 4.11 SEM cross-section micrographs of specimen A (a-b) matrix with EDX spectrum, line scan and wt.\%, (c-d) near oxide scale with EDX spectrum, line scan and wt.\% after 360 cycles, and (e) near oxide scale after 600 cycles 66

Fig. 4.12 As sintered specimen B outer surface SEM micrograph (a), EDX spectrum with wt.\%

(b). 67

Fig. 4.13 Oxide scale SEM micrographs of specimen A after 80 cycles (a-b) grey portion and (cd) dark portion with EDX spectrum, line scan and wt.\%, respectively. 69

Fig. 4.14 Oxide scale SEM micrographs after 440 cycles (a) specimen A, (b) specimen B with their EDX spectrum and wt.\% (c), and (d) XRD spectrum of specimen A after 600 cycles. 71

Fig. 4.15 Schematic illustrations: The outer Ni-rich oxide cracks together with alumina scale at longer oxidation cycles above, 500 cycles (d-e) but remains adherent. Upon insertion and heating Ni-rich oxide is able to form in the cracks before alumina re-heals at higher temperature. 72

Fig. 4.16 Modeling parameters for sinusoidal interface and FEA mesh 74

Fig. 4.17 Modeling parameters of smooth interface and boundary conditions for structural analysis. 75

Fig. 4.18 Temperature distribution after transient analysis and model coordinate system. 76

Fig. 4.19 Residual stress distributions in the $\mathrm{NiO}$ (a and c) and alumina scale (b and d) for both smooth and sinusoidal interfaces, respectively...... 78 
Fig. 4.20 Shear stress distributions in an alumina scale for both smooth and sinusoidal interfaces.

Fig. 4.21 Cyclic oxidation at $1100{ }^{\circ} \mathrm{C}$ in air: (a) weight gain, (b) microindentation stiffness

response

Fig. 4.22 Schematic of multilayer thermal and oxidation protection system: (a) TBC [145], (b)

ODS alloy coating with micro-channel cooling..................................................... 84

Fig. 4.23 Heat transfer analysis comparison of TBC systems and ODS alloy coating with microchannel cooling system: (a) model boundary condition, nodal temperature distribution (b) TBC systems, (c) micro-channel cooling located at the edge of ODS alloy, and (d)

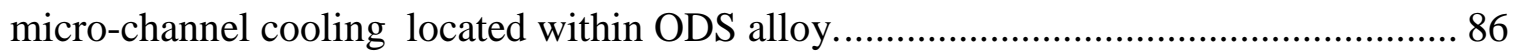

Fig. 4.24 Heat transfer analysis comparison of nodal temperature distribution in the substrate for TBC systems and ODS alloy coating with and without micro-channel cooling system: (a) TBC systems, (b) ODS alloy coating without micro-channel cooling (c) micro-channel cooling located at the edge of ODS alloy, and (d) micro-channel cooling located within

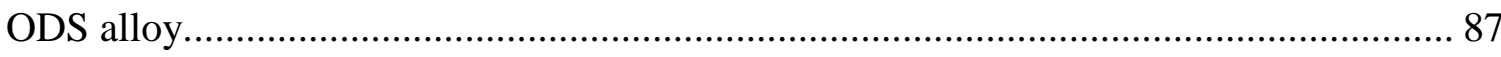

Fig. 4.25 Nodal temperature distribution plot: (a) along the substrate top, (b) across the model

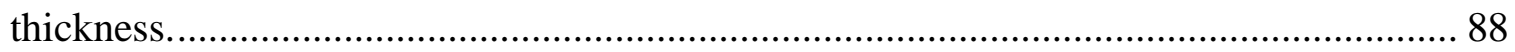

Fig 6.1 Schematic of implementing micro-channel cooling system using ODS alloy coating. ... 93 


\section{INTRODUCTION}

The growing demand for energy consumption related to increasing of world population and the need to addressing environmental consciousness should be complemented by increasing the efficiency of modern power plants and reducing wastes released from such plants. To increase the efficiency of modern power plants such as gas turbines and nuclear power plants are designed to operate at high temperatures creating harsh environments for structural materials exposed to the operating temperatures [1-3]. For gas turbines, the temperature of the exhaust gas entering the turbine (turbine inlet temperature) can be as high as $1200{ }^{\circ} \mathrm{C}-1400{ }^{\circ} \mathrm{C}$.

The elevated turbine inlet temperature directly affects the materials at the hottest sections, such as combustion chamber, blades and vanes. Therefore, the hottest sections should satisfy a number of material requirements such as high creep strength, ductility at low temperature, high temperature oxidation and corrosion resistance. Such requirements are nowadays satisfied by implementing superalloys [4-10]. The development of new chemical composition and different processing routes of superalloys and implementing turbine blade coating (TBC) system let to increase turbine inlet temperature, which therefore increases the net efficiency of gas turbines.

Superalloys are known for their many high temperature applications. There are three types of superalloys: nickel-based, iron-based and cobalt-based superalloys [1, 4]. Oxide dispersion strengthened (ODS) superalloys such as MA 956 or MA 6000, produced through mechanical alloying and consolidation process are generally used at temperatures above $800{ }^{\circ} \mathrm{C}$, which satisfies the intermediate strength as well as elevated temperature strength near to the alloy melting temperature [11-14]. Nickel-based ODS superalloys are the most widely used and the most complex high temperature materials strengthened by gamma prime precipitates $(\gamma$-Ni matrix and $\gamma^{\prime}-\mathrm{Ni}_{3} \mathrm{Al}$ ) and nano-sized yttrium oxide particles. Yttrium oxide particles serve for interfacial 
pinning of the moving dislocations. ODS alloys, such as ferritic-martensite (F/M) Fe-Ni-based alloys offer low void swelling at conditions of high energy high speed neutron irradiation and a candidate structural materials in super critical water reactor withstanding not only high temperature creep, corrosion, and oxidation but also radiation damage and other degradation mechanisms [5, 15-16]. Like Ni-based and Fe-based alloys, Co-based ODS alloys strengthened by nanosized oxide dispersion and $\gamma^{\prime}$ precipitates are potential high temperature structural materials [17]. Mechanical alloying (MA) is a main technique employed to synthesize advanced ODS alloys, which plays an important role on the microstructure formation and the resulting properties.

General processing of all ODS alloys involved a complicated, costly and time-consuming process of mechanical alloying (MA) powder metallurgical process, compaction, and extrusion by hot deformation and post heat treatment process for final geometry and recrystallization $[16,18$ 19]. Mechanical alloying is a powerful powder processing method, which is a solid-state synthesis using ball milling process [20-21] in which elemental alloy powders or oxide compounds are subjected to high energy ball milling or rod milling for anywhere between 24 to 72 hours to produce homogeneously mixed, heavily deformed, cold welded composite particles. A homogeneous distribution of oxide dispersion provides the materials more stability at elevated temperatures by which the nano-sized yttrium oxide particles are expected to form the dispersion throughout the master particles. After MA processing, the mixed and alloyed powders are then canned and consolidated by a number of compacting methods which includes cold isostatic pressing (CIP), hot isostatic pressing (HIP) or hot extrusion [22]. A final annealing and aging process at very high temperature is required to develop a stable and recrystallized microstructure including the coarse and highly elongated grain structure and strengthening precipitates [3]. 
Nickel-based ODS alloys produced by MA process attract great attention as advanced high temperature structural materials. More importantly, ODS alloys can be used as coating [23-24] on superalloys at the hottest sections of modern gas turbines as the inlet temperature is increased to values exceeding the capabilities of superalloys with respect to mechanical strength and environmental stability. They retain useful strength up to a relatively high temperature due to direct strengthening of fine, uniformly dispersed and stable oxide particles which acts as a dislocation motion barriers and their ability to form a protective $\mathrm{Cr}$-oxide and Al-oxide surface layer during exposure [25-28]. Moreover, the ability to exhibit improved scale adherence, decreased oxide growth rates, enhanced selective oxidation and decreased oxide grain size compared to corresponding non-ODS alloys [28] made ODS alloys potentially a suitable structural materials for components facing hostile service conditions. 


\section{LITERATURE REVIEW}

\subsection{TBC System}

A major factor supporting research within engineering fields is the desire to improve the performance of devices. One such device is the gas turbine (GT), forms of which are used as landbased electrical power generations and aerospace engines, Fig. 2.1. In some recent gas turbines, the inlet temperature reaches a peak value that can exceed $1500{ }^{\circ} \mathrm{C}$. However, the maximum operating temperature among the metallic components within a GT is near $1100{ }^{\circ} \mathrm{C}$. To reduce or prevent the degradation and failure of these parts, they must be protected from the heat flux produced by the combustion gases during engine operation. The employed protection typically consists of two types: an internal airflow to cool the component convectively and a thermal barrier coating (TBC) deposited on the component to insulate it from the combustion heat flux.

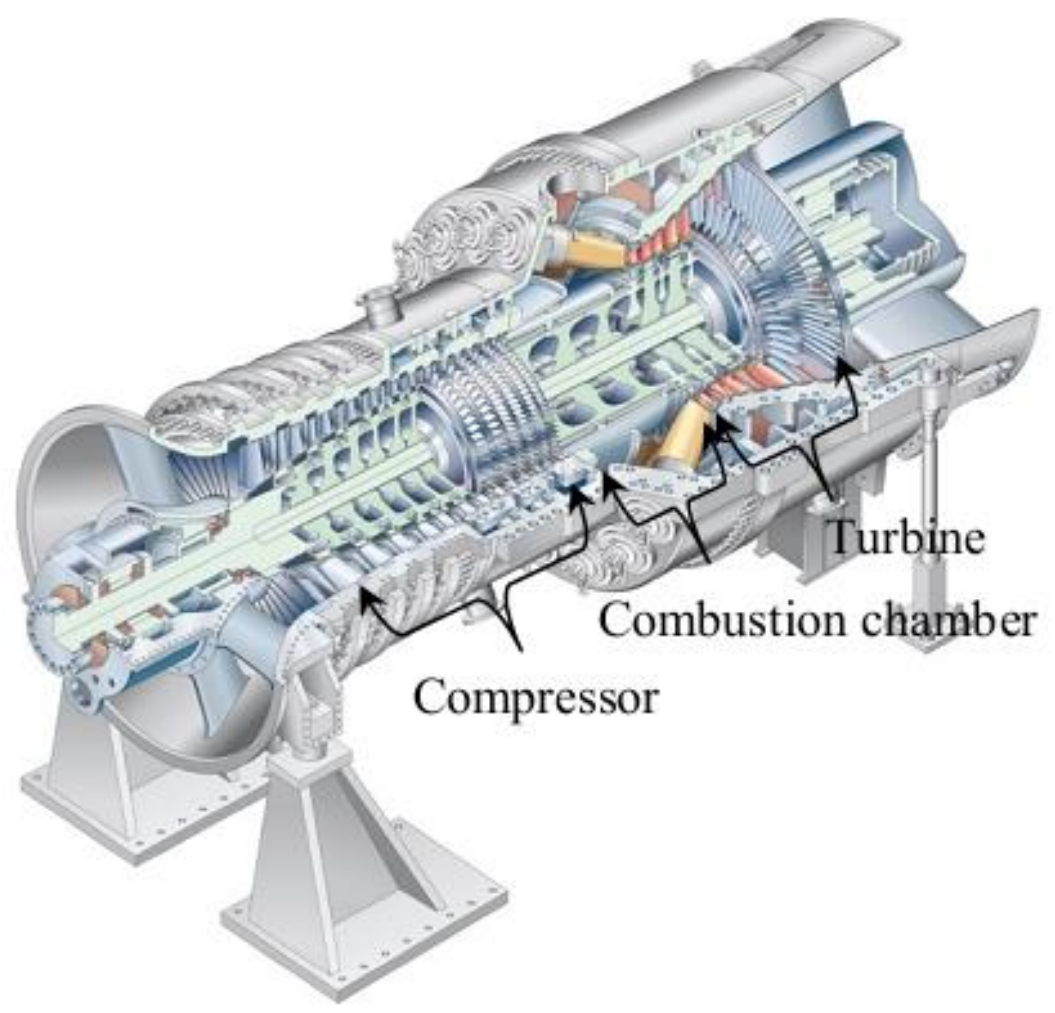

Fig. 2.1 Gas turbine - SIEMENS SGT5-8000H (340MW) [1]. 
TBC systems [29-30] are widely used in gas turbines to protect superalloy blades and components from high operating temperatures that may routinely exceed the superalloy melting temperature. TBC systems consist of four different materials with specific properties and functions (i) a ceramic top coat (TC), most commonly yttria-stablized zirconia (YSZ), (ii) thermally grown oxide (TGO), (iii) metallic bond coat (BC) residing between and applied onto (iv) a superalloy component in the gas turbine. Combined with internal cooling, modern TBCs are required to not only limit heat transfer through the coating but to also protect engine components from oxidation and hot corrosion. Research in the past decades has led to a preferred coating system consisting of three separate layers [31] to achieve long term effectiveness in the high temperature, oxidative and corrosive use environment for which they are intended to function. Fig. 2.2 shows a schematic illustration of a modern TBC system consisting of a thermally insulating thermal barrier coating, a thermally grown oxide, and a bond coat with internally cooled superalloy turbine blade.

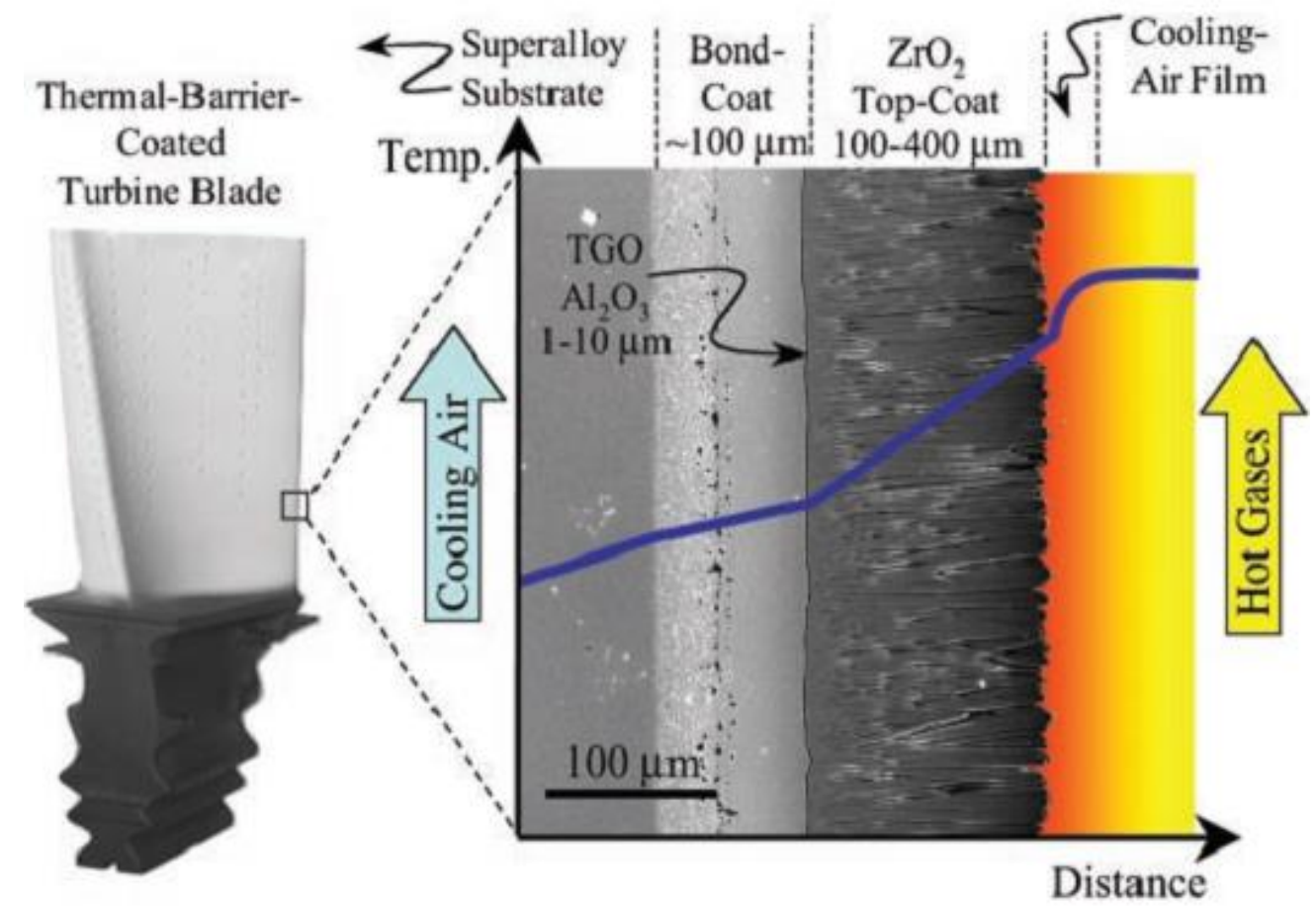

Fig. 2.2 Cross-sectional scanning electron micrograph (SEM) of typical TBC system [31]. 


\subsubsection{Ceramic Top Coat}

The outer layer in a TBC system is a ceramic top coat with a low thermal conductivity which is required to maximize the thermal drop across the thickness of the coating as it is exposed to the high temperature combustion gasses. This layer is therefore required to possess a high melting temperature, a high thermal reflectivity, low thermal conductivity, high coefficient of thermal expansion, and chemical stability. However, the thermal expansion coefficient differs from the component to which it is applied. Therefore, it should have a high in-plane compliance to accommodate the thermal expansion mismatch between the TBC and the underlying nickel superalloy component. Based on the above requirements, $\mathrm{ZrO}_{2}$ stabilized with $6-8 \% \mathrm{Y}_{2} \mathrm{O}_{3}$ is commonly used as TBC top coat [29-30].

Two processing technologies are widely accepted to deposit ceramic topcoats [32-34], which include air plasma spraying (APS) [35-36] and electron-beam physical vapor deposition (EB-PVD) [37-38]. APS coatings are built up from the continuous impact of molten particles directed at high velocity on to the substrate, and rapidly solidifying to form a "splat" (a flattened particle). The deposit developed by successive impingement and inter-bonding among the splats result in a lamellar structure. The adhesion behavior between the molten particles and the substrate is primarily mechanical as the molten particles flatten and solidify very rapidly. Void formation is a typical behavior of APS coating, which includes (10-20\% porosity), Fig. 2.3(a). The porosity reduces the thermal conductivity and increase the strain tolerance.

In EB-PVD process, vapors are produced by heating the source material with an electron beam in a vacuum chamber, and the evaporated atoms condense on the substrate. The EB-PVD processing has shown an industrial application due to its high deposition rate, high strain tolerance during thermal cyclic exposure, and good surface finish. However, EB-PVD TBC has high thermal 
conductivity as compared to APS TBC. A typical EB-PVD processed TBC has a columnar microstructure with elongated inter columnar pores that become predominantly aligned perpendicular to the plane of the coating as its thickness increases, Fig. 2.3(b).
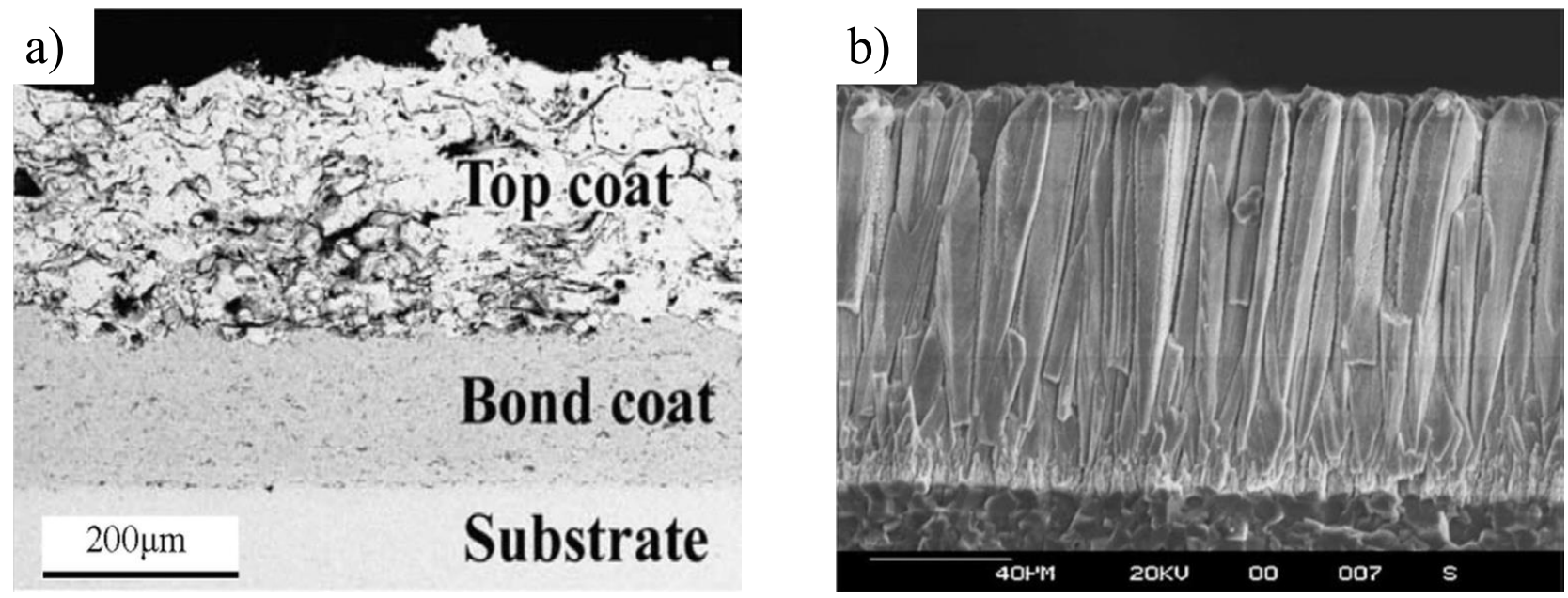

Fig. 2.3 Microstructure of YSZ TBC deposited by (a) EB-PVD, (b) APS [32].

The thermal expansion mismatch between ceramic and metallic components is better accommodated by the columnar morphology than by the porosity and micro cracks of APS YSZTBCs. The adhesive strength between the substrate and YSZ is 10 times higher for EB-PVD than for APS YSZ-TBCs, which is an important factor in preventing premature spallation of the YSZ layer.

\subsubsection{Metallic Bond Coat}

The ceramic top coat in a TBC system is permeable to oxygen which leads to oxidation of the underlying substrate. In protecting the oxidation of the base material, which typically reduces the spallation of the ceramic top coat, should be protected against oxidation and corrosion by using a bond coat (BC) [39-40]. This metallic BC deposited between ceramic top coat and superalloy substrate plays a vital role in TBC life by supplying a slow growing, uniform and defect free oxide layer (such as $\alpha-\mathrm{Al}_{2} \mathrm{O}_{3}$ ) in protecting the top coat spallation and the substrate from oxidation and 
high temperature corrosion. Moreover, a small coefficient of thermal expansion (CTE) difference between substrate and TBC is required.

The bond coat composition is designed to obtain highly adherent thermally grown oxides. The bond coat is required to have sufficient amount of aluminum (Al) in the reservoir so that the formation of a slow growing and adherent $\alpha-\mathrm{Al}_{2} \mathrm{O}_{3}$ is maintained. Otherwise, fast growing $\mathrm{Ni}$ and Cr-rich oxide scales dominate the oxide scale, the case when $\mathrm{Al}$ is depleted [41], Fig. 2.4(a) and (b). The significant contribution of the bond coat to the oxidation protection and adherence in a TBC system is illustrated in Fig. 2.4(c). A cross-section of superalloy IN738 partially coated with TBC system with NiCoCrAlY bond coat after oxidation for $2835 \mathrm{hrs}$ in air at $1050^{\circ} \mathrm{C}$. As can be seen on the cross-section micrographs, on the side where the surface covered by a $\mathrm{BC}$, a thin protective alumina scale is formed and the ceramic coating is still adherent, whereas, on the uncoated side the spallation of non-protective oxide scales lead to fast metal consumption.

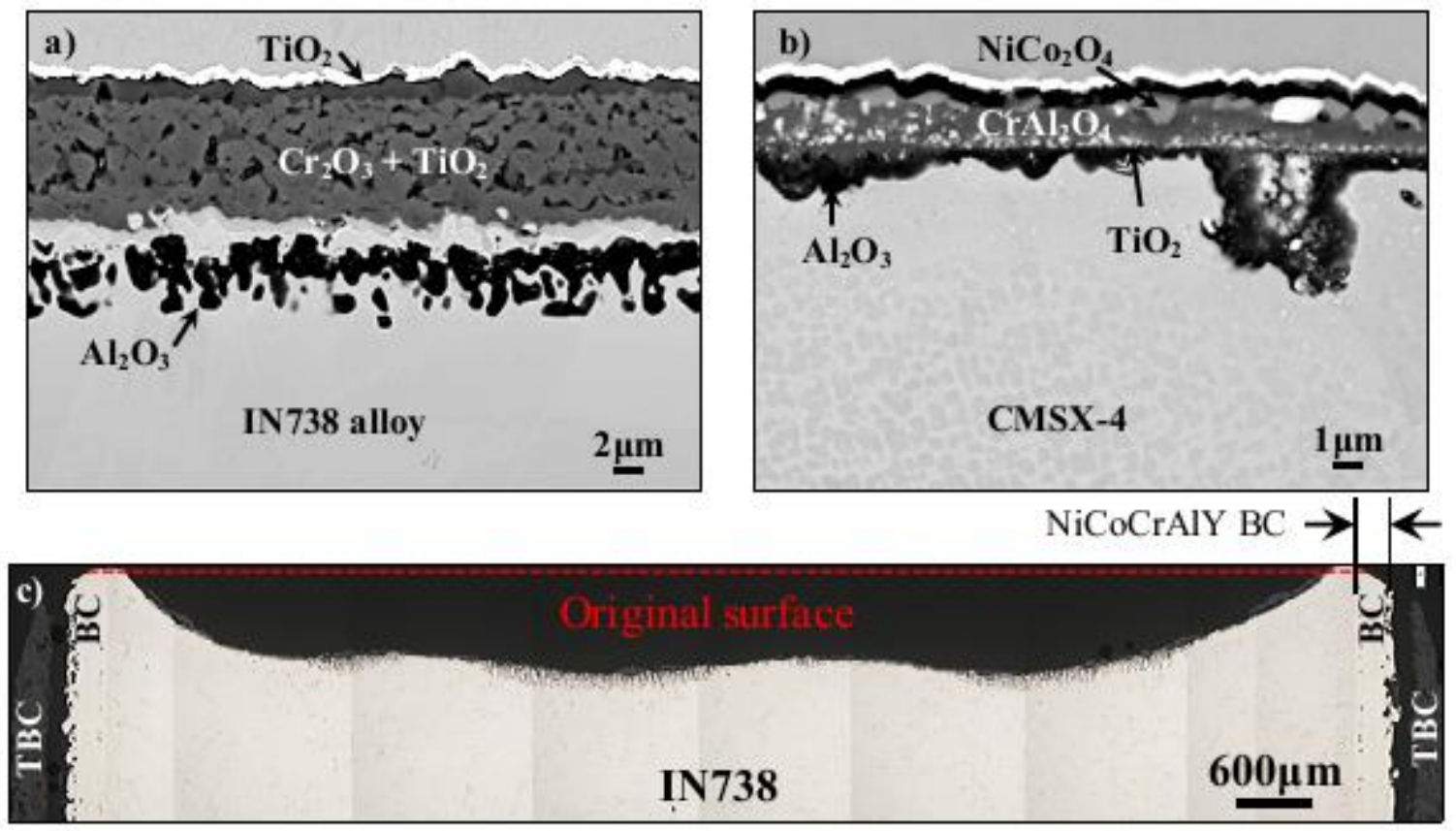

Fig. 2.4 Cross-sections of Ni-based superalloys a) IN738 and b) CMSX-4 after exposure in air for $24 \mathrm{hrs}$ at $1050{ }^{\circ} \mathrm{C}$; c) IN738 after oxidation for $2835 \mathrm{hrs}$ in air at $1050{ }^{\circ} \mathrm{C}$ [1]. 
Two types of bond coats are commonly accepted for TBC systems containing sufficient Al content: MCrAlY, where (M=Ni, Co) [42-45] and diffusion aluminide coating [46-49]. Due to the ability to form dense and adherent $\mathrm{Al}_{2} \mathrm{O}_{3}$ scales, MCrAlY bond coats are commonly used in gasturbine and aircraft engine components as an intermediate layer between the Ni-based superalloy and the YSZ TBC. Platinum modified diffusion aluminide coatings ( $\beta$-NiAl) are commonly applied to provide oxidation and corrosion resistance to high strength superalloys whose protective capacity is based on their ability to form an adherent layer of slow-growing $\mathrm{Al}_{2} \mathrm{O}_{3}$.

MCrAlY coatings can be classified into NiCrAlY, CoCrAlY and NiCoCrAlY with different corrosion and oxidation resistance at high temperature. NiCrAlY coatings are designed for high oxidation resistance but with poor corrosion resistance, CoCrAlY coatings for high corrosion resistance and $\mathrm{NiCoCrAlY} / \mathrm{CoNiCrAlY}$ coatings to obtain an optimum balance of both properties [50]. Fig. 2.5 shows schematically the corrosion and oxidation resistance of different MCrAlY bond coats. There are usually two phases in the MCrAlY bond coat: $\beta$-NiAl and $\gamma$-Ni (fcc) solid solutions. A higher $\mathrm{Cr}$ and $\mathrm{Al}$ contents in MCrAlY bond coats are beneficial with respect to oxidation and corrosion resistance. However, there is an adverse effect observed in the ductility of the coating which necessitates the optimization of $\mathrm{Al}$ and $\mathrm{Cr}$ contents [1].

The MCrAlY coating are manufactured and deposited to the superalloy surface using different methods, such as atmospheric plasma spray (APS), which results in a porous metallic coating with moderate oxidation resistance, vacuum plasma-spray (VPS), which provides a bond coat with minimal porosity and superior oxidation resistance [51], EB-PVD, which provides comparable clean bond coats to APS [52], and high velocity oxy-fuel spraying (HVOF) [53]. A thin protective $\mathrm{Al}_{2} \mathrm{O}_{3}$ scale during high-temperature exposure, which is the basis for the oxidation resistance of the bond coat formed along the rough bond coat-YSZ interface by selective oxidation 
of $\mathrm{Al}$ in the metallic coating. Additions of reactive elements such as $\mathrm{Hf}, \mathrm{La}, \mathrm{Ce}$, and $\mathrm{Zr}$ enhance the oxidation resistance via oxide scale adherence.

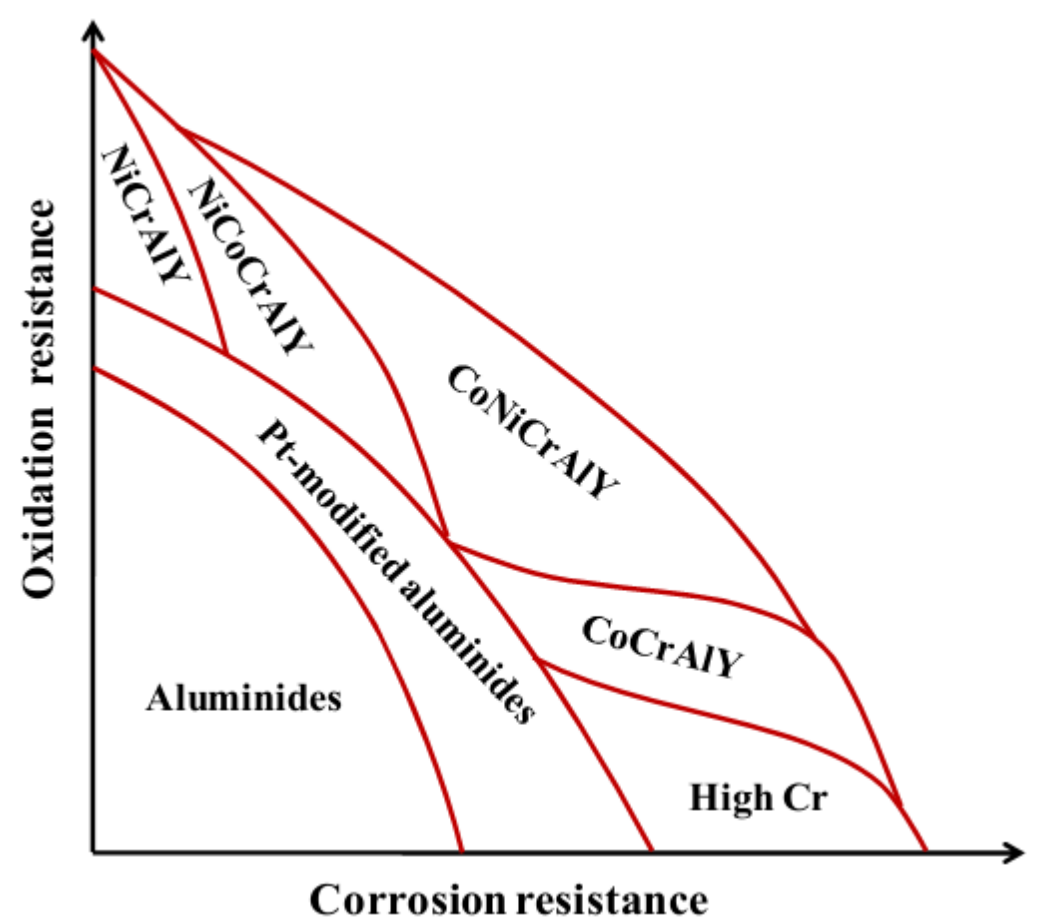

Fig. 2.5 Relative oxidation and corrosion resistance of high temperature coating systems [50].

The diffusion aluminide coatings are commonly used in high pressure turbine blades and nozzles in jet engines. Platinum is applied by electrolytic deposition on to the Ni-based superalloy with $7 \sim 9 \mu \mathrm{m}$ Pt layer, which is usually followed by heat treatment at $1000{ }^{\circ} \mathrm{C}$ under vacuum before aluminizing via pack cementation. Then aluminide coatings obtained via the pack cementation, a modified chemical vapor deposition (CVD) process is frequently applied on the nickel-based superalloys to protect them against high-temperature oxidation, which facilitates the formation of a nickel aluminide ( $\beta$-NiAl) layer [47]. Depending on the processing conditions for further improvement in oxidation and hot corrosion resistance, platinum is commonly added to the diffusion. Compared to MCrAlY bond coats, NiPtAl bond coats exhibited superior oxidation resistance and provide longer life time for TBCs. 


\subsubsection{Turbine Blade Superalloy (Substrate)}

The development of superalloys for high temperature applications dated back to 1940, where the first wrought alloys were produced. In recent years the elemental compositions and structures of the superalloys have been changed from Fe-based, and (Ni, $\mathrm{Fe}$ )-based to a purely $\mathrm{Ni}$ based and also with an inclusion of oxide dispersion strengthening. Use of $\mathrm{Fe}$ and $(\mathrm{Fe}, \mathrm{Ni})$-based alloys in an industrial settings are still considered in areas where weight is not a major issue, but where cost is. In addition to $\mathrm{Fe}$ and $(\mathrm{Fe}, \mathrm{Ni})$-based alloys, Co-based alloys are also considered in areas where corrosion is a problem [54].

These alloys were developed with high temperature requirements to possess the most important properties of resistance to high temperature corrosion, creep and fatigue. To get these properties, the method of processing has been changed through time with the first generation superalloys, which generally were strengthened by solid-solutions (Fe, Ni)-based alloys having a similar behavior to stainless steel. Conventional cast (CC), directional solidification (DS), single crystal (SC) fabrication, and oxide dispersion strengthening are among the processes implemented to improve the high temperature creep resistance, dislocation movement, oxidation, and corrosion resistance of such superalloys [54-57].

The directional solidification process greatly improved the creep strength, ductility and fatigue properties in the longitudinal direction of the turbine blades. The single crystal alloys developed in 1980 has helped, due to the removal of the grain boundaries in raising the incipient melting point as well as enabling solution treatment at higher temperature of $1300{ }^{\circ} \mathrm{C}$ or more. Whereas ODS superalloys, due to the dispersion hardening by $\mathrm{Y}_{2} \mathrm{O}_{3}$ enhanced the high temperature creep exceeding $1100^{\circ} \mathrm{C}$. 
Nickel-based superalloys have an exceptional combined high temperature strength, toughness, and resistance to degradation in high temperature oxidation and corrosive environments, which is a typical condition in high-temperature components (e.g., combustors and high-pressure turbine blades and vanes), with recent emphasis given to ODS superalloys for their exceptional creep properties as compared to conventional superalloys. Nickel-based superalloys are strengthened by $\gamma$-matrix and $\gamma^{\prime}-\mathrm{Ni}_{3} \mathrm{Al}$ precipitates. The precipitates are used to prevent dislocation movement through the alloy, a creep mechanism after the grain boundaries are removed from the alloy as in a single crystal superalloy [54]. In addition, these Ni-based materials are commonly alloyed with $\mathrm{Cr}$ and $\mathrm{Al}$ to promote the formation of protective oxide layers $\mathrm{Cr}_{2} \mathrm{O}_{3}$ and $\mathrm{Al}_{2} \mathrm{O}_{3}$ for providing corrosion and oxidation resistance, respectively. The chemical composition and their processing of four commercial superalloys used in gas turbine blades are presented in Table 1.

Table 1 Chemical composition of typical Ni-based superalloys for turbine blades and vanes [56].

\begin{tabular}{|c|c|c|c|c|c|c|c|c|c|c|c|c|c|c|c|}
\hline \multirow[t]{2}{*}{ Process } & \multirow[t]{2}{*}{ Alloy } & \multicolumn{14}{|c|}{ Composition (wt\%, Ni balance) } \\
\hline & & $\mathrm{Co}$ & $\mathrm{Cr}$ & Mo & W & $\mathrm{Al}$ & $\mathrm{Ti}$ & $\mathrm{Nb}$ & $\mathrm{Ta}$ & Hf & $\mathrm{Re}$ & $\mathrm{C}$ & B & $\mathrm{Zr}$ & Others \\
\hline $\mathrm{CC}$ & IN 738 & 8.5 & 16 & 1.7 & 2.6 & 3.4 & 3.4 & - & 1.7 & - & - & 0.17 & 0.01 & 0.1 & - \\
\hline DS & PWA1426 & 12 & 6.5 & 1.7 & 6.5 & 6 & - & - & 4 & 1.5 & 3 & 0.1 & 0.015 & 0.015 & - \\
\hline $\mathrm{SC}$ & TMS-162 & 5.8 & 2.9 & 3.9 & 5.8 & 5.8 & - & - & 5.6 & 0.09 & 4.9 & - & - & - & $6.0 \mathrm{Ru}$ \\
\hline ODS & MA-6000 & 2 & 15 & 2 & 4 & 4.5 & 2.5 & - & 2 & - & - & 0.05 & 0.01 & 0.15 & $1.1 \mathrm{Y}_{2} \mathrm{O}_{3}$ \\
\hline
\end{tabular}

\subsubsection{Failure Mechanisms of TBC Systems}

While there are many mechanisms by which YSZ-TBCs can fail, residual stress caused by the oxidation of $\mathrm{BC}$ has been repeatedly identified as one of the important factors affecting the durability of YSZ-TBCs during service and a portion of the coating either buckle or delaminate 
and spalled away to expose a portion of the underlying component [58-62]. Residual stresses develop in TBCs due to the thermal expansion mismatch between the different layers of the TBC system which gives rise to deformation of the coated specimen and initiate micro cracks at the $\mathrm{BC} / \mathrm{TC}$ interface and thus lead to spallation of the coatings. Thermally grown oxide (TGO) scales, mainly consisting of $\alpha-\mathrm{Al}_{2} \mathrm{O}_{3}$ and $\mathrm{Cr}_{2} \mathrm{O}_{3}$, forming along the irregular $\mathrm{BC} / \mathrm{TC}$ interface at elevated temperatures are considered to be the main cause to create stress at the BC/TC interface [52, 6364].

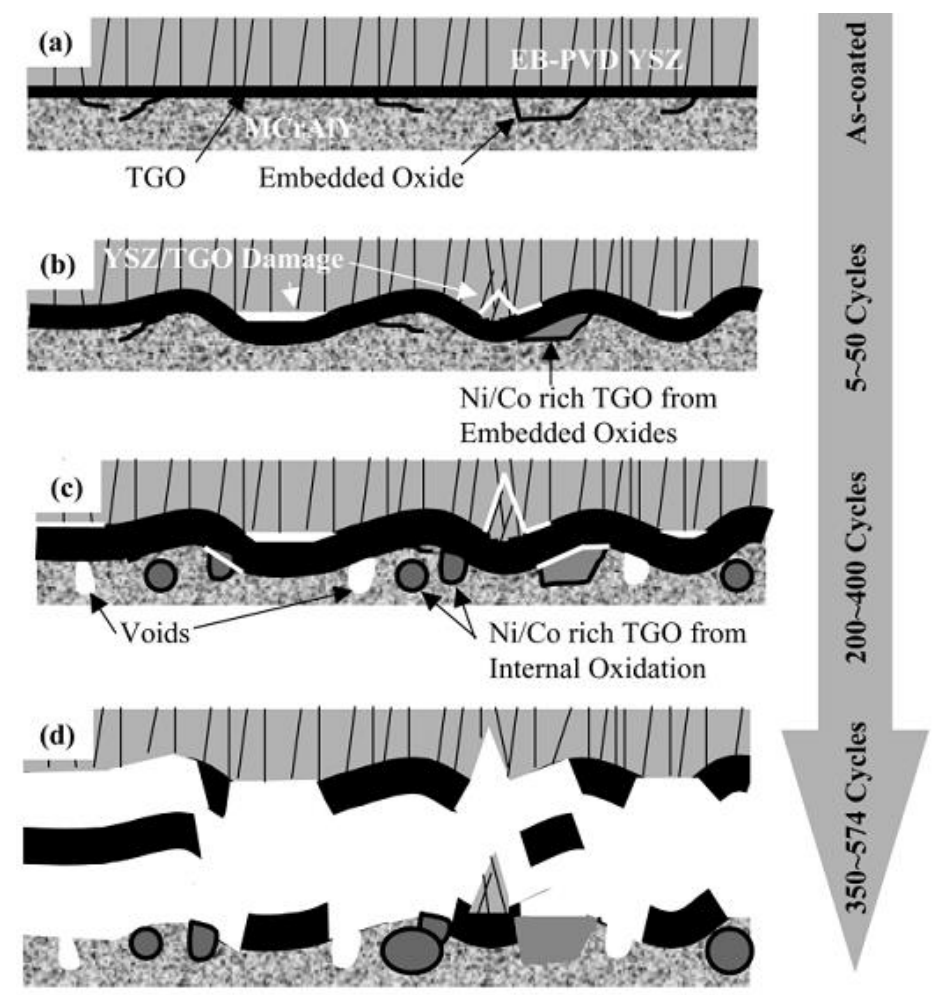

Fig. 2.6 Schematic illustrations showing the progressive microstructural evolution and damage accumulation during cyclic oxidation leading to the spallation failure of TBC [62].

The TGO film for durable YSZ-TBCs should consist of a fine grained, low growth, uniformly thick, and dense mixed-oxide zone in addition to a uniform and smooth microstructural transition into the continuous oxide zone. Fig. 2.6 illustrates a sequential schematic of microstructural development from as deposited to the failure of EB-PVD produced TBC with (a) 
as-coated; (b) YSZ/TGO interface damage due to rumpling, and formation of TGO rich in Ni/Co due to embedded oxide; (c) void formation and internal oxidation; and (d) final spallation.

\subsection{ODS Alloys}

Oxide dispersion strengthened (ODS) alloys are the most promising class of high temperature materials. Compared to precipitation-strengthened alloys, the ODS alloys have much higher strength and creep resistance at high temperatures. The existence of fine uniformly dispersed and stable oxide, usually $\mathrm{Y}_{2} \mathrm{O}_{3}$ particles which act as barriers to dislocation motion at high temperatures increases the strength of ODS alloys by direct strengthening. According to the application areas of ODS alloys, there are different ways of processing to the final product where the microstructure and average grain size are controlled $[3,65]$. Hence, in addition to the direct strengthening of fine dispersed oxides, the grain aspect ratio (GAR) is also an important parameter affecting high temperature strength of ODS alloys $[3,57,66]$. The formation of protecting oxide layers at elevated temperature, such as alumina $\left(\alpha-\mathrm{Al}_{2} \mathrm{O}_{3}\right)$ and chromia $\left(\mathrm{Cr}_{2} \mathrm{O}_{3}\right)$ are the characteristic behavior of ODS alloys for which they can be applied in high temperature severe corrosion and oxidation environments [67]. These two common oxide layers have specific protection capabilities as chromia scale is an ideal against the oxidation below $1000{ }^{\circ} \mathrm{C}$ and hot corrosion (700-800 $\left.{ }^{\circ} \mathrm{C}\right)$. However, alumina scale in $\alpha$ phase is excellent against the hightemperature oxidation above $1000{ }^{\circ} \mathrm{C}$ and hot corrosion $\left(800-950{ }^{\circ} \mathrm{C}\right)$.

\subsubsection{ODS Alloy Types}

Depending on the base metal there are a number of different ODS alloys for turbine system material applications. Among them, the major commercial and experimental ODS alloys are Nibased, Fe-based, and Co-based alloys having a basic alloy systems of NiCrAl, FeCrAl, and CoCrAl respectively [16-17, 68-73]. 
The addition of reactive elements (RE) (mostly yttrium and yttria) changes the oxidation kinetics of chromia and alumina forming alloys, which normally decreases than the cases of nonODS alloys. This phenomenon can be interpreted by using a grain boundary (GB) segregation model, by which the addition of RE dispersoid suppresses the outward diffusion of cations [25]. This is more pronounced in chromia forming alloys than alumina forming alloys. The reason is normally associated with the fact that the alloys form $\alpha$-alumina scales, whose growth is in any case dominated by oxygen transport. However, this usually depends on the oxidation temperature for which at around $1000{ }^{\circ} \mathrm{C}$ or below, $\theta$-alumina is formed by diffusion of aluminum cations.

\subsubsection{ODS-NiCrAl Alloy}

The oxidation resistance behavior of nickel-based superalloys mainly depends on the contents of chromium and aluminum. Practically, the ability to form continuous layers of chromia and alumina and the time required for the formation of these layers rely on the actual concentration of chromium and aluminum in ODS-NiCrAl alloy system as well as oxidation conditions (temperature and oxygen pressure in the environment). Commercial ODS-NiCrAl alloy has been under intense investigation for the past decades $[3,25,57]$. In as extruded condition, it has been highlighted that the GAR played the crucial role in affecting the microstructural feature and strength of ODS-NiCrAl alloy at elevated temperature. The fatigue behavior of commercial ODS superalloys, Inconel MA 754 and MA 6000 as compared with that of conventional (nonODS) superalloys of nearly identical elemental composition showed behavioral differences on the basis of two primary microstructural differences, grain structure and the fine particle dispersion. The recrystallization defects in the form of fine grains are the primary cause of crack initiation in the ODS materials. 
A few examples of ODS-NiCrAl alloys include MA754, MA 6000 (INCO Alloys International, Ltd.), and PM 3030 (PM Hochtemperatur-Metall GmbH), each with a different strengthening mechanism. The composition, strengthening mechanisms, and oxidation protection information are summarized in Table 2.

Table 2 Nominal composition of ODS-NiCrAl alloy [14, 74].

\begin{tabular}{|l|c|l|l|}
\hline & MA 754 & MA 6000 & PM 3030 \\
\hline Composition (wt.\%) & $\begin{array}{l}\text { Ni-20Cr-0.2Al- } \\
0.2 \mathrm{Ti}-0.5 \mathrm{Y}_{2} \mathrm{O}_{3}\end{array}$ & $\begin{array}{l}\mathrm{Ni}-15 \mathrm{Cr}-4.5 \mathrm{Al}-2 \mathrm{Ti}-2 \mathrm{~W}- \\
2 \mathrm{Mo}-2 \mathrm{Ta}-1 \mathrm{Y}_{2} \mathrm{O}_{3}\end{array}$ & $\begin{array}{l}\text { Ni-17Cr-6Al-3.5W-2Mo- } \\
2 \mathrm{Ta}-0.95 \mathrm{Si}-1.1 \mathrm{Y}_{2} \mathrm{O}_{3}\end{array}$ \\
\hline $\begin{array}{l}\text { Oxide Protective } \\
\text { Scale (Primary) }\end{array}$ & $\mathrm{Cr}_{2} \mathrm{O}_{3}$ & $\mathrm{Al}_{2} \mathrm{O}_{3}$ & $\mathrm{Al}_{2} \mathrm{O}_{3}$ \\
\hline $\begin{array}{l}\text { Strengthening } \\
\text { Mechanism }\end{array}$ & ODS & Precipitation $\left(\gamma^{\prime}\right)+\mathrm{ODS}$ & Precipitation $\left(\gamma^{\prime}\right)+\mathrm{ODS}$ \\
\hline
\end{tabular}

In addition to the commercial available ODS-NiCrAl alloy compositions, experimentally designed compositions tailored to improving the corrosion, erosion, oxidation, and creep challenges imposed by the operating environment of components such as gas turbines are under investigation. The dispersion strengthening is capable of raising the operating temperature up to 0.9 of melting temperature (TM) of the alloy. He et al. [23] studied the phase composition and microstructure of a $\mathrm{Y}_{2} \mathrm{O}_{3}$ dispersion strengthened Ni-based ODS alloy with composition of Ni28.2Fe-20.2Cr-5.2Al-1.1 $\mathrm{Y}_{2} \mathrm{O}_{3}$ in wt.\% having $0.1 \mathrm{~mm}$ thickness deposited by EB-PVD technology and followed by HIP treatment, performed on the as-deposited and HIPed specimen.

A typical microstructure of HIPed ODS-NiCrAl alloys cross-section observation is shown in Fig. 2.7, in which particles of $\mathrm{Y}_{2} \mathrm{O}_{3}$ homogeneously dispersed in the alloy. It is a typical phenomenon to observe elongated, coarse columnar crystals having an equiaxed grains in extruded specimens [70]. Fig 2.7 depicts typical grains of as-deposited SEM microstructure (a), oxide 
dispersions of as-deposited alloy (b), grains of HIPed alloy (c), and oxide dispersions of HIPed ODS alloy (d).
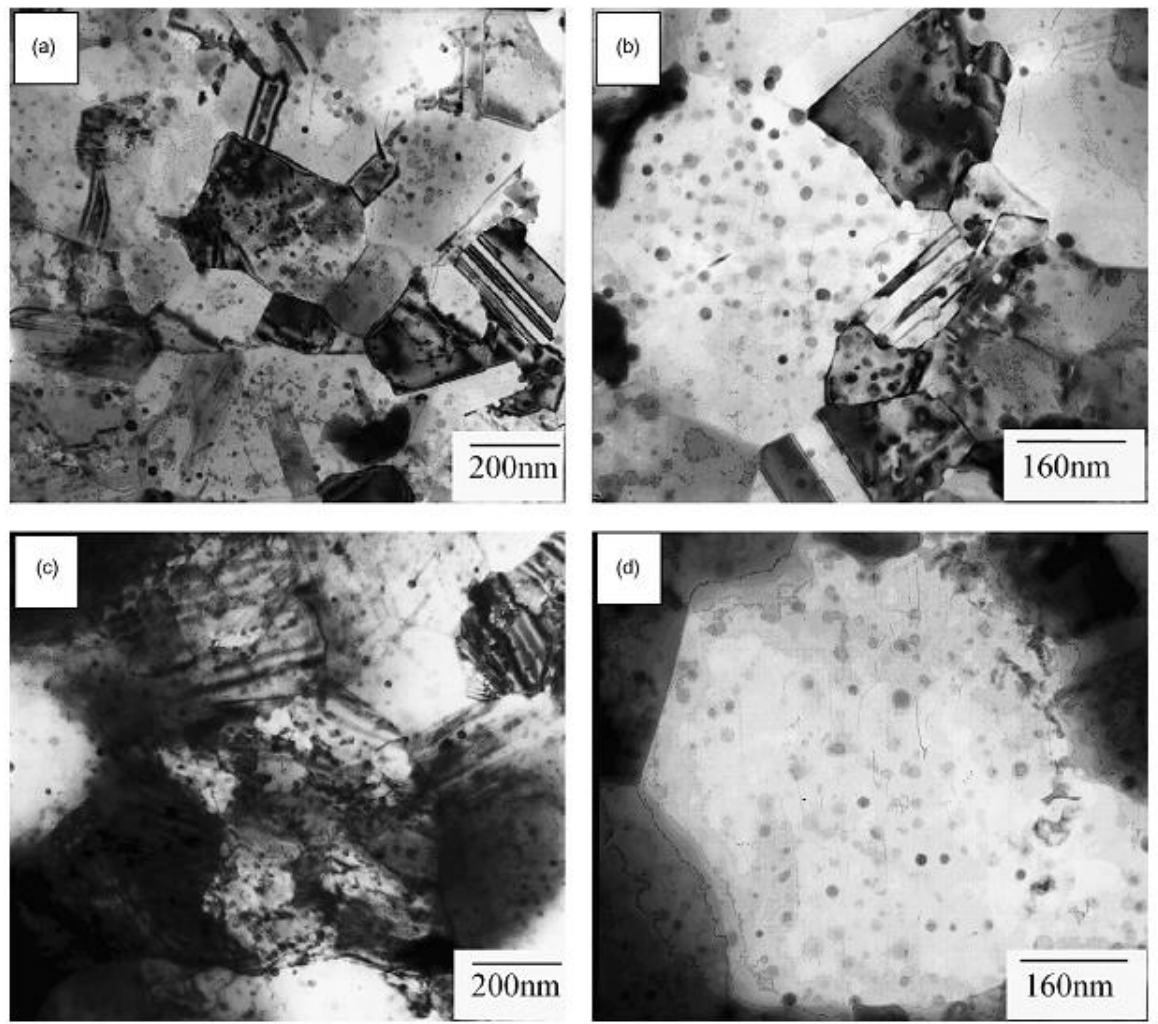

Fig. 2.7 Microstructure of $\mathrm{Y}_{2} \mathrm{O}_{3}$ dispersed Ni-based alloys [23].

\subsubsection{ODS-FeCrAl Alloy}

There are a number of commercial and experimental ODS-FeCrAl alloys being developed and investigated for their resistance in high temperature oxidation, hot corrosion and erosion. Commercial ODS products are available and include MA 956 and PM 2000 from Special Metals Corporation in the United States and Metallwerk Plansee GmbH in Germany, respectively [16]. The long-term isothermal oxidation behaviors of some ODS-FeCrAl alloys have been studied [11], which indicated the microstructure appear to depend on the contents of alloying elements. Thus, MA 956 showed the alumina scale formed was equiaxed containing irregularly shaped titaniumrich oxide particle, whereas ODM 751 showed distinctly columnar and contained elongated 
yttrium-rich oxide particles. A detailed review works on ODS-FeCrAl can be found [16]. Some commercial ODS-FeCrAl alloy compositions are summarized in Table 3.

Table 3 Nominal chemical composition ODS-FeCrAl alloy $[8,11]$.

\begin{tabular}{|l|l|l|l|}
\hline & MA 956 & PM 2000 & ODM 751 \\
\hline $\begin{array}{l}\text { Composition } \\
\text { (wt.\%) }\end{array}$ & $\begin{array}{l}\text { Fe-20Cr-4.5Al- } \\
0.5 \mathrm{Ti}-0.5 \mathrm{Y}_{2} \mathrm{O}_{3}\end{array}$ & $\begin{array}{l}\text { Fe-20Cr-5.5Al-0.5Ti- } \\
0.5 \mathrm{Y}_{2} \mathrm{O}_{3}\end{array}$ & $\begin{array}{l}\text { Fe-16.5Cr-4.5Al-0.6Ti- } \\
1.5 \mathrm{Mo}-0.5 \mathrm{Y}_{2} \mathrm{O}_{3}\end{array}$ \\
\hline
\end{tabular}

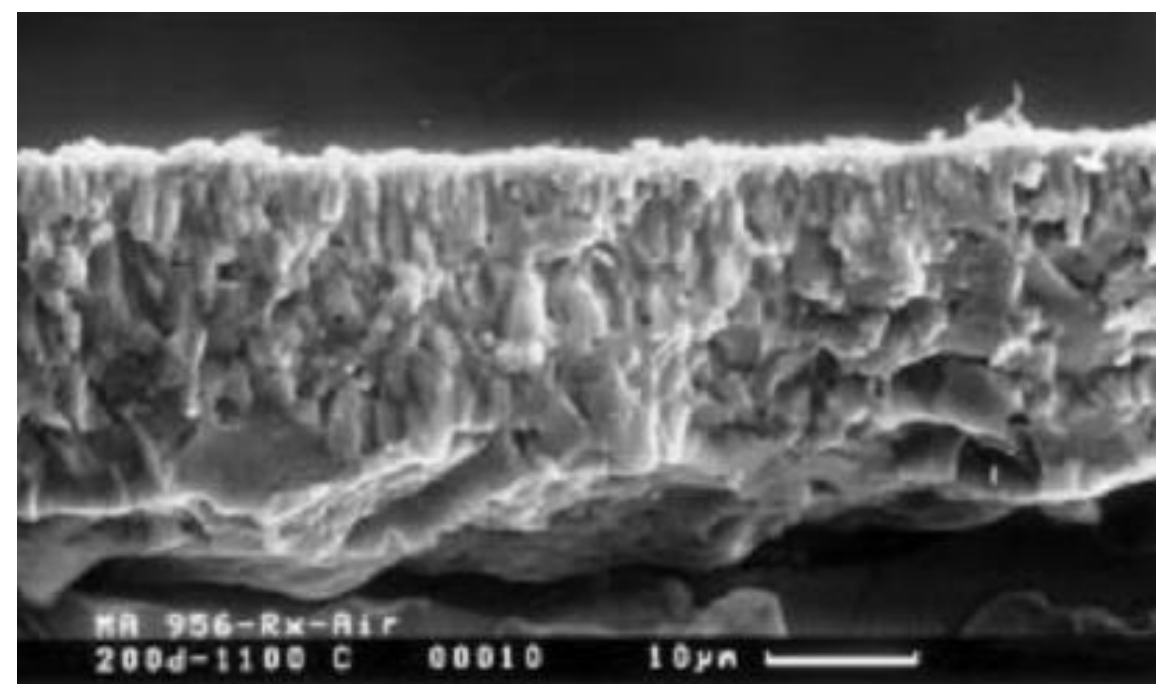

Fig. 2.8 Fracture surface of alumina scale formed on MA 956 sheet [11].

In addition to commercial ODS-FeCrAl, experimental investigation continued to fully exploit their application including developing of ODS alloy coatings due to their excellent high temperature strength and oxidation resistance [24]. A creep mechanism study based on high temperature tensile/compression tests [8], effect of mechanical alloying and consolidation processes on the microstructure and properties [20,76-77], and the investigation of the degradation mechanism due to oxidation and hot corrosion and role of formation of protective oxide films of ODS-FeCrAl alloys [78] are among the vast experimental works to mention a few. The formation of stable oxide scale on ODS alloy surface is one of the requirements at high temperature to protect 
the inner section. Fig. 2.8 showed an oxide scale grown on MA 956 sheet exposed at $1100{ }^{\circ} \mathrm{C}$ in air for 4800 hrs. It generally showed a fairly irregular but somehow equiaxed grain which depends on the exposure temperature and time.

\subsubsection{ODS-CoCrAl Alloy}

The increased demand for high temperature structural materials used in aerospace and power generation industries always look for new materials. Co-based ODS alloys are one of those developed for improving the oxidation resistance, strength and creep properties of conventional Co-based alloys as they lack sufficient high-temperature mechanical properties because of the coarsening or dissolution of carbides at elevated temperature [17, 79]. Oxide dispersion strengthened alloys are capable of operating at a relatively higher temperature as compared to $\gamma^{\prime}$ precipitates which are capable of intermediate temperature applications.

Unlike the conventional Co-based superalloys comprising of $\mathrm{CoCrAl}$ main compositions, Co-based ODS alloys do not contain Cr. Instead of Cr, W is used and little known about Co-based ODS alloys [17, 79-80], but Al remains the most alloying element. The microstructural formation mechanism of Co-based ODS alloys are elaborated more in detail [79] with the main compositions of Co-based ODS alloy being Co-Al-W- $\mathrm{Y}_{2} \mathrm{O}_{3}$.

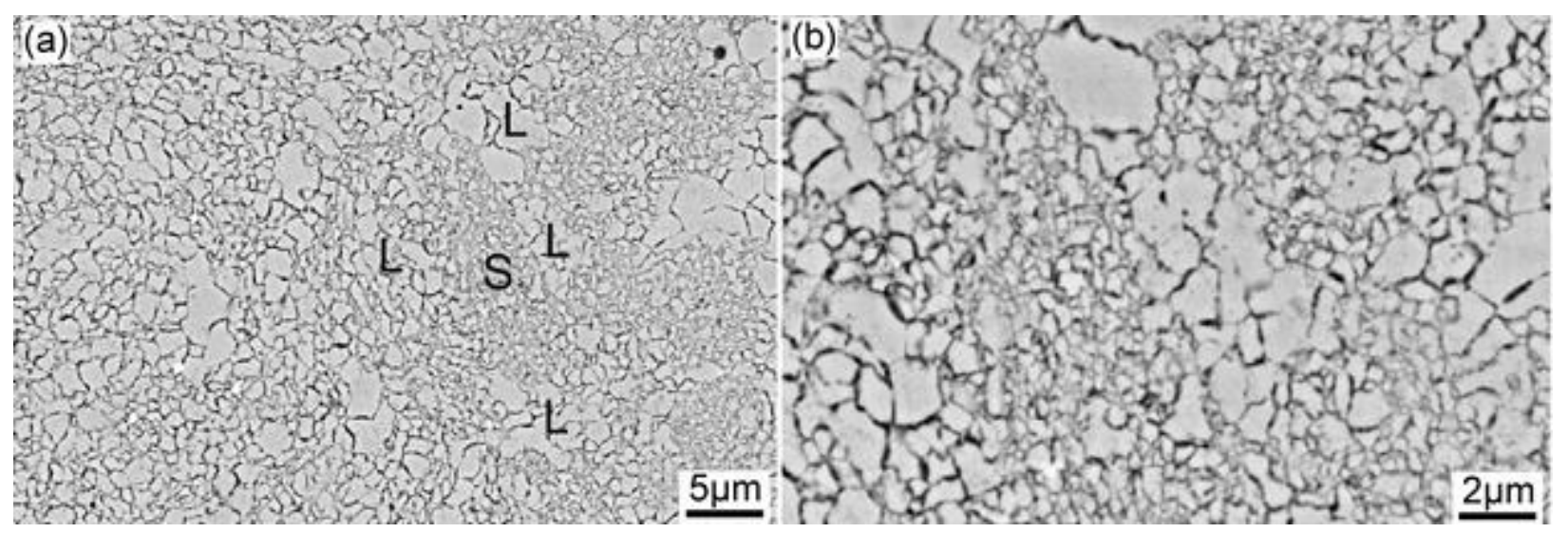

Fig. 2.9 Grain structure of Co-based ODS alloy [79]. 
Fig. 2.9 shows grain structure of heat treated Co-based ODS alloy with two types of grain size, small (S) and large (L) as in (a), which is attributed to the pinning of oxide dispersion and precipitates. Fig. 2.9(b) also indicates that the ultrafine grains are surrounded by the relatively large grains. The density, size, and local distribution of dispersoids affect the pinning of dislocations of ODS alloys, which is a major relevance to the creep resistance.

\subsubsection{ODS Alloy Processing Methods}

As discussed above in the ODS alloy types section, the two common classes of alloys, which are commercially significant are the ODS-NiCrAl and ODS-FeCrAl alloys. Both contain chromium and/or aluminum for corrosion and oxidation resistance, and yttrium or titanium oxides for creep strength. With yttrium oxide cannot be introduced into either iron or nickel by any method other than mechanical alloying (MA), which is the main driving force behind the 1968 development of mechanical alloying by the International Nickel Company [19].

With the main target of producing complex oxide dispersion strengthened alloys, mechanical alloying is a solid state alloying process which produces alloys that are difficult or impossible to produce by conventional melting and casting techniques. The Mechanical alloying is usually directed to producing high temperature strength materials from a fine homogeneous oxide particles (typically $\mathrm{Y}_{2} \mathrm{O}_{3}$ ) and elemental powders of chromium, aluminum, and titanium for corrosion and oxidation resistance, milled together with base metals (iron, nickel) in high-energy ball mill to complete solid state alloying of the resulting particulate agglomerates. MA is a very time consuming and energy intensive process. In contrast, conventional ball milling can be used to reduce the size of powders which has the competing process of cold-welding in lower energy environments. This requires the use of process control agents (PCA) to obtain a balanced coldwelding and fracturing. Detail review works of MA can be found [18-19]. 
However, the ball milling time can be reduced by using Hosokawa mechano-chemical bonding (MCB), a technique that can bond elemental particles together using only mechanical energy in a dry phase without needing solvents or external heating. This can avoid potential contaminations and reactions to the powder. It is an effective approach to blend alloying powders, forming composite particles consisting of hosting particles as core and small particles or fibers that are coated around the core particles [81]. During MCB processing, the starting powder mixtures are subjected to high compression, shear, and impact forces as they pass through a narrow gap in a high speed rotating device, for which the elemental particles are dispersed, mixed, shaped, and bonded together forming composite particles of the starting ingredients. So far, the green MCB technology has been utilized to make various composite particles used in the fields of functional gradient materials, batteries, cermets, fuel cells, polymers, cosmetics, and pharmaceuticals [8183]. Preliminary studies showed that utilization of MCB processing to blend nickel-based ODS alloying powders was able to homogenously disperse yttrium oxide particles on the base hosting particles to form composite structure, generating a nano-sized Y-Al-O enriched film around the hosting particles [84-85].

After performing mechanical alloying, which produces controlled extremely fine microstructure with repeated welding, fracturing, and swelling of mixtures of powder particles in a high energy ball milling, subsequent steps of powder consolidation and thermal-mechanical processing are needed to get the final ODS alloy products. Fig. 2.10 explains a typical process steps to get to the final steps of obtaining high temperature ODS alloys [86]. The steps of processing include, but not limited to milling of metal powders, canning, hot consolidation, and post consolidation thermal-mechanical treatment. The milled powders are commonly canned and vacuum degassed before consolidation by fabrication processes, such as hot isostatic pressing 
(HIPing), cold die compaction, hydrostatic compaction, vacuum sintering or hot extrusion, producing high density products. The fabrication processes are reviewed in detail by Moyer [22].

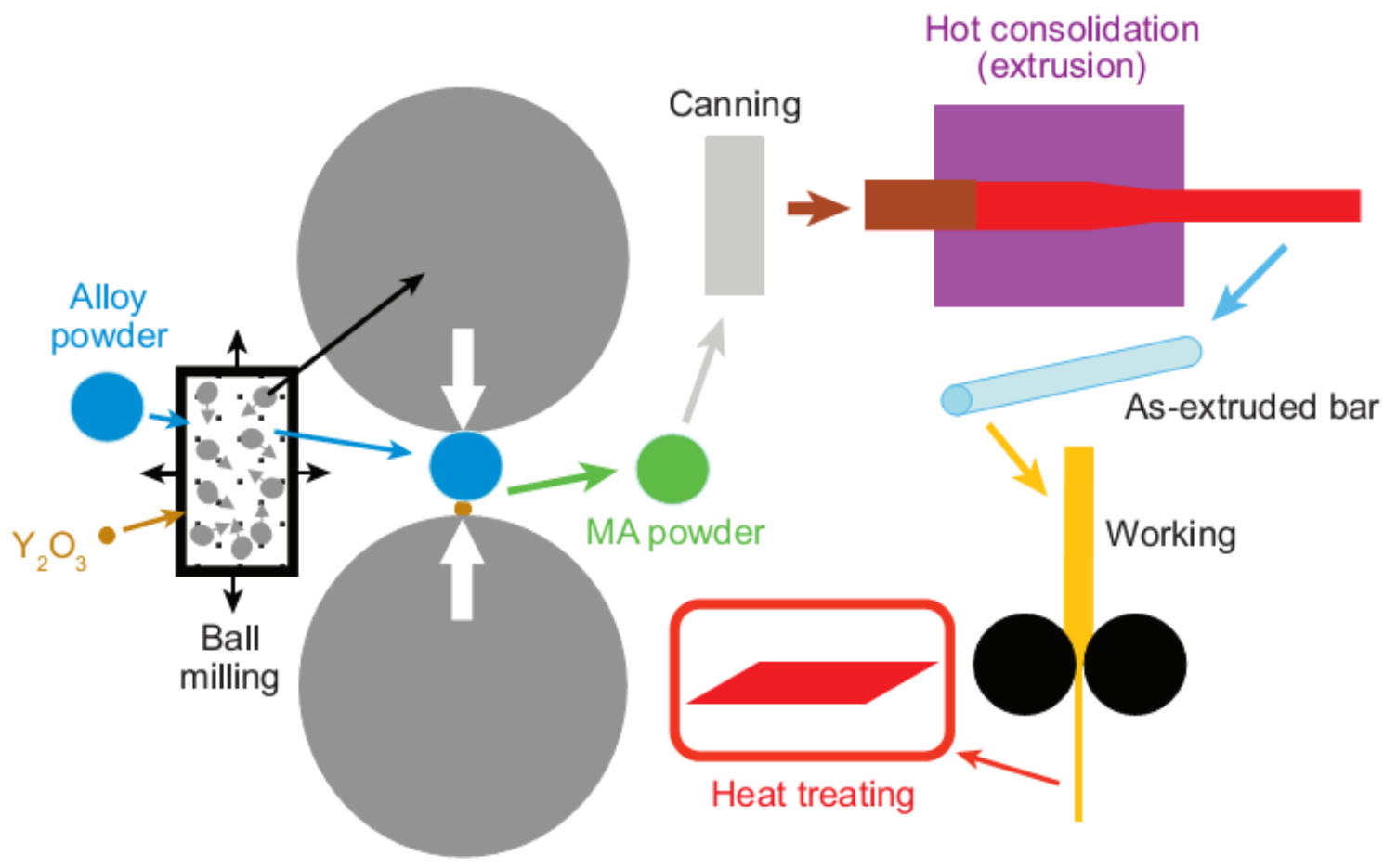

Fig 2.10 Typical processing steps of ODS powder to reach final products [86].

Usually for experimental investigation of ODS alloys different routes of consolidation is followed than the one presented in Fig. 2.10, which it is usually applicable for ODS superalloy processing. After MA or ball milling (typical experimental setup), ODS powders consolidated by HIPing or hydrostatic pressing can be heat treated by using sintering in conventional furnaces without passing through extrusion step.

\subsubsection{ODS Alloy Applications}

Compared to conventional superalloys, ODS alloys have distinct advantages in that they exhibit high temperature creep strength, exceptional inherent resistance to high-temperature corrosion and oxidation, low swelling and no embrittlement with exposure to high-energy neutrons. Because of these properties, ODS alloys provide alternative structural material choices for power 
plants such as land based and aerospace turbine components (blades, vanes, and heat exchangers) [3, 11, 87-88], and for advanced fission and fusion technologies (advanced fast reactor fuel cladding materials, fusion reactor materials) [89-98].

Most of the main material requirements in ODS alloys for power plants were discussed in the previous sections. Yvon and Carre [90] reviewed the material requirements for advanced nuclear systems, which covers high temperature structural materials, fast neutron resistant core materials, and reactor and power conversion technologies, such as intermediate heat exchanger, turbo-machinery, high temperature electrolytic etc. The main requirements for which these reactor system materials should satisfy are: (a) dimensional stability of in-core materials under irradiation, which may be under stress (irradiation creep or relaxation) or without stress (swelling, growth), (b) acceptable mechanical properties after aging (tensile strength, ductility, creep resistance, fracture toughness, resilience), and (c) retain material properties in corrosive environments (reactor coolant or process fluid). The materials which satisfy the above requirements include ferritic/martensitic and nickel based ODS alloys.

\subsection{ODS Alloy Mechanical and Microstructure Characterization Methods}

Due to ODS alloy applications in severe high temperature environments, they are subjected to high temperature creep, fatigue loading, corrosion and oxidation. In gas turbine components either aircraft propulsion or land-based power generation plants, high temperature creep and fatigue loadings occur simultaneously in the root sections [99]. These alloys, on commercial products have been studied extensively for their resistance to such environments for their full implementation either in real time environments or in laboratory scale facilities, but experimental works are still exploring new ways of manufacturing and testing methods. Some of the tests implemented very often are described in the subsequent sections. 


\subsubsection{Oxidation Test (Cyclic Testing, Isothermal Testing)}

The two major environmental effects at high temperature on ODS alloys are oxidation and hot corrosion. Below $980^{\circ} \mathrm{C}$, the level of oxidation resistance is a function of the chromium content as $\mathrm{Cr}_{2} \mathrm{O}_{3}$ is formed as a protective oxide. However, above $980{ }^{\circ} \mathrm{C}$ the aluminum content becomes crucial for the formation of a dominant protective $\mathrm{Al}_{2} \mathrm{O}_{3}$ [100]. Hot corrosion usually called as sulfidation, occurs due to the presence of sulfur in the fuel combined with salt from the environment (eg. $\mathrm{Na}_{2} \mathrm{SO}_{4}$ ). The combined protective oxide forming nature of chromium and aluminum is very important in ODS alloy application for long term corrosion and oxidation resistance. Oxidation and corrosion tests are among the common ODS alloy characterization tests implemented at higher temperature.

There are a number of research works conducted on the oxidation of nickel based ODS alloy at elevated temperatures [101-106]. The oxidation kinetics, which is found from the weight gain, microstructure, and mechanical properties are the main focus while conducting oxidation tests, such as cyclic and isothermal in air or laboratory air at high temperature. The oxidation kinetics is one of the most important factors for high temperature materials exposed for longer times at elevated temperatures [11]. The change in oxidation rate is related to the consumption of protective scale forming elements from the matrix, which affects the external oxide scale formation and hence the life of the materials.

Angermann et al. [14] investigated the oxidation behavior of commercial nickel based MA 6000 and PM 3030 at $1150{ }^{\circ} \mathrm{C}$ for different holding times up to $200 \mathrm{hrs}$ to see the initial oxidation impact on the formation of protective oxides. It was concluded that the protectiveness of secondary $\mathrm{Al}_{2} \mathrm{O}_{3}$ at a later stage is determined by initial stages of oxidation. In addition, Guttmann et al. [26] investigated the cyclic and isothermal oxidation of commercial nickel based MA 6000 in the 
temperature range of $900-1050{ }^{\circ} \mathrm{C}$, with emphasis given at $1050{ }^{\circ} \mathrm{C}$. Excellent oxidation resistance based on the formation of an internal continuous $\mathrm{Al}_{2} \mathrm{O}_{3}$ layer was evident. It was noted that the oxidation involved complex mechanisms and alteration of the oxidation behavior occurred after long term exposure.

Furthermore, Weinbruch et al. [25] studied the oxidation behavior of two ODS superalloys, the chromia-forming PM 1000 (nickel-based) and the alumina-forming PM 2000 (iron-based) at temperatures between 900 and $1300{ }^{\circ} \mathrm{C}$ in air. They reported a subparabolic time dependence and an Arrhenius-type temperature dependence rate constants for oxide scale growth rates of both alloys. It is concluded that complete depletion of yttrium within the oxide scales indicated the diffusion of yttrium to the surface of the oxide scales for both alloys. Moreover, after the depletion of yttrium, scale growth takes place by simultaneous inward diffusion of oxygen and outward diffusion of cations, which makes the oxidation process similar to conventional (non ODS) alloys of the same base composition, at least in a qualitative way. The mechanism of yttrium depletion is shown as in Fig. 2.11.
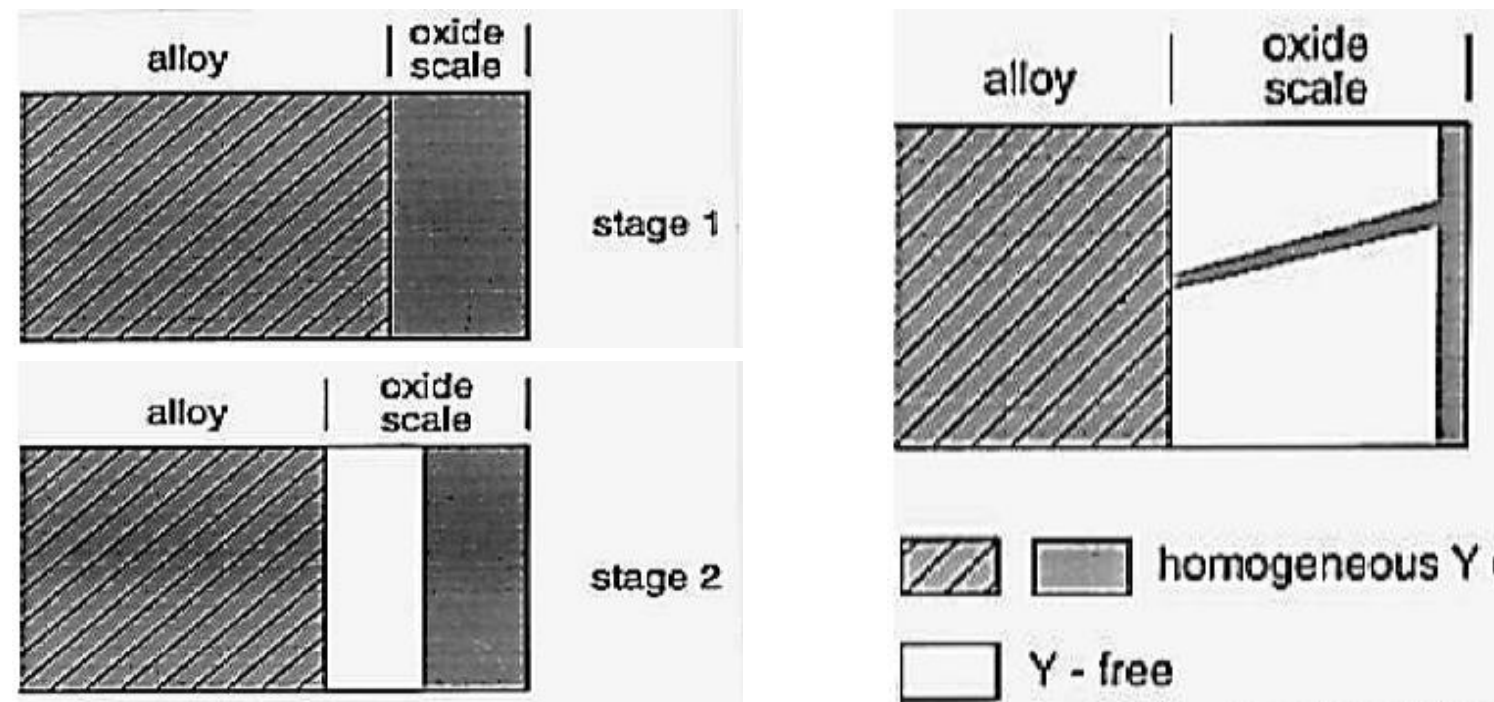

stage 3

stage 2

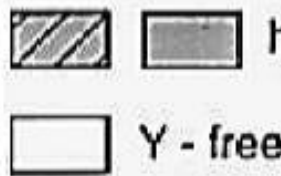
homogeneous $Y$ distribution

Fig. 2.11 Schematic illustration showing different stages of yttrium distribution within the oxide scale [25]. 
Moreover, Pint et al. [102] characterized the alumina scales formed during cyclic oxidation at $1200{ }^{\circ} \mathrm{C}$ on three $\mathrm{Y}_{2} \mathrm{O}_{3}-\mathrm{Al}_{2} \mathrm{O}_{3}$-dispersed alloys: $\mathrm{Ni}_{3} \mathrm{Al}, \beta-\mathrm{NiAl}$, and $\mathrm{FeCrAl}$ (Inco alloy MA956). It is reported that in each case, the $\mathrm{Y}_{2} \mathrm{O}_{3}$ dispersion improved the $\alpha-\mathrm{Al}_{2} \mathrm{O}_{3}$ scale adhesion. However, in the case of $\mathrm{Ni}_{3} \mathrm{Al}$, an external Ni-rich oxide spalled and regrew, indicating a less-adherent scale. Furthermore in their study of using scanning-transmission electron microscope (STEM) analysis of the scale near the metal-scale interface revealed that the scale formed on ODS FeCrAl showed no base metal-oxide formation, but the scale formed on $\mathrm{ODS} \mathrm{Ni} 3 \mathrm{Al}_{3}$ showed evidence of cracking and Ni-rich oxide formation. They suggested a diagram showing the different oxide scales formed on both ODS $\mathrm{Ni}_{3} \mathrm{Al}$ and ODS FeCrAl alloys, Fig. 2.12.
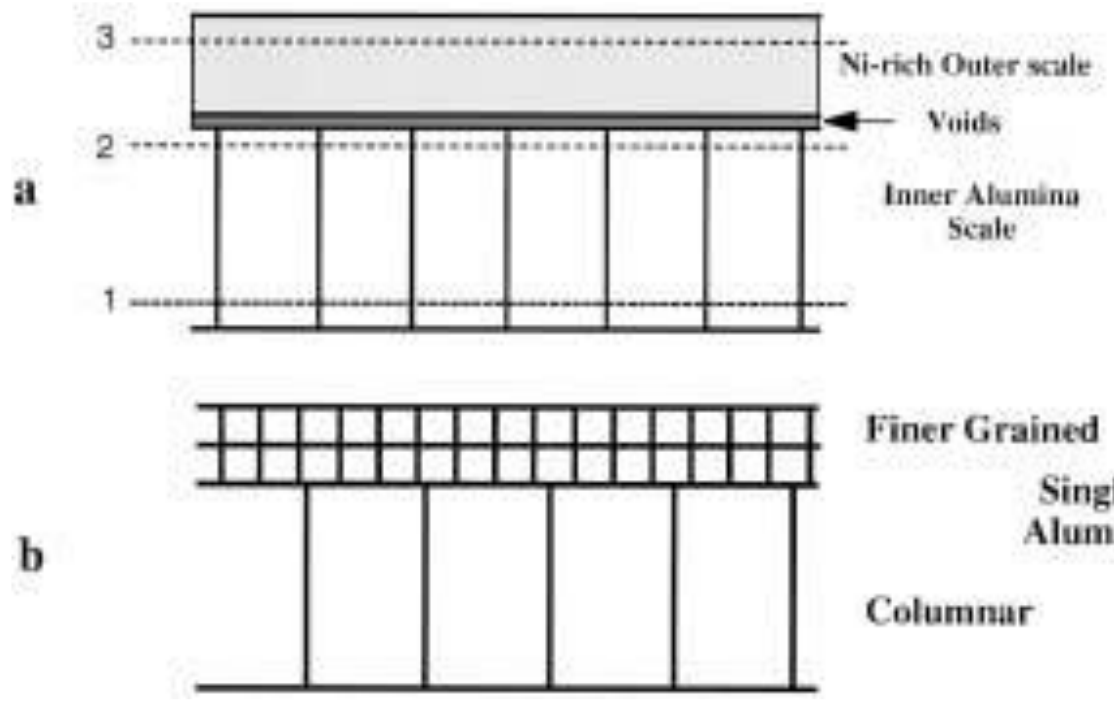

Finer Grained

\section{Single Layer \\ Alumina Seale}

\section{Columnar}

Fig. 2.12 Schematic of the scale formed on (a) ODS Ni $\mathrm{Nl}_{3}$ and (b) OD NiAl and ODS FeCrAl [102].

Additionally, they suggested a mechanism of Ni-rich outer scale spallation and regrowth on ODS $\mathrm{Ni}_{3} \mathrm{Al}$, shown in Fig. 2.13. The underlying $\mathrm{Al}_{2} \mathrm{O}_{3}$ scale cracks but remains adherent to the metal, Fig. 2.13(b). Due to the low Al content, Ni-rich oxide is able to form in the cracks before a healing alumina layer forms and under continued thermal cycling, the layer grows back. 


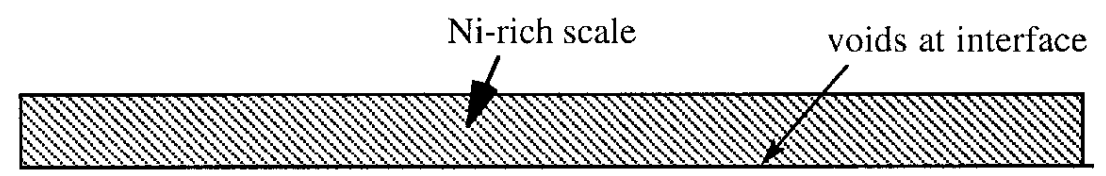

$\mathrm{Al}_{2} \mathrm{O}_{3}$ scale

ODS $\mathrm{Ni}_{3} \mathrm{Al}$

$\mathrm{Al}_{2} \mathrm{O}_{3}$ scale

(a) scale at temperature, prior to cooling.

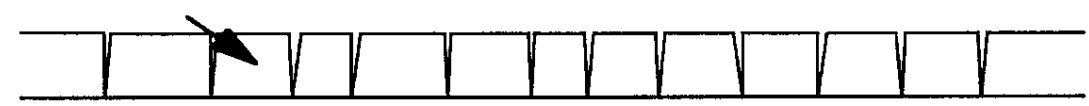

b) after cooling to room temperature, outer scale spalled, inner scale cracked.

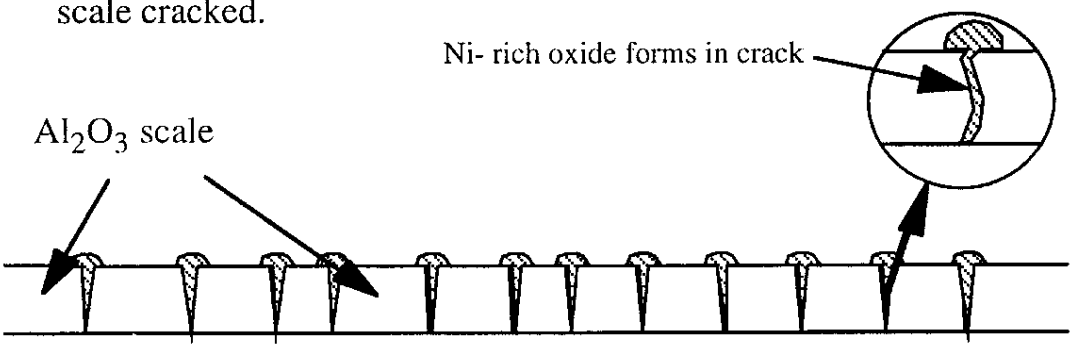

c) shortly after reinsertion, $\mathrm{Ni}$-rich oxides form in the cracks.

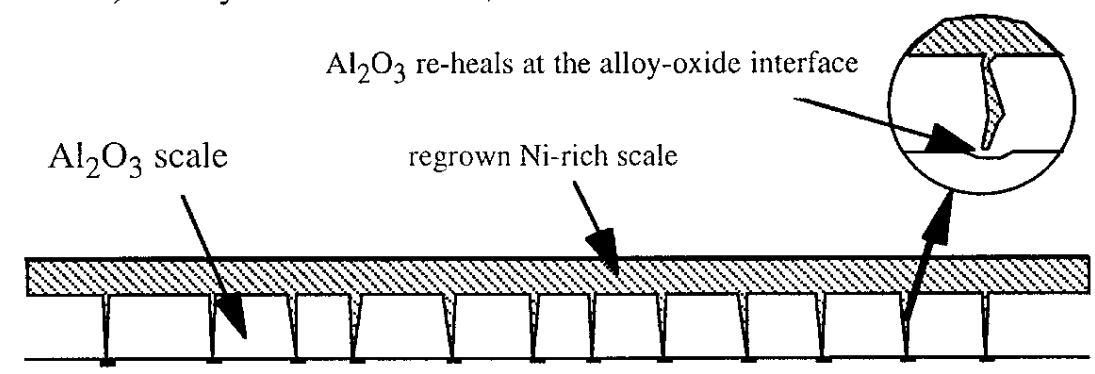

d) at longer times, the cracks reheal preventing further Ni-rich oxide formation.

Fig. 2.13 Schematic mechanism of spallation and regrowth of the Ni-rich outer scale on ODS $\mathrm{Ni}_{3} \mathrm{Al}[102]$.

\subsubsection{Thermo-Mechanical Test}

High temperature materials usually subjected to thermal, mechanical, and thermomechanical combined loads at operation. Thus, it is critical to study these loading systems for ODS alloys at high temperature environments. The common tests in combination with microscopy and spectroscopy observation includes tensile, compression, hardness, fatigue, creep tests and a combination of the latter two. 
Eastrin et al. [107] studied the high temperature tensile creep behavior of ODS nickelbased alloy PM 1000 at $900{ }^{\circ} \mathrm{C}$ in air so as to investigate the effect of grain orientation and grain aspect ratio (GAR). They tested three different heats of PM 1000 (i) a (100)-fiber structured bar material with a grain aspect ratio of 10 along the longitudinal direction, (ii) a (111)-fiber structured bar material with a GAR of 4 and (iii) a pancake structured sheet material with a GAR of 4 and (100) $\{011\}$ cube on edge texture deformed in the (110) axial direction. They reported at high strain rate the creep resistance dependence on texture. But at low creep rates instead of the texture effect; its dependence was on tertiary creep processes (such as void formation and void growth on transverse grain boundaries and in fine grained enclaves) and the creep life being controlled by creep ductility.

In addition, Heilmaier et al. [108] studied the cyclic stress-strain behavior of ODS nickelbased alloy PM 1000 under constant and variable amplitude loading conditions. They carried single-step tests with constant total strain amplitude and incremental step tests with the same amplitude range at 850 and $1000{ }^{\circ} \mathrm{C}$. It was indicated that the interaction of the dislocations with the fine, homogeneously distributed oxide dispersoids found to suppress the formation of dislocation cell structures. Moreover, it was reported that the presence of slight deviation in the cyclic stress-strain curve obtained from constant amplitude tests and the incremental step tests despite of the similar microstructures.

Furthermore, Ngala and Maier [99] studied the creep-fatigue interaction of ODS nickelbased superalloy PM 1000. They used, fully reversed symmetrical push-pull isothermal fatigue, thermo-mechanical fatigue (TMF), slow-fast and tensile hold time tests in the temperature range of 450 to $1050{ }^{\circ} \mathrm{C}$. They reported that TMF tests resulted in unexpectedly low fatigue lives and 
grain boundary cavitation observation in the in-phase TMF tests which indicates creep damage to play an important role under TMF loading conditions.

Moreover, Kovan et al. [109] studied the cyclic deformation and lifetime behavior of nickel-based ODS superalloy, PM 1000 under thermal-mechanical fatigue conditions in the temperature range of $450-850{ }^{\circ} \mathrm{C}$. They indicated that isothermal fatigue from literature exhibited a longer life time than thermal-mechanical fatigue at corresponding mechanical strain amplitude. Also in thermal-mechanical fatigue loading, cracks tended to initiate intergranularly and propagate transgranularly. Moreover they developed life prediction models to evaluate the possibility of predicting both thermal-mechanical fatigue and isothermal fatigue lifetimes.

Finally, He et al. [23] studied ODS nickel-based superalloy foil $0.1 \mathrm{~mm}$ thick deposited by EB-PVD technology and followed by HIP treatment. They reported the results of room temperature tensile tests, which indicates the increase in ultimate tensile strength and plastic properties of the foil after HIP compared to the as-deposited.

\subsubsection{Indentation (Microhardness, Nanoindentation) Testing}

Indentation tests like the rest of the tests mentioned above is used to evaluate the mechanical properties, especially the hardness and stiffness responses of high temperature materials at room temperature using commercial nanoindentation and microindentation techniques [110-118] or at elevated temperature using in house made micro indentation system [119]. In indentation system the information on material behaviors or properties are obtained from the indenter load and depth, measured continuously during loading and unloading by using pointed or spherical indenters, Fig 2.14. 


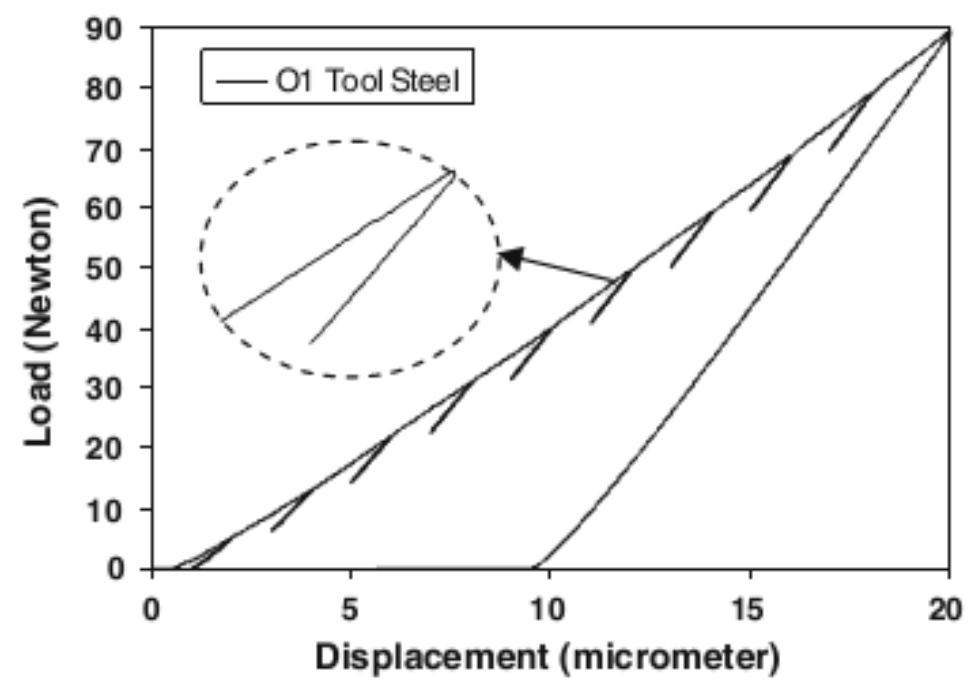

Fig. 2.14 Typical experimental load-displacement curve obtained with multiple partial unloading [117].

Formation of stable and adherent protective oxide scales, on high temperature materials are very important aspects to withstand degradation from reaction with gases and condensed products. The mechanical properties of such thermally grown surface oxides are very important for the integration and protectiveness of the underlying materials. Tortorelli et al. [110] reviewed and discussed the use of mechanical property microprobe (MPM) based on low-load, depth-sensing submicrometer indentation testing for examining surface mechanical properties such as determination of elastic and plastic properties of oxide scales.

Yang and Vehoff [112] systematically studied the dependence of nanohardness indentation size and grain size on pulse-electrodeposited nanocrystalline nickel specimen and heat-treated to produce grain sizes from the nanoscale to microscale. They reported quantitatively the relative dependence of plastic zone size to indentation size. Also reported the local interaction between dislocations and grain boundaries in single grains led the different dependences of hardness upon indentation depth. Moreover, they related the dislocations, which nucleate below the indenter tip, 
to only interact directly with the surrounding interfaces for grains below $900 \mathrm{~nm}$ for which the nanohardness and pop-in width are grain size dependent.

With regard to the application of indentation tests on ODS alloys, Liu et al. [113] studied the radiation-hardening of ODS alloys exposed to ion irradiation using microindentation. They reported the microhardness measurements carried out on ion-irradiated three ODS specimens with ultra-low load indention for which the indentation results mentioned an increase in hardness after irradiation on all the three samples. In addition, Kasada et al. [119] investigated the irradiation hardening of Fe-based model ferritic alloys after Fe-ion irradiation experiments in order to deduce mechanistically based nominal hardness from the nano-indentation tests on the ion-irradiated surface.

Furthermore, Tannenbaum [120] developed a load-based micro-indentation method for nondestructive evaluation (NDE) of high temperature materials exposed to thermal loads in air and laboratory air and evaluated TBC coating surface stiffness responses capable of assessing damage accumulation and macroscopic debonding failure sites following thermal exposure to elevated temperatures. He followed a classical Hertzian contact mechanics approach, a micro-indentation technique that does not require system compliance calibration or the use of high precision depth sensors, which led to the development of both portable and high-temperature micro-indentation system for $\mathrm{TBC}$ and in general high temperature materials mechanical property evaluation up to $1100{ }^{\circ} \mathrm{C}$.

More recently, Lin et al. [121] fabricated ferritic ODS alloy foils with high oxide contents, as high as $8.5 \mathrm{wt} \%$ in which the dispersoids in the ODS alloy fabricated by this method are mainly composed of bcc structured yttria and with no Y-Al-O nanocluster detected. They obtained that the hardness was found to increase linearly with the yttria content. 


\subsection{ODS Alloy Coating}

Research indicated that ODS alloys are not only used in their bulk form produced in mass by extrusion, they can also be used as coatings produced by deposition due to their excellent high temperature property. Therefore, ODS alloy coatings are believed to enhance the high temperature oxidation and corrosion resistances of high temperature materials with their dispersion strengthening and microcrystalline structure [23-24, 75].

He et al. [75] used special electro-spark deposition technique to deposit Ni-20Cr- $\mathrm{Y}_{2} \mathrm{O}_{3}$ ODS alloy coatings on the surface of Ni-20Cr alloy. They reported that the ODS coatings possessed micro-crystalline structure and good metallurgical bonding with the substrates studied. In addition, the experimental results of high-temperature oxidation in air at $1000{ }^{\circ} \mathrm{C}$ were reported that the formation of $\mathrm{Cr}_{2} \mathrm{O}_{3}$ scale has been promoted on these coatings with excellent scale spallation resistance by selective oxidation of $\mathrm{Cr}$. In another paper with the same author [24], FeCr-Ni-Al- $\mathrm{Y}_{2} \mathrm{O}_{3}$ ODS alloy coatings were deposited on the surface of $1 \mathrm{Cr} 18 \mathrm{Ni9Ti}$ stainless steel by using high-frequency electric-spark technique. As reported these ODS coatings possessed micro or nano-crystalline structure with metallurgical bonding to the substrates observed by transmission electron microscopy (TEM). The results of high-temperature oxidation performed in air at $1000{ }^{\circ} \mathrm{C}$ indicated that the selective oxidation of $\mathrm{Cr}$ was greatly promoted and the scale spallation resistance significantly improved.

In addition, Hongmei et al. [122] used a simple but more efficient technique highfrequency electropulse deposition technique to produce microcrystalline MGH754 ODS alloy (Ni20Cr-0.5Ti-0.3Al- $0.6 \mathrm{Y}_{2} \mathrm{O}_{3}$ ) coatings on $1 \mathrm{Cr} 18 \mathrm{Ni} 9 \mathrm{Ti}$ stainless steel substrate. The result obtained indicated that their coating has a very fine grain size of 30-300 nm and good metallurgical bonding with the substrate. It is also reported that the isothermal oxidation in air at $1000{ }^{\circ} \mathrm{C}$ for $100 \mathrm{hrs}$ 
showed micro-crystallization and dispersed oxide particles promoted the selective oxidation of $\mathrm{Cr}$ to form a protective and continuous $\mathrm{Cr}_{2} \mathrm{O}_{3}$ scale. This scale reported to greatly improve the scale spallation resistance and increasing the oxidation resistance of the $1 \mathrm{Cr} 18 \mathrm{Ni}$ Ti substrate.

Furthermore, He et al. [23] studied $\mathrm{Y}_{2} \mathrm{O}_{3}$ dispersion strengthened Ni-based superalloy foil $0.1 \mathrm{~mm}$ thick deposited by EB-PVD technology and followed by HIP treatment. The microstructure investigations on as-deposited and HIPed superalloy foils were reported as columnar crystals formed on the evaporation side and equiaxed grains formed on the substrate side. In addition, the cross-section observation was reported to contain $150-300 \mathrm{~nm}$ grains of matrix with 10-25 nm particles of $\mathrm{Y}_{2} \mathrm{O}_{3}$ homogeneously dispersed in the matrix. Furthermore, after HIP treatment the columnar crystals were reported to be turned into equiaxed grains and little growth of oxide dispersoids observed. Additionally, they studied room temperature tensile tests and compared the as deposited with HIP treated foils. It is reported that the ultimate tensile strength and elongation percentage were $1230 \mathrm{MPa}$ and 0.92 for $\mathrm{HIPed}$ and $725 \mathrm{MPa}$ and 0.49 for asdeposited foil, respectively.

Moreover, Song et al. [123] studied a $\mathrm{Y}_{2} \mathrm{O}_{3}$ dispersion strengthened nickel-based superalloy sheet $(0.15 \mathrm{~mm}$ thick) prepared by EB-PVD technology. They used different heat treatments to improve the mechanical properties of the alloy sheet and conducted tensile tests at room temperature on specimens of as-deposited and heat treated. It is reported that the results showed equiaxed grains on the substrate side and columnar grains on the evaporation side of the as deposited sheet. In addition, the as-deposited sheet was reported to have poor ductility due to micro-pores between columnar grains. It was mentioned that the strength and ductility were found to be improved effectively by annealing at $800{ }^{\circ} \mathrm{C}$ for $3 \mathrm{hrs}$. However, for samples treated at $1100^{\circ} \mathrm{C}$, the strength found to drop down due to the precipitates of $\mathrm{Y}_{3} \mathrm{Al}_{5} \mathrm{O}_{12}$ (YAG). 
Finally, Liu et al. [124] studied newly designed and laser cladded cobalt-free, nickel-based ODS alloy coating (Ni-3) as a further step in obtaining high temperature wear and corrosion performances used for sealing surfaces of nuclear power valves. It was reported that the micro hardness of the Ni-3 coating is about HV500. After high temperature wear and corrosion study, they concluded that this newly designed and laser cladded Ni-3 alloy coating appeared to be the viable alternative material and technique for Co-free alloy, especially used in the nuclear valve sealing surfaces.

\subsection{Motivation}

In the survey of TBC systems, it is indicated that TBC systems are good protective materials in severe high temperature environments, however their complicated failure mechanisms especially the TGO formation makes their life shorter. The search for high temperature structural materials supporting or replacing TBC systems is always active and ODS alloys are receiving great attention due to their exceptional high temperature properties and their ability to be used as a coating system in high temperature environments. Due to these ODS alloy properties, they can be a candidate material for coating of advanced turbine components with the possibility of implementing micro-channel cooling system within or beneath the ODS alloy coating system.

Therefore, the motivation of this research work is to investigate MCB plus ball milled nickel-based ODS alloys mechanical and microstructure properties at high temperature environments for their structural integrity in their intended application as a structural coating system in advanced gas turbine components. Further motivation is implementing finite element

analysis (FEA) of ODS alloy coating with micro-channel cooling system as a possible means of implementing ODS alloy applications as a stand-alone structural coating, which compares the thermal protectiveness with TBC systems. 


\subsection{Objective}

The objective of this research work is to investigate the mechanical and microstructure property of ODS alloys processed by combined MCB technique and ball milling subjected to high temperature exposure for their structural integrity applicable to high temperature ODS alloy coating capable of implementing micro-channel cooling system.

The specific objectives are:

- Analysis of the microstructure and elemental distribution of ODS alloys subjected to high temperature oxidation at $1100{ }^{\circ} \mathrm{C}$, matrix and oxide scale.

- Investigation of the mechanical property (stiffness response) of ODS alloys subjected to high temperature oxidation at $1100^{\circ} \mathrm{C}$.

- Simulation of heat transfer through ODS alloy coating with micro-channel cooing system using finite element method.

- Compare the thermal distribution of ODS alloy coating with micro-channel cooling system and TBC system using finite element method. 


\section{MATERIALS AND EXPERIMENTAL METHODS}

\subsection{Materials}

The raw materials used in this study were commercial metal and ceramics powders including $\mathrm{Y}_{2} \mathrm{O}_{3}(<50 \mathrm{~nm}, 99.99 \%$ pure $), \mathrm{Al}(4.5-7 \mu \mathrm{m}, 97.5 \%$ pure $)$ and $\mathrm{Ni}(4 \sim 8 \mu \mathrm{m}, 99.9 \%$ pure $)$ purchased from Sigma Aldrich Inc., Alfa Aesar and Atlantic Equipment Engineers respectively. $\mathrm{Cr}(7.5 \sim 10 \mu \mathrm{m}$ and $8 \sim 12 \mu \mathrm{m}, 99.5 \%$ pure, $), \mathrm{W}(0.5 \sim 1 \mu \mathrm{m}$ and $2 \sim 4 \mu \mathrm{m}, 99.95 \%$ pure $)$ and high density Ni powder $(8 \sim 15 \mu \mathrm{m})$ were provided by F.W. Winter Inc. \& Co., Buffalo Tungsten Inc., and Inco Special Products respectively. These powders were stored separately in an inert environment in sealed bottles full of argon gas. Four batches of ODS alloying powder samples were prepared according to master alloy powder size ( $\mathrm{Ni}$ and $\mathrm{Cr}$ ) with an addition of trace refractory powder, tungsten powder, to explore the effects of master powder size and trace refractory powder on mechanical alloying produced by the MCB process. Considering the short time milling as well as no ball-powder-ball collision involved during MCB process [125], the average sizes of all starting powder constituents ranged from 0.5 to 15 microns. For conventional ball milling or rod milling MA process, however, the starting powders usually have average diameters ranging from 1 to 500 micron [126]. Since aluminum powder is usually soft and easy to deform, the size of aluminum powder was kept constant. In order to examine the dispersion effect caused by MCB-induced mechanical alloying, the composition and particle size of yttrium oxide nanoparticle were kept constant in all powder samples. Early studies showed that the addition of hard-to-deform refractory elements, such as Mo, Ta, or W, to ODS alloys could stabilize the yttrium oxide particles in ODS alloys at elevated temperatures [127]. The high chromium content was added to increase strength and improve corrosion resistance. The aluminum content enhances the formation of a stable and adherent $\alpha-\mathrm{Al}_{2} \mathrm{O}_{3}$ scale providing excellent high temperature 
oxidation resistance. For each ODS powder sample, the powder components were weighted according to the designed composition, initially mechanically blended, and then placed into a bottle that was sealed and filled with argon gas to prevent oxidation of powders. All these operations were done under argon gas environment inside a glove box chamber. Each bottle containing ODS powder sample weighed approximately 200 gm. Table 4 lists the sample identification number, element composition (wt.\%), and powder sizes. Specifically for this research work powder samples A1 and B1 are used for further analysis.

Table 4 Starting chemical composition of ODS powders before MCB process [125].

\begin{tabular}{|c|c|c|c|c|c|}
\hline & $\mathrm{Cr}(7.5 \sim 10 \mu \mathrm{m})$ & $\mathrm{Al}(4.5 \sim 7 \mu \mathrm{m})$ & $\mathrm{Y}_{2} \mathrm{O}_{3}<50 \mathrm{~nm}$ & $\mathrm{~W}(\sim 1 \mu \mathrm{m})$ & $\mathrm{Ni}(4 \sim 8 \mu \mathrm{m})$ \\
\hline $\mathrm{A} 1$ & 20 & 5 & 1.5 & 0 & 73.5 \\
\hline $\mathrm{A} 2$ & 20 & 5 & 1.5 & 3 & 70.5 \\
\hline & $\mathrm{Cr}(8 \sim 12 \mu \mathrm{m})$ & $\mathrm{Al}(4.5 \sim 7 \mu \mathrm{m})$ & $\mathrm{Y}_{2} \mathrm{O}_{3}<50 \mathrm{~nm}$ & $\mathrm{~W}(2 \sim 4 \mu \mathrm{m})$ & $\mathrm{Ni}(8 \sim 15 \mu \mathrm{m})$ \\
\hline $\mathrm{B} 1$ & 20 & 5 & 1.5 & 0 & 73.5 \\
\hline $\mathrm{B} 2$ & 20 & 5 & 1.5 & 3 & 70.5 \\
\hline
\end{tabular}

\subsection{Experimental Methods}

In order to investigate the microstructure and mechanical properties of ODS alloys, experimental setups including ball milling of MCB processed powders, powder compacting and sintering, high temperature thermal cyclic testing, and microindentation testing procedures were performed. Also, surface and metallographic cross-section characterization methods were employed. Furthermore, thermal analysis was conducted using finite element analysis (FEA) for a procedure which may enhance the application and capability of ODS alloys as high temperature coating by implementing micro-channel cooling system within the ODS coating or between ODS coating and substrate. 


\subsubsection{ODS Powder Processing by MCB and Mechanical Alloying}

The as-initially-blended powder samples were stored in bottles filled with argon gas and sent to Hosokawa Micron Powder Systems, Summit, NJ, for the preparation of ODS powders using MCB technique. The MCB technology was developed by Hosokawa Micron Corporation, Osaka, Japan and has been utilized to make various composite particles used in the fields of functional gradient materials, batteries, cermets, fuel cells, polymers, cosmetics, and pharmaceuticals. It is often considered as an enhancement or alternative to the conventional mechanical alloying (MA) process using ball milling or rod milling [128-129]. Also, the newly developed MCB processing technique is simple, environmentally friendly, and can be scaled up to 300 liters per batch. The MCB particle bonding process takes place in the solid state without needing solvents or external heating. During MCB processing, the starting powder mixtures were subjected to high compression, shear, and impact forces as they pass through a narrow gap in a high speed rotating device (typically around $4000 \mathrm{rpm}$ ). As a result, the particles were dispersed, mixed, shaped, and bonded together. Consequently, the composite particles consisting of various combinations of the starting ingredients were formed. In this study, the starting powder mixtures were MCB processed for only 30 minutes. It was expected to have $\mathrm{Y}_{2} \mathrm{O}_{3}$ nanoparticles dispersed and bonded onto the surfaces of larger hosting particles such as $\mathrm{Ni}$ and $\mathrm{Cr}$ particles, which in turn creating oxide dispersion effects. After MCB processing, the powders were stored in sealed bottles filled with argon gas. Small amounts of MCB-processed (5 gm) powders were taken for analysis using transmission electron microscopy (TEM), scanning electron microscopy (SEM) and X-ray diffraction (XRD).

In order to obtain ODS alloy powders with good microstructure and optimum oxide dispersion powder size, mechanical alloying was performed on MCB processed powders discussed 
above in a planetary ball mill for different time durations with three different sized stainless steel balls (20, 10 and $6 \mathrm{~mm}$ in diameter) having a ball to powder ratio (BPR) of 30:1 and a speed of $300 \mathrm{rpm}$. The steel jars loaded with powders were sealed in a glove box under argon atmosphere in order to avoid oxidation of powders during ball milling. Mechanical alloying experiments on MCB processed powders were carried out for 5, 40, 60, 80 and 120 hrs to identify the optimum ball milling time to produce the desirable ODS composite particles. $0.5 \mathrm{wt} \%$ stearic acid was used as a process control agent (PCA) to minimize cold welding between powder particles and inhibit agglomeration.

\subsubsection{ODS Powder Compacting and Sintering}

After mechanical alloying, ODS powders were compacted into cylindrical pellets. Before ODS alloy powders were compacted in to cylindrical pellets, the powders were pre-heated in a conventional tube furnace for $60 \mathrm{~min}$ at a temperature of $800{ }^{\circ} \mathrm{C}$ under an inert argon gas environment. This pre-heating at a lower temperature helped to avoid the use of binding chemicals while compacting the pellets and also burned out some chemicals (such as PCA) that were incurred during the ball milling process. To consolidate the ball-milled ODS alloy powders, cylindrical pellets (diameter $12.7 \mathrm{~mm}$ and height $2 \mathrm{~mm}$ ) were pressed at 10.5 ton using a uniaxial semiautomatic hydraulic press (model \#3912 CARVER laboratory equipment, 11 ton capacity). The powders were held under the press for about $10 \mathrm{~min}$ to obtain uniform compaction. The compacted pellets were sintered in the same furnace and argon gas environment for 60 min (specimen group designated by A and C) and 120 min (specimen group designated by B and D) at a temperature of $1300{ }^{\circ} \mathrm{C}$ with a heating rate of $5{ }^{\circ} \mathrm{C} / \mathrm{min}$ and cooling rate of $3{ }^{\circ} \mathrm{C} / \mathrm{min}$ (Fig. 3.1) to get fully consolidated ODS alloy compacts suitable for thermal exposure testing, microstructure evaluation 
and mechanical property determination. Table 5 describes the specimens sintering conditions and their purposes.

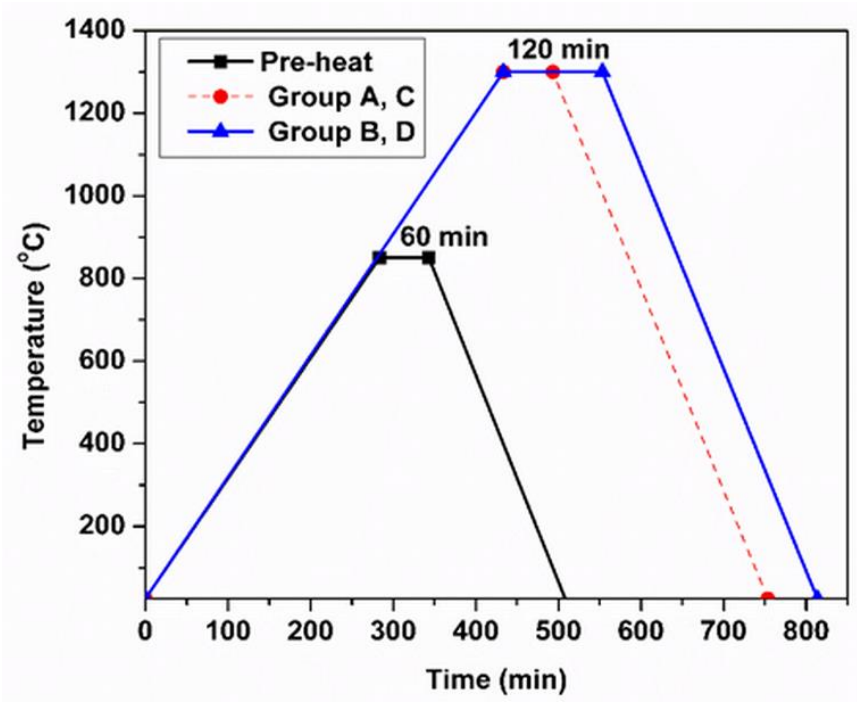

Fig. 3.1 Powder pre-heating and specimen sintering temperature profile; specimen group A and C, B and D sintered for one and two hrs, respectively.

Table 5 Sintering conditions (pre-heated at $800{ }^{\circ} \mathrm{C}$ and sintered at $1300{ }^{\circ} \mathrm{C}$ )

\begin{tabular}{lllll}
\hline ODS Alloy & Milling time & Pre-heat & Sintering time & Purpose \\
\hline Specimen group A & $40 \mathrm{hrs}$ & $60 \mathrm{~min}$ & $60 \mathrm{~min}$ & Microstructure, mechanical property \\
Specimen group B & $40 \mathrm{hrs}$ & $60 \mathrm{~min}$ & $120 \mathrm{~min}$ & Microstructure, mechanical property \\
Specimen group C & $40 \mathrm{hrs}$ & $60 \mathrm{~min}$ & $60 \mathrm{~min}$ & Weight gain \\
Specimen group D & $40 \mathrm{hrs}$ & $60 \mathrm{~min}$ & $120 \mathrm{~min}$ & Weight gain \\
\hline
\end{tabular}

\subsubsection{Thermal Cyclic Testing}

Thermal cyclic oxidation testing was conducted in air at a temperature of $1100{ }^{\circ} \mathrm{C}$ in a horizontal tube furnace controlled by external electronic controller. The cyclic exposure were designed in such a way that, during each cycle the specimens were brought to a temperature of $1100{ }^{\circ} \mathrm{C}$ within $15 \mathrm{~min}$, held at that temperature for $45 \mathrm{~min}$, subsequently the specimens were 
removed from the furnace within $15 \mathrm{~min}$ and cooled for $45 \mathrm{~min}$ at room temperature. The testing sequence was controlled by a pre-programmed external electronic controller, Fig. 3.2. Group of specimens (A, B) were exposed together so that same test environments were maintained to identify the $60 \mathrm{~min}$ and $120 \mathrm{~min}$ sintering effect on the mechanical and microstructure properties of the studied specimens. Specimens group C and D were exposed for 20-24 cycles each time and the weight gain were measured with a precision balance of accuracy $0.1 \mathrm{mg}$.

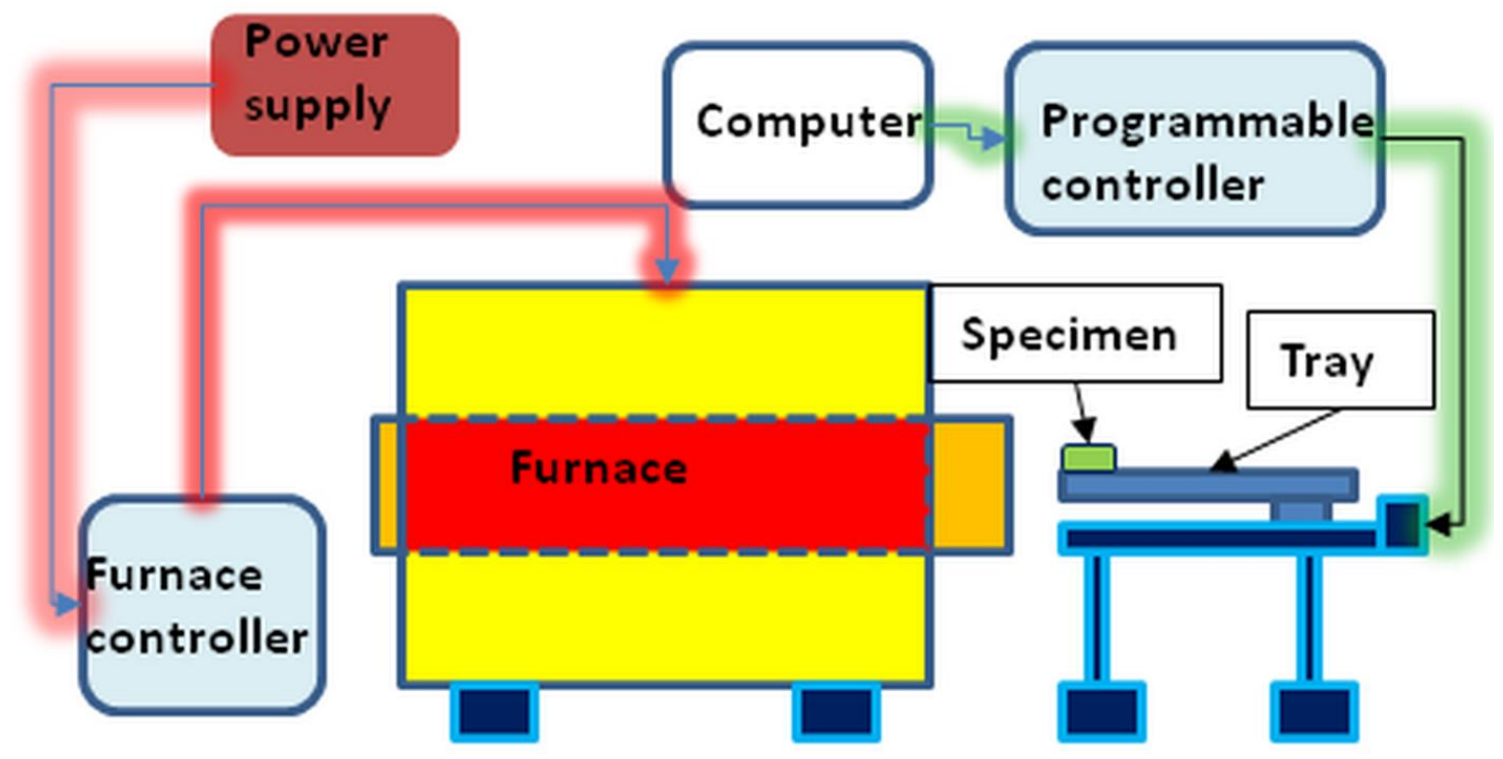

Fig. 3.2 Schematic of the thermal exposure apparatus setup.

\subsubsection{Microindentation Testing}

The mechanical properties of ODS alloys before and after thermal cyclic exposure was studied by in-house made microindentation instrument technique. The in-house made microindentation system is capable of measuring room temperature stiffness response. Indicated in Fig 3.3 is a table top room temperature indentation system comprises of (i) $3.6 \mathrm{~nm}$ resolution physik Instrumente P-239.9S $180 \mu \mathrm{m}$ piezoelectric actuator, (ii) $\pm 0.15 \%$ accuracy honeywell (model 31) $100 \mathrm{lb}$ load cell, (iii) spherical tungsten carbide (WC) $750 \mu \mathrm{m}$ radius indenter, and (iv) specimen stage [120]. For indentation tests, the ODS specimens were polished after thermal cyclic 
exposure to get the stiffness response on the oxide free surface or directly on the oxide surface to get the stiffness response of the oxide scale and its adhesion property to the ODS alloy it grows on.

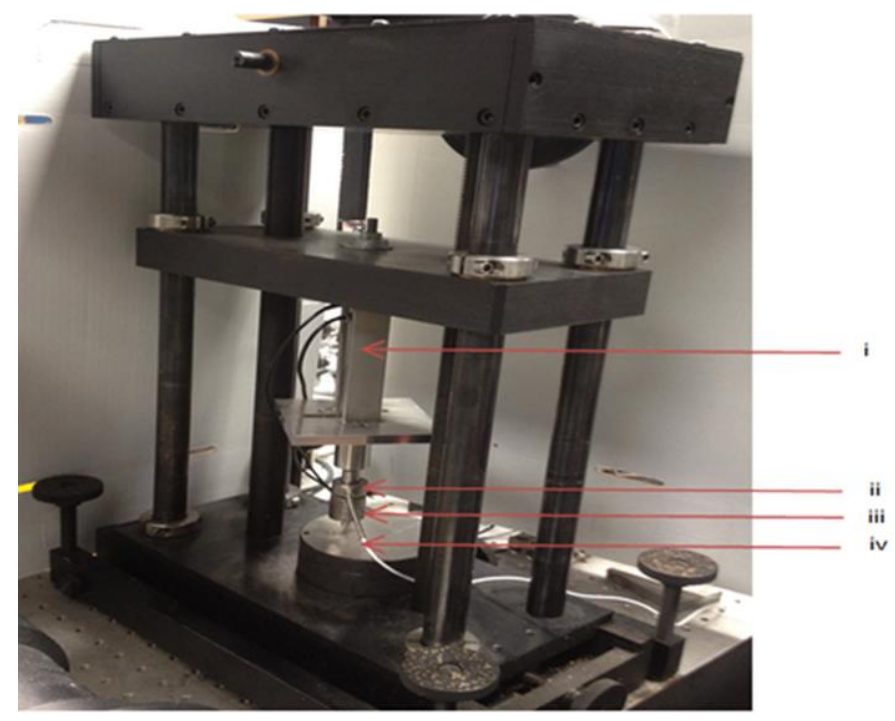

Fig. 3.3 Table top room temperature microindentation system [120].

\subsubsection{Microstructure Characterization}

\subsubsection{Electron Microscope (EM) Analysis}

The surface morphology of ODS alloy powders after MCB, ball milling, sintering, and thermal cyclic exposure testing were studied using a JEOL JSM-7600F and Hitachi S-4700F scanning electron microscopy (SEM) with a field emission gun. The elemental distribution was studied by using energy dispersive X-ray spectroscopy (EDX). Before SEM and EDX analysis, the as-sintered and thermal cycled coupons were polished to $1 \mu \mathrm{m}$ surface finish. All specimens' cross-sections were sputter coated by AuPd prior to viewing as it was required to reduce the amount of specimen charging throughout imaging. A TECNAI-G2-F30 transmission electron microscope with a $300 \mathrm{KeV}$ field emission gun was used to characterize the MCB processed powders. Samples were analyzed using the conventional bright field (BF) and selected-area diffraction (SAD). The elemental distribution was also determined using the corresponding X-ray 
energy dispersive sepectrometry (EDX) under the STEM mode. For STEM/EDX mode, the electron probe with a size of $0.2 \mathrm{~nm}$ was used to examine the dedicated area of sample.

\subsubsection{X-Ray Diffraction Analysis}

The different phases of ODS alloy powders after MCB, ball milling, pre-heating and ODS alloy specimens after sintering and thermal cyclic exposure testing were analyzed using PANALYTICAL X'PERT PRO X-ray diffraction (XRD) with $\mathrm{Cu} \mathrm{K \alpha}$.

\subsubsection{Heat Transfer Analysis of ODS Alloy Coating with Micro-Channel Cooling System using FEA}

In order to demonstrate the application of ODS alloy coatings with micro-channel cooling system and without the use of TBC system to protect the underlying superalloy substrate in harsh high temperature environments, the heat transfer property of ODS alloy coating with microchannel cooling system was studied by using finite element analysis (FEA). The following outline was followed in the FEA analysis.

- The thermal property (thermal conductivity, convective heat transfer coefficient) was collected from similar experimental works on related ODS alloy materials.

- A simple geometry including the substrate, ODS alloy coating with micro-channel cooling systems, and oxide scales on the coating was modeled and heat transfer analysis carried.

- The thermal contour plots were obtained and discussed on each three material systems subjected to conductive and convective heat source on the ODS alloy coating and inside the micro-channel cooling systems.

- For comparison purpose, a typical TBC system and ODS alloy without micro-channel cooling system were also modeled and results were analyzed accordingly. 


\section{RESULTS AND DISSCUSSIONS}

\subsection{ODS Powder Processing and Consolidation}

In this section results obtained from experimental works on ODS powders processed by MCB, MCB plus ball milling, pre-heated and consolidated ODS alloy coupons are discussed.

\subsubsection{Mechano-Chemical Bonding (MCB) Processed Powders}

Fig. 4.1(a) presented the XRD patterns of as-blended and 30 min MCB processed Ni-Cr$\mathrm{Al}-\mathrm{Y}_{2} \mathrm{O}_{3}$ powders. The diffraction peaks of all alloying elements $\mathrm{Al}, \mathrm{Cr}$, and $\mathrm{Ni}$ were observed in the XRD spectrum of MCB processed powders. However, the peak of $\mathrm{Y}_{2} \mathrm{O}_{3}$ was not present, suggesting the MCB process would change the crystallographic structure of the nano-sized $\mathrm{Y}_{2} \mathrm{O}_{3}$ particle. Compared to the starting as-blended powders, the MCB-processed powders showed the diffraction peaks with similar width at the same diffraction angels, $2 \theta$, as well as absence of new detectable peaks, indicating that the end products processed by MCB were still intact mixture of starting ingredients without any undesirable reactions occurring among the elemental powders. The XRD analysis performed on both as-blended and MCB processed powders indicated that the MCB process in this study would not change the crystallographic structure and particle size of process elemental powders $\mathrm{Al}, \mathrm{Cr}$, and $\mathrm{Ni}$, but change the crystallographic structure of nano-sized $\mathrm{Y}_{2} \mathrm{O}_{3}$ particle, resulting in the disappearance of $\mathrm{Y}_{2} \mathrm{O}_{3}$ peak from XRD spectrum.

Additionally, SEM micrographs of MCB processed powders as seen in Fig. 4.1(b) indicated the near spherical shapes of the major particles, with the exception of some minor particles formed as fragments with random shape and size. Furthermore, SEM EDX element mapping and spectrum were utilized to examine the elemental distribution of the MCB processed powders as shown in Fig. 4.1(c-g). As seen in the elemental mapping Fig. 4.1(c-f), the master elemental particles identified by EDX analysis as $\mathrm{Ni}$ and $\mathrm{Cr}$ kept spherical shapes and minor 
particles identified as mostly $\mathrm{Al}$ formed the fragments with random shape and size. The minor particles such as $\mathrm{Al}$ tended to attach on the surface of the large particles to form the composite particles. As SEM EDX mapping micrographs exhibited the master elemental powders such as $\mathrm{Ni}$ and $\mathrm{Cr}$ particles played the role of hosting particles to entrap the minor elemental powders such as $\mathrm{Y}_{2} \mathrm{O}_{3}$ and $\mathrm{Al}$ particles. Mapping micrographs evidently showed that $\mathrm{Y}_{2} \mathrm{O}_{3}$ has been dispersed homogeneously throughout the host particles after MCB processing. Smaller size deformed Al fragments were found attached on the hosting particles or separately distributed in mixture of powders. The distribution of Al fragments appeared heterogeneous among the powders, suggesting that the soft $\mathrm{Al}$ particles were subjected to mechanical deformation and fracturing, forming fragments with reduced size during $\mathrm{MCB}$ processing. The $\mathrm{Al}$ fragments were randomly distributed or bonded on to the hosting particles. The inter-diffusion of $\mathrm{Y}_{2} \mathrm{O}_{3}$ and $\mathrm{Al}$ on hosting particles was observed in the mapping micrographs. As can be seen in Fig. 4.1 (g), the aluminum wt.\% is higher than the starting composition indicating the non-uniform distribution due to its soft nature.
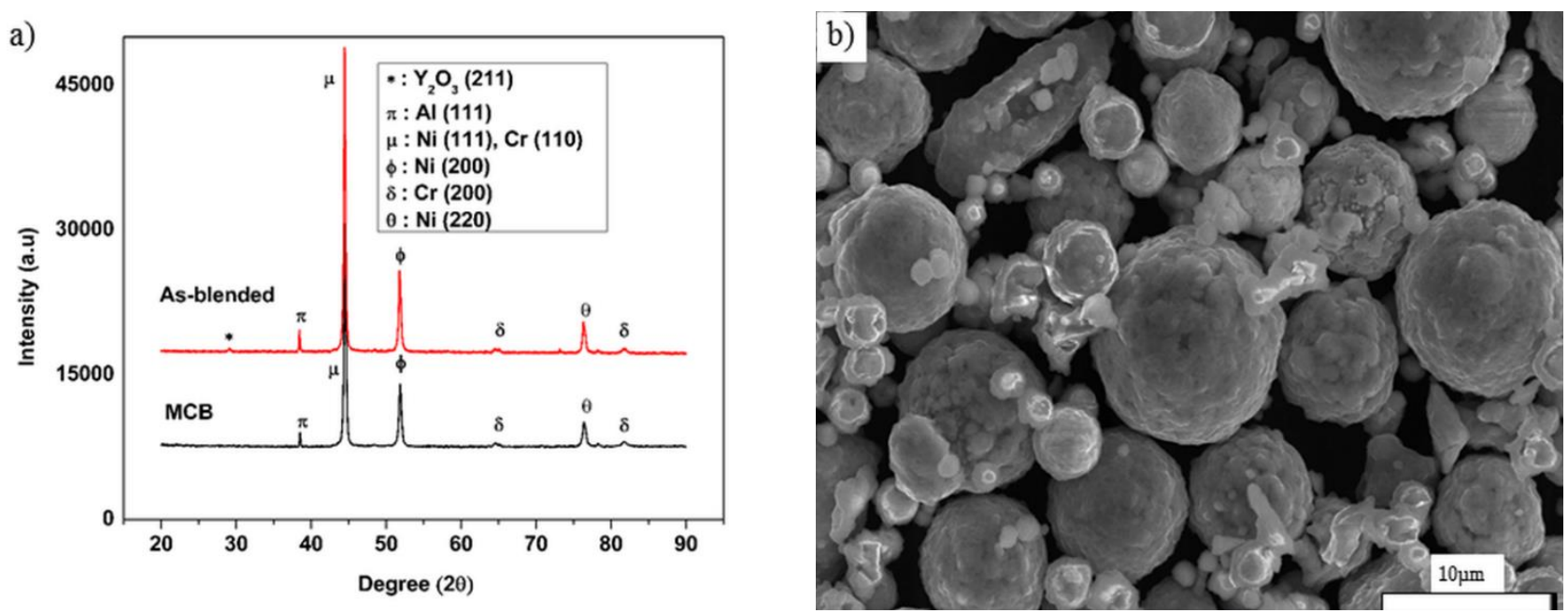

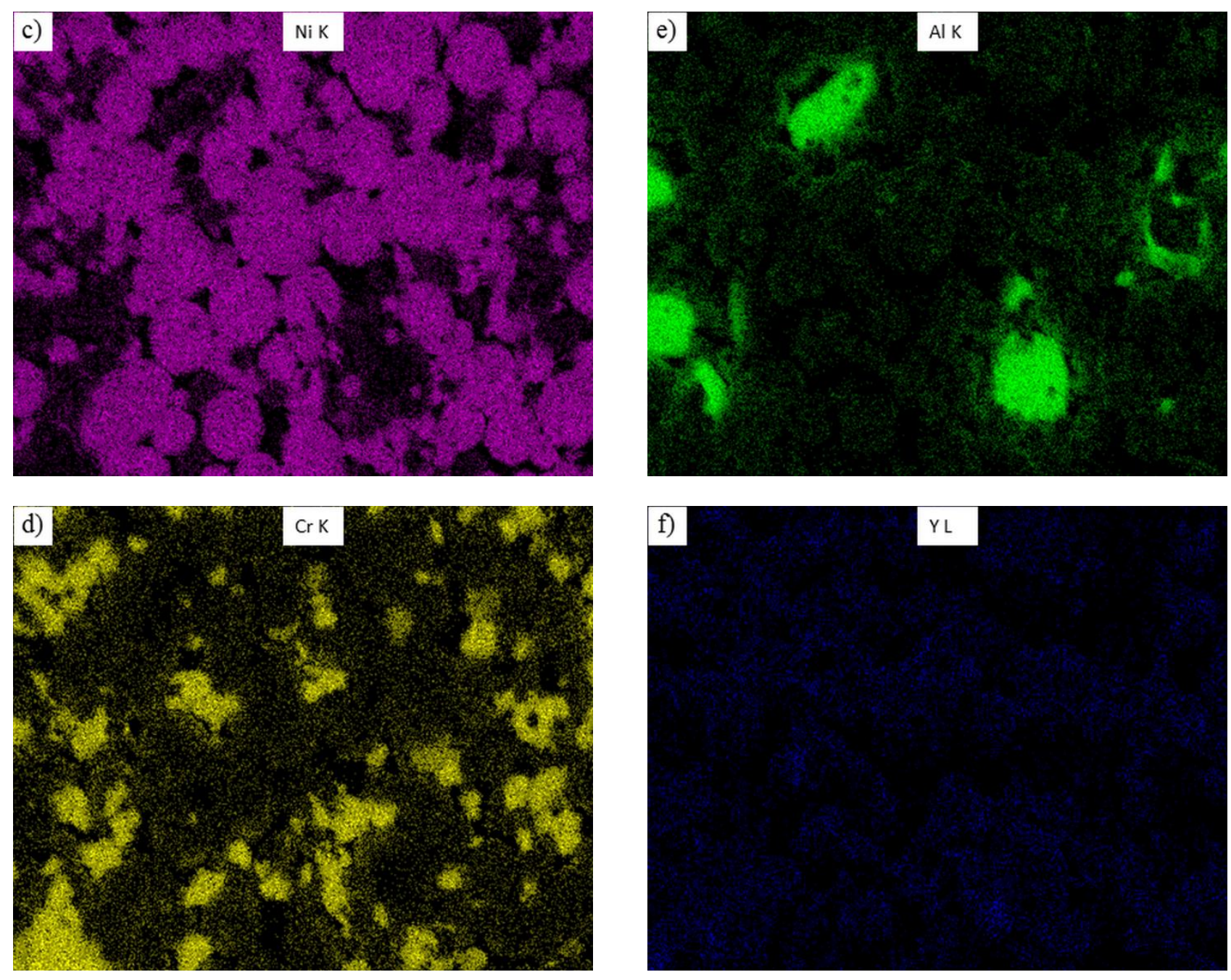

d)

\begin{tabular}{cc} 
Element & $\mathrm{Wt} \%$ \\
\hline $\mathrm{OK}$ & 2.77 \\
$\mathrm{AlK}$ & 15.40 \\
$\mathrm{YL}$ & 2.16 \\
$\mathrm{CrK}$ & 15.42 \\
$\mathrm{NiK}$ & 64.25
\end{tabular}

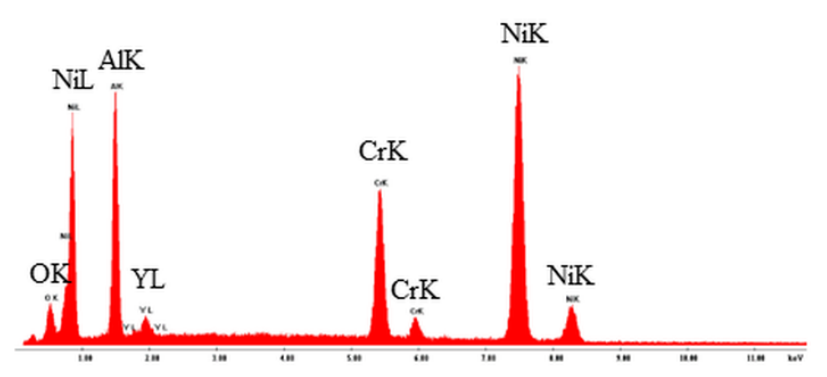

Fig. 4.1 MCB processed powders (a) XRD spectrum, (b) SEM micrograph, (c-f) EDX mapping micrographs, and (g) EDX element spectrum and wt.\%. 
Therefore, SEM microscopic and spectroscopic characterization of MCB processed powders summarized that elemental powder $\mathrm{Y}_{2} \mathrm{O}_{3}$ had been mixed homogeneously and the composite particles hosted by the master elemental particles such as $\mathrm{Ni}$ and $\mathrm{Cr}$ could be created through the MCB processing. The composite particles contained elements $\mathrm{Y}$ and $\mathrm{O}$ which had been dispersed and mixed with hosting particles through MCB processing. The soft Al powders were deformed and fractured to form fragments and attached on to the hosting particles or became discrete particles after MCB processing.

However, the presence of elemental $\mathrm{Y}$ and $\mathrm{O}$ confirmed by SEM EDX mapping and spectrum, Fig. 4.1(g) of MCB processed powders showed the discrepancy with the results of XRD, wherein the $\mathrm{Y}_{2} \mathrm{O}_{3}$ peak was not detected, Fig. 4.1(a). To explore reasons for the absence of $\mathrm{Y}_{2} \mathrm{O}_{3}$ peak in the XRD spectrum and to identify the microstructures of composite particles induced by MCB processing, the powders were subjected to transmission electron microscopy (TEM) and high resolution transmission electron microscopy (HRTEM) analysis. Fig. 4.2(a) and 4.2(b) presented the TEM BF (bright field) and HRTEM images of MCB processed powders, respectively. The low magnification of TEM BF image, Fig. 4.2(a), showed that the hosting particles displayed in dark contrast due to their thickness with limited detailed information. Increasing the magnification of TEM imaging revealed a thin film with thickness of 20-25 nm around the hosting particles, Ni and Cr. As can be seen in Fig. 4.2(b), the HRTEM image indicated the thin film to be amorphous and very few crystalline structures were evident. The embedded FFT (fast Fourier transform) image revealed diffusive features and spots associated with amorphous and crystalline structures, respectively. Moreover, the thin film around the hosting particle was observed in Zcontrast image, generated in STEM mode, as shown in the inset image of Fig. 4.2(c), wherein the thin film showed the bright contrast around the particle. As expected, STEM EDX examination of 
these thin film regions confirmed that the thin film contained elements of $\mathrm{Ni}, \mathrm{Cr}, \mathrm{Al}, \mathrm{Y}$ and $\mathrm{O}$ at which the convergent electron beam with a probe size of $0.2 \mathrm{~nm}$ was located in the particle edge marked in Fig. 2(c) to examine the chemical composition of the dedicated location. Therefore, based on the SEM EDX, TEM, HRTEM, STEM EDX analysis, it could be concluded that $\mathrm{Y}_{2} \mathrm{O}_{3}$ was manifested as the amorphous thin film dispersed and coated on the hosting particles after MCB processing, resulting in disappearance of $\mathrm{Y}_{2} \mathrm{O}_{3}$ peak in the XRD spectrum. However, tiny fraction of $\mathrm{Y}_{2} \mathrm{O}_{3}$ crystalline particles might still exist within the film which was too weak to be detected by XRD.

a)

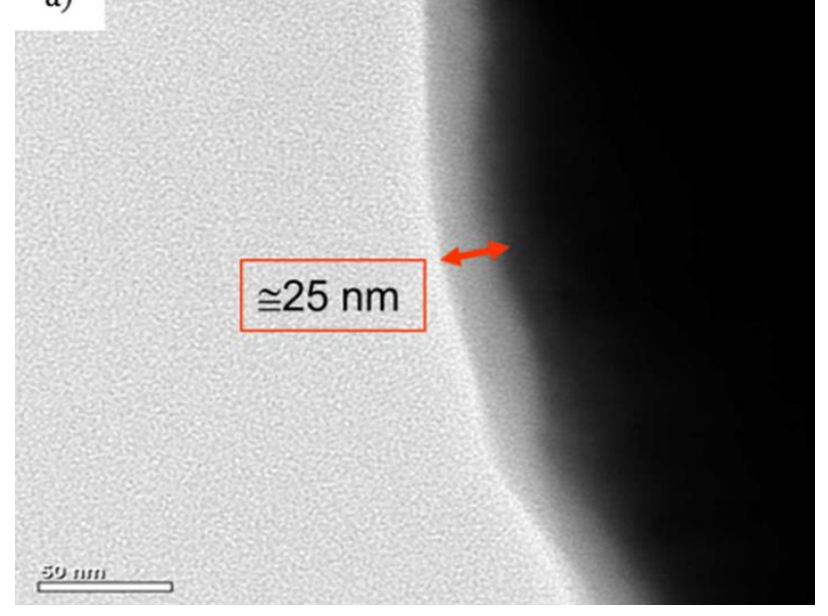

c)

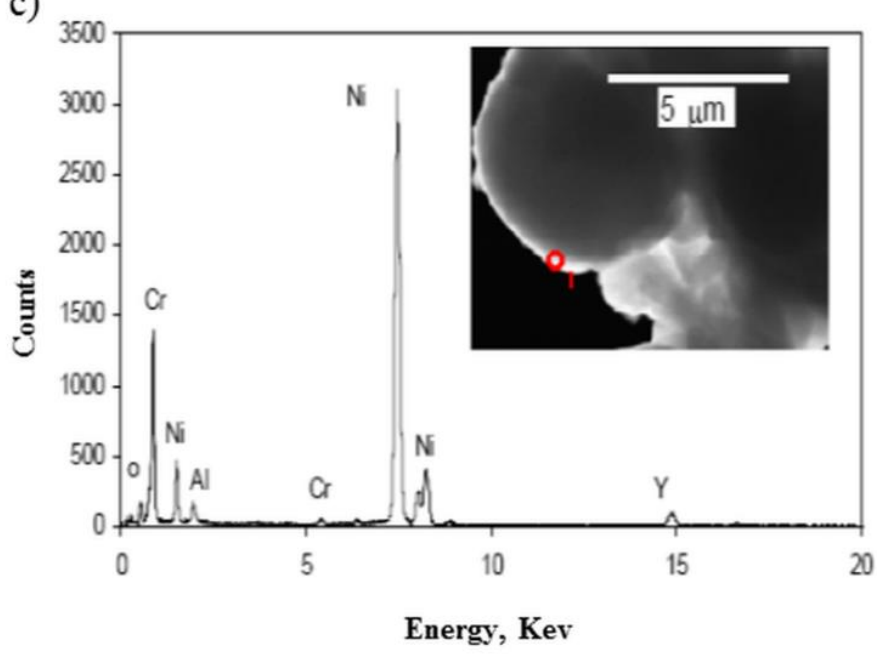

b)

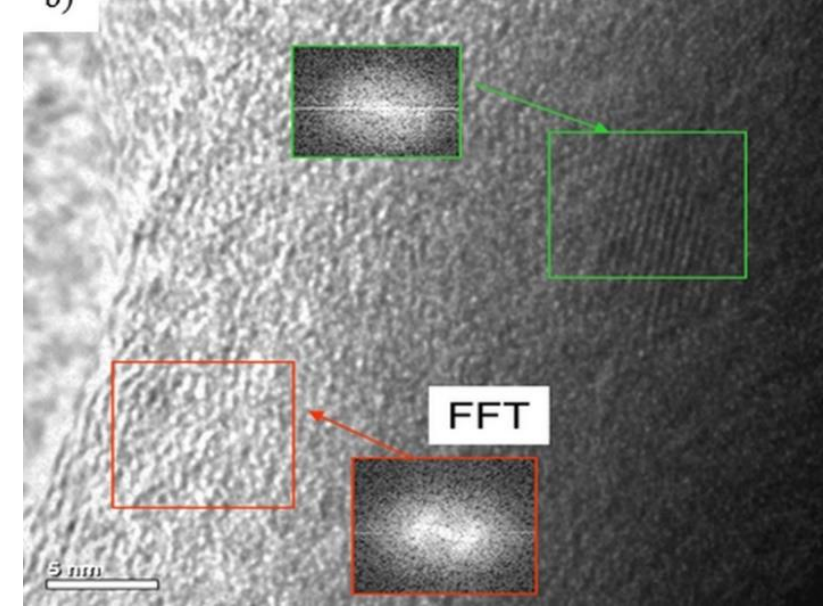

Fig. 4.2 MCB processed powders (a) TEM BF image, (b) HRTEM image, (c) STEM EDX image. 


\subsubsection{Mechano-Chemical Bonding (MCB) plus Ball Milled Processed Powders}

To further improve the alloying properties, MCB processed powders were subjected to ball milling for 5, 40, 60, and 120 hrs with their SEM micrographs depicted in Fig. 4.3(a-d). As can be seen in Fig. 4.3(a) after 5 hrs, the milled powders showed irregular shape and fragments with lamellate structures, suggesting that large deformation, cold welding and fracturing of particles occurred during processing. After $40 \mathrm{hrs}$ of milling shown in Fig. 4.3(b), the particles became more spherical and some of the smaller fragmented particles appeared to be cold welded on to the larger particles. After 60 hrs of milling indicated in Fig. 4.3(c), most of the particles appeared to have uniform particle size and spherical in shape with less smaller particles observed on larger particles. At longer milling time of $120 \mathrm{hrs}$ observed in Fig. 4.3(d), the particles became smaller in size with rough surfaces, which indicated fracturing and separation of the already cold welded particles. A ball milled FeCrAl ODS alloy powder reported by Chen and Dong [20], indicated decreasing in particle size through ball milling. A similar manner was observed in this study as the particles morphology exhibited a progressive change with ball milling time. At a lower milling time the particles appeared to be more of lamellate structure and irregular in shape, while at an intermediate milling time the shape became more of spherical and uniform, indicating the balanced cold welding and fracturing. However, at longer milling time the particles became more severely fractured.

Furthermore, to study the phases evolved during ball milling, XRD analysis was performed at different stages of milling 30, 40, 60, 80, and $120 \mathrm{hrs}$ as indicated in Fig. 4.3(e). The XRD spectrum revealed peak changes with ball milling time, for which some of the spectrum peaks were disappeared, and then reappeared, indicating the process of cold welding and fracturing of particles that could affect the crystallographic structure of the powders. This could indicate the presence of an optimum ball milling time to obtain an ODS composite alloy with desirable particle size and 
crystalline structure. After $30 \mathrm{hrs}$ of ball milling the Al peak observed in the MCB processed powders disappeared from the XRD spectrum and Ni solid solution was observed, to be explained later and this usually happens at lower ball milling time. At $40 \mathrm{hrs}$ of ball milling, the XRD spectrum of additional peaks started to disappear and at $60 \mathrm{hrs}$ only one spectrum observed. At longer ball milling of beyond $80 \mathrm{hrs,} \mathrm{the} \mathrm{smaller} \mathrm{peaks} \mathrm{started} \mathrm{to} \mathrm{appear} \mathrm{again.} \mathrm{Based} \mathrm{on} \mathrm{the} \mathrm{XRD}$ analysis and the SEM microstructure study, it could be summarized that the optimum ball milling time to get a good particle size, shape and phase distribution after MCB plus ball milling process was 40 to $60 \mathrm{hrs}$ and $40 \mathrm{hrs}$ was adopted for further study.
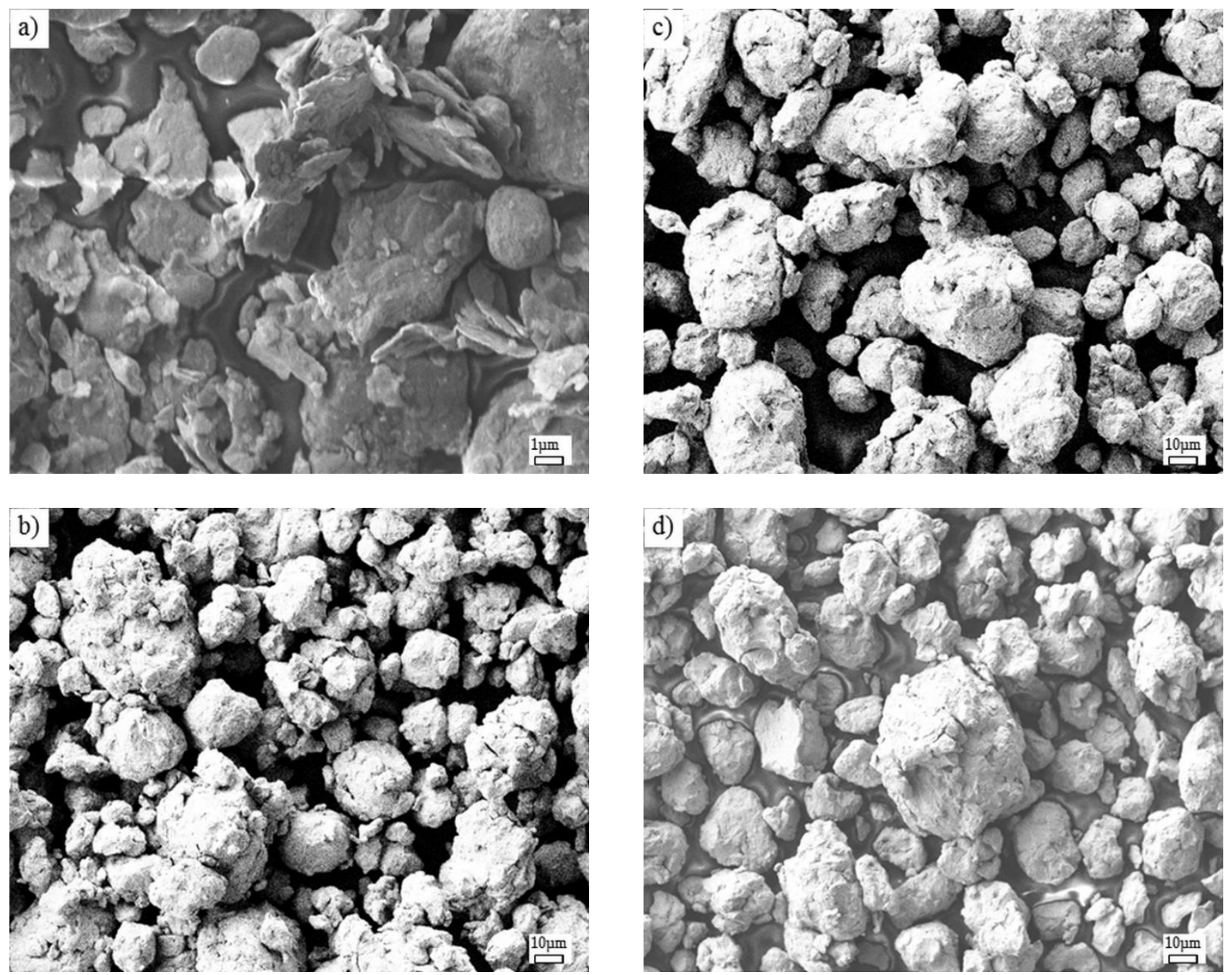


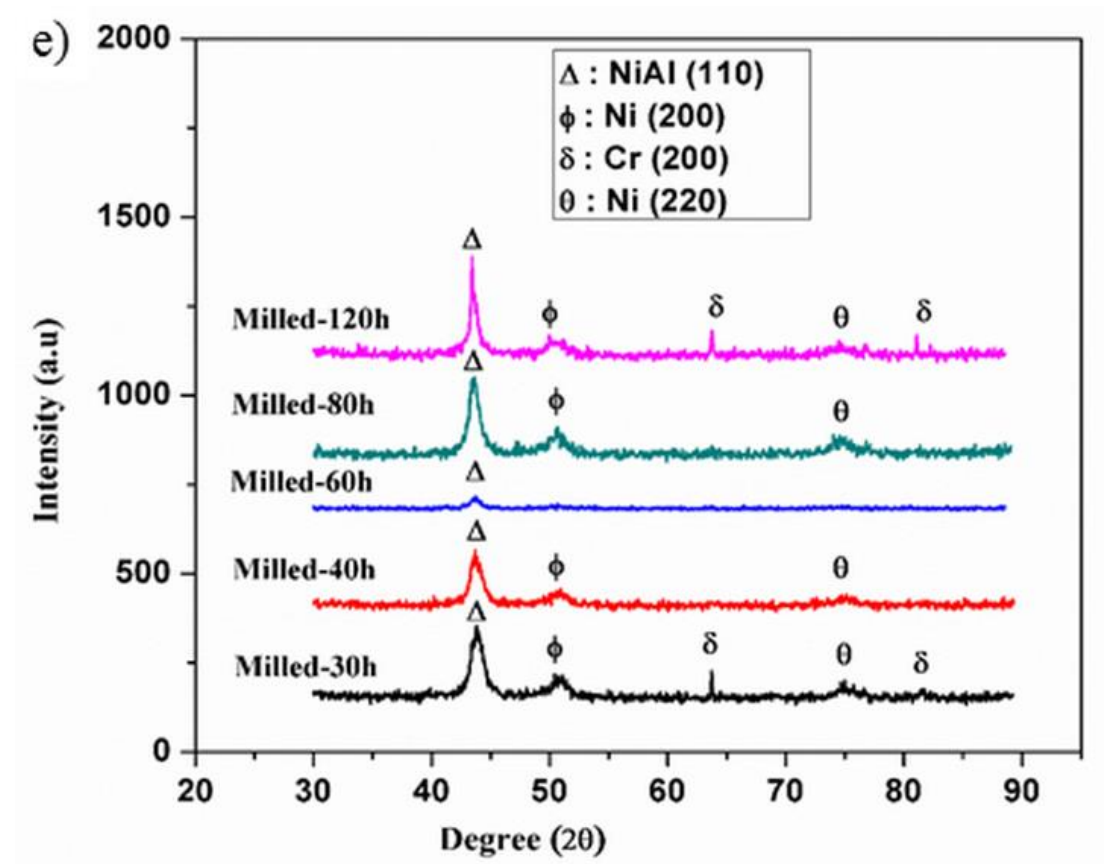

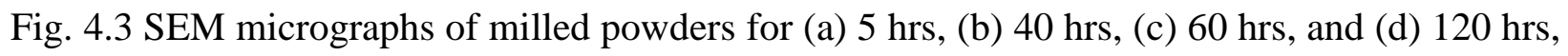
and (e) XRD spectrum.

Moreover, SEM EDX analysis was performed on $40 \mathrm{hrs}$ processed powders as indicated in Fig. 4.4(a-g). The uniform distribution of alloying elements with the host elements ( $\mathrm{Ni}$ and $\mathrm{Cr}$ ) is evident from EDX mapping micrographs after ball milling process, Fig. 4.4(b-f). Elemental Al, which was observed fragmented and randomly distributed or bonded on to the hosting particles after MCB process, is now appeared to be uniformly distributed as indicated in the EDX mapping, Fig. 4.4(d) and EDX line scan, Fig. 4.4(g). The wt.\% of each elemental powders are more closer to the starting powders, indicating uniform distribution of elements after MCB plus ball milling process. Additionally, to study the polycrystalline nature of ball milled powders, TEM SAD (selected area diffraction) image was taken as seen in Fig 4.4(h). It showed heavy deformation, well mixed, and polycrystalline structure of powders after combined MCB and ball milling process. 

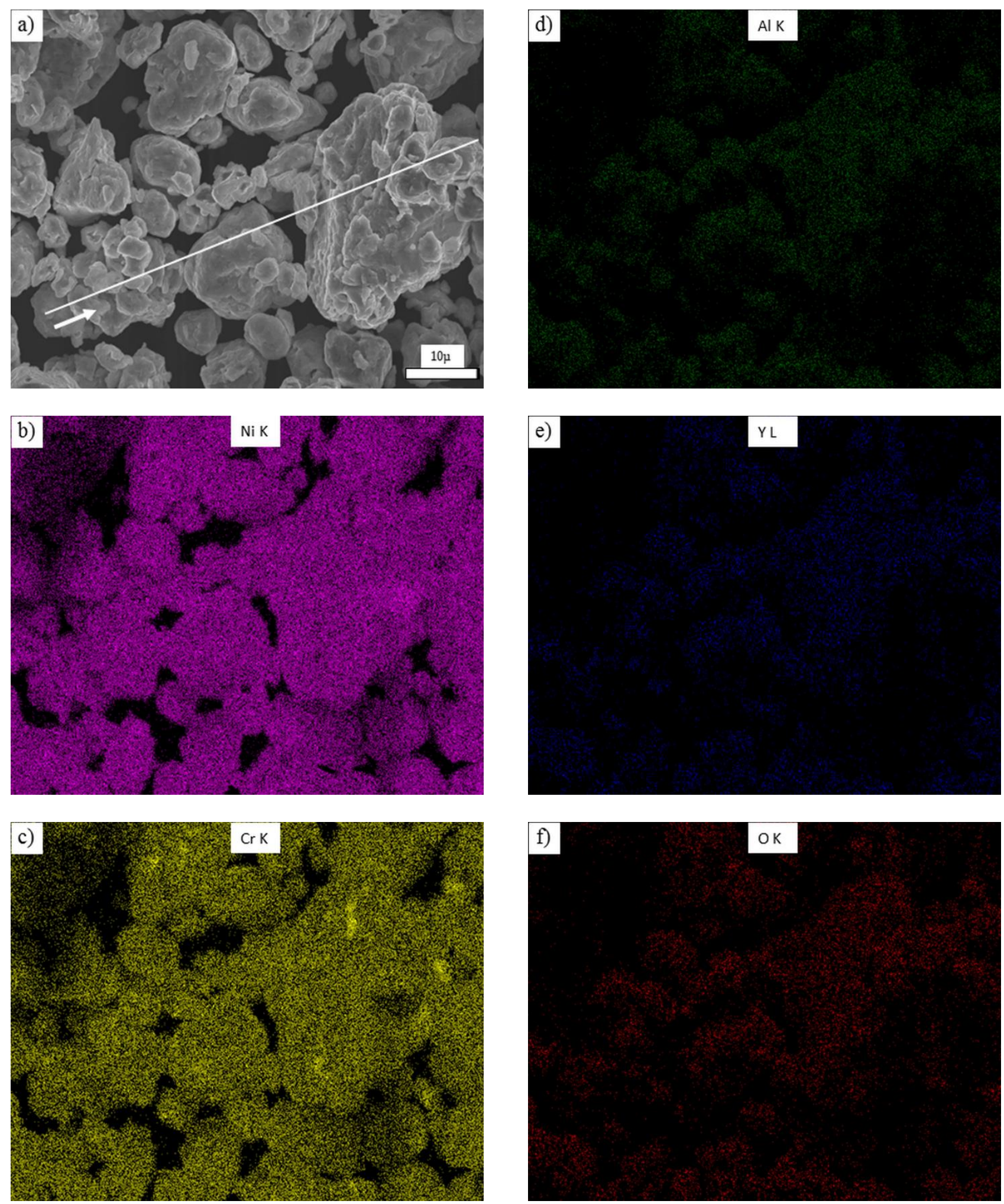

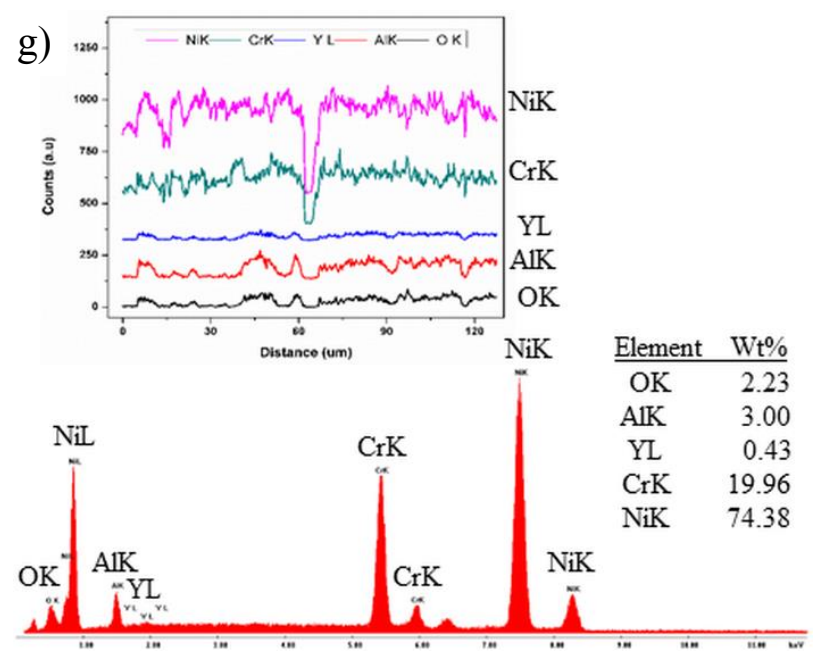

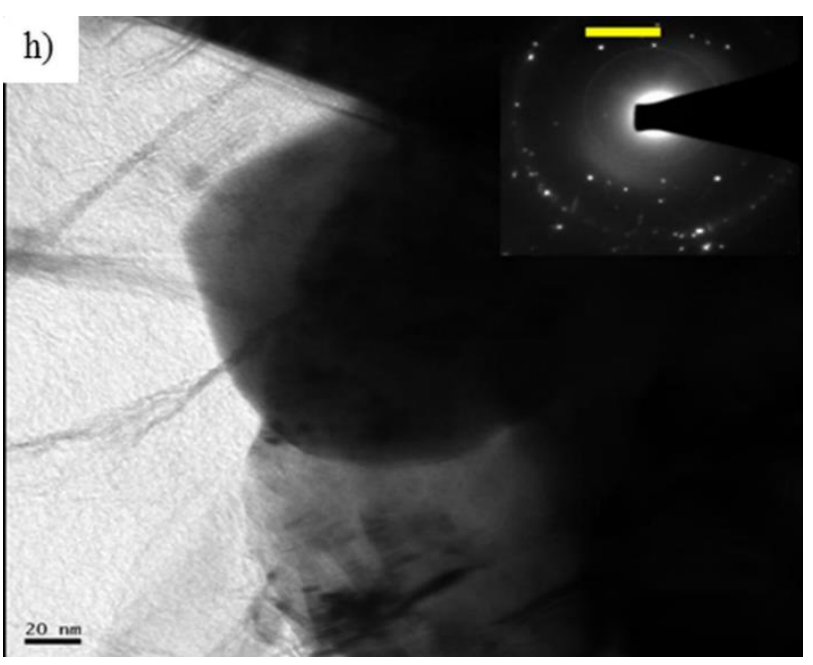

Fig. 4.440 hrs milled powders (a) SEM micrograph, (b-f) EDX mapping micrographs, (g) EDX spectrum and line scan across elements, and (h) TEM SAD image.

\subsubsection{Low Temperature Pre-Heat Treatment and Powder Consolidation}

To avoid the usage of binding chemicals while performing powder compacting, powder pre-heating methodology was implemented at lower temperature indicated in the experimental procedures section. The SEM microstructure and EDX elemental mapping of the pre-heated powders, Fig. 4.5(a-f) appeared to be similar to that of $40 \mathrm{hrs}$ milled powders, but the pre-heating is believed to relieve the strains associated with cold welding and fracturing of powders imposed during ball milling in addition to burning out the chemicals such as PCA. This could also make the powders more manageable while performing powder pressing as compared to non-pre-heated powders. Fig. 4.5(g) indicated EDX elemental spectrum and line scan on pre-heated powders including the wt.\% of each elemental powders. The wt.\% is now much more closer to the starting powders indicating uniformity of powder distribution. Fig. 4.5(h) presented the XRD spectrum comparison of MCB processed, $40 \mathrm{hrs}$ ball milled, pre-heated powders, and as sintered ODS alloy coupons. As indicated in Fig. 4.5(h) the peak positions of $40 \mathrm{hrs}$ milled powders showed a slight shift to a lower $2 \theta$ angles with broadened and reduced peak intensities compared to MCB 
processed powders, which could be a result of grain refinement and/or increasing lattice strains associated with cold welding and fracturing during longer ball milling [20]. The disappearance of Al peak in the MCB plus ball milled powders compared to only MCB processed powders suggests that the matrix contains $(\mathrm{Ni}, \mathrm{Cr})$ solid solution with $\mathrm{Al}$ as the main solute. The pre-heated powders showed the same XRD peaks as that of the $40 \mathrm{hrs}$ processed powders, but with narrow and stronger peak intensity. The narrow and stronger peak intensity could be the result of strain relaxation provided by pre-heating. However, the XRD peaks of the as-sintered samples showed a slight shift to a lower $2 \theta$ angles with reduced peak intensities compared to the $40 \mathrm{hrs}$ processed and pre-heated powders indicating $\mathrm{Ni}_{3} \mathrm{Al}$ precipitate formation.
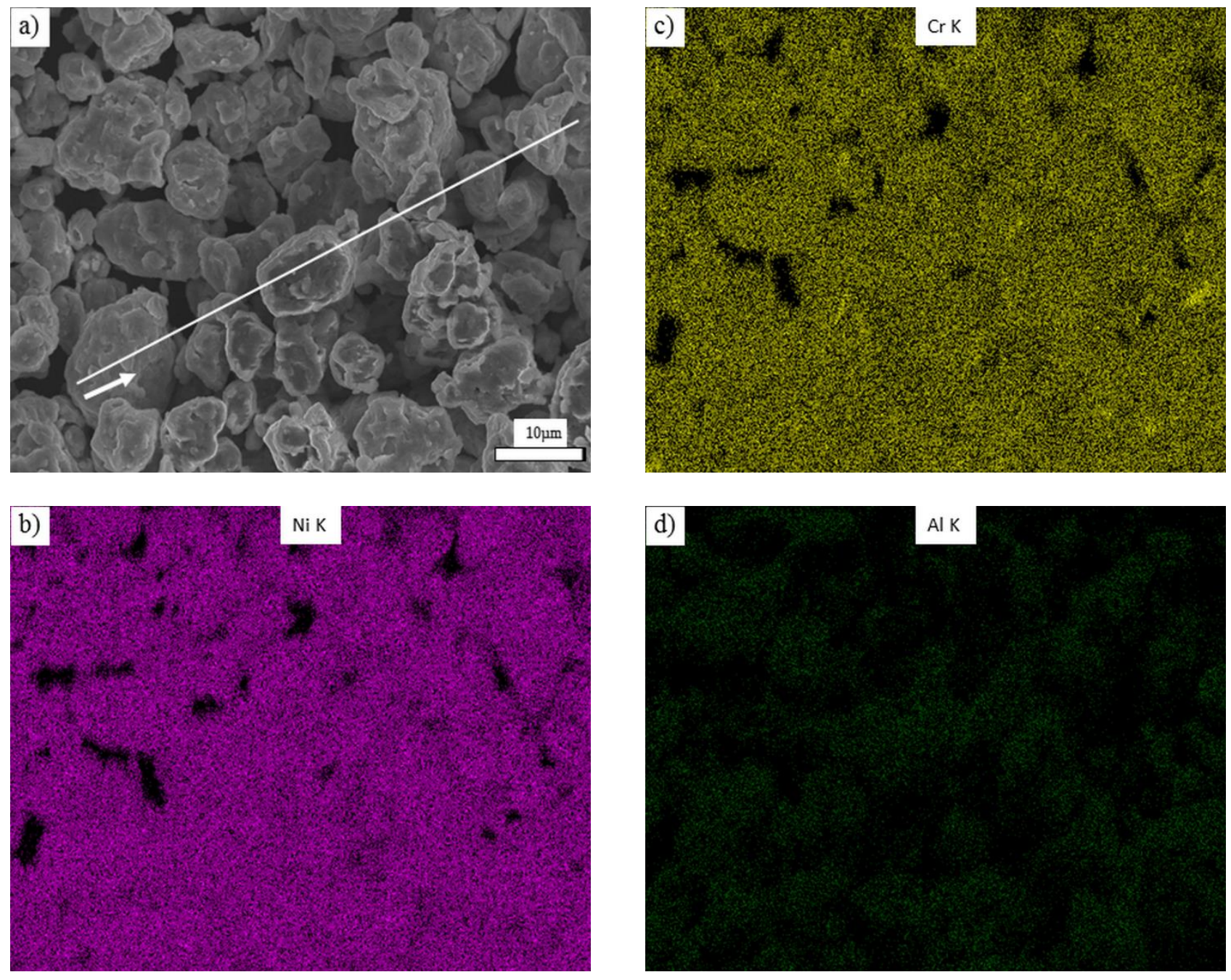

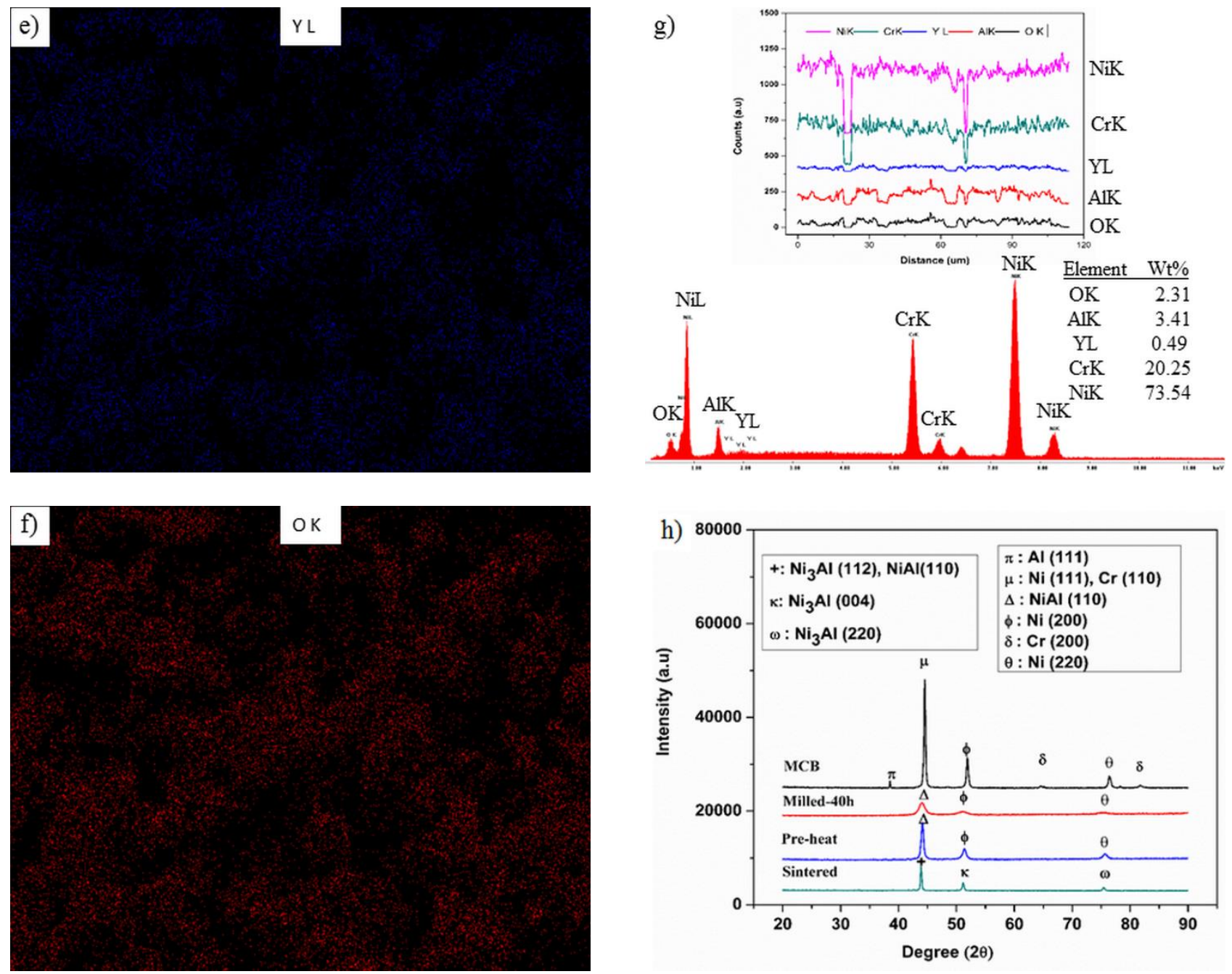

Fig. 4.5 Pre-heated powders (a) SEM micrograph, (b-f) EDX mapping micrographs, (g) EDX spectrum and line scan across particles with wt.\%, and (h) XRD spectrum comparisons of different hrs of milling and sintering.

Powder consolidation as discussed in the experimental setup was performed by using uniaxial pressing at 10.5 ton. The as consolidated (green) compacts were sintered for 60 and 120 min in a horizontal tube furnace using argon gas environment. The relative densities of the as sintered coupons were measured by using the Archimedes method. The measured densities from this compacting and sintering method were in the ranges of $60-65 \%$ theoretical. This density range makes the ODS alloy coupons to be porous as most characterization tests at room temperature and 
elevated temperature are expected to be performed on homogeneous and dense materials (usually greater than $95 \%$ theoretical density) [22]. However, the intended application of this research work is mainly developing the MCB plus ball milled ODS alloys for high temperature oxidation and corrosion protection coatings on superalloy substrates [130]. Furthermore, the implementation of micro-channel cooling systems beneath or within these porous ODS alloy systems may enhance the heat removal capabilities of the cooling system by permitting diffusion of coolants through the porous mediums to some extent. Moreover, oxidation behavior of porous or inhomogeneous coating has not been widely reported and it might provide some useful information for potential application of this material on more reactive metallic substrates besides superalloys [131] or 3D additive manufacturing [132-133], which is difficult to achieve high dense products due to manufacturing defects and gas entrapments.

\subsection{ODS Alloy Thermal Cyclic Testing and Microindentation}

ODS alloy coupons subjected to thermal cyclic exposure at $1100{ }^{\circ} \mathrm{C}$ in air are discussed in this section for microstructure and mechanical property evaluations.

\subsubsection{Polished Surface Analysis of Thermal Cycled ODS Alloys}

The SEM images for as-sintered specimens of A and B were indicated in Fig. 4.6(a) and (b), respectively. Both specimens showed uniform microstructure with fewer pores. The difference in the sintering time between the two specimens show little microstructure differences at this stage. It should be noted that the dark spots shown on both specimens are a combination of micro-pores and fine second phase of carbides (Cr-rich), as it will be confirmed by EDX analysis. 

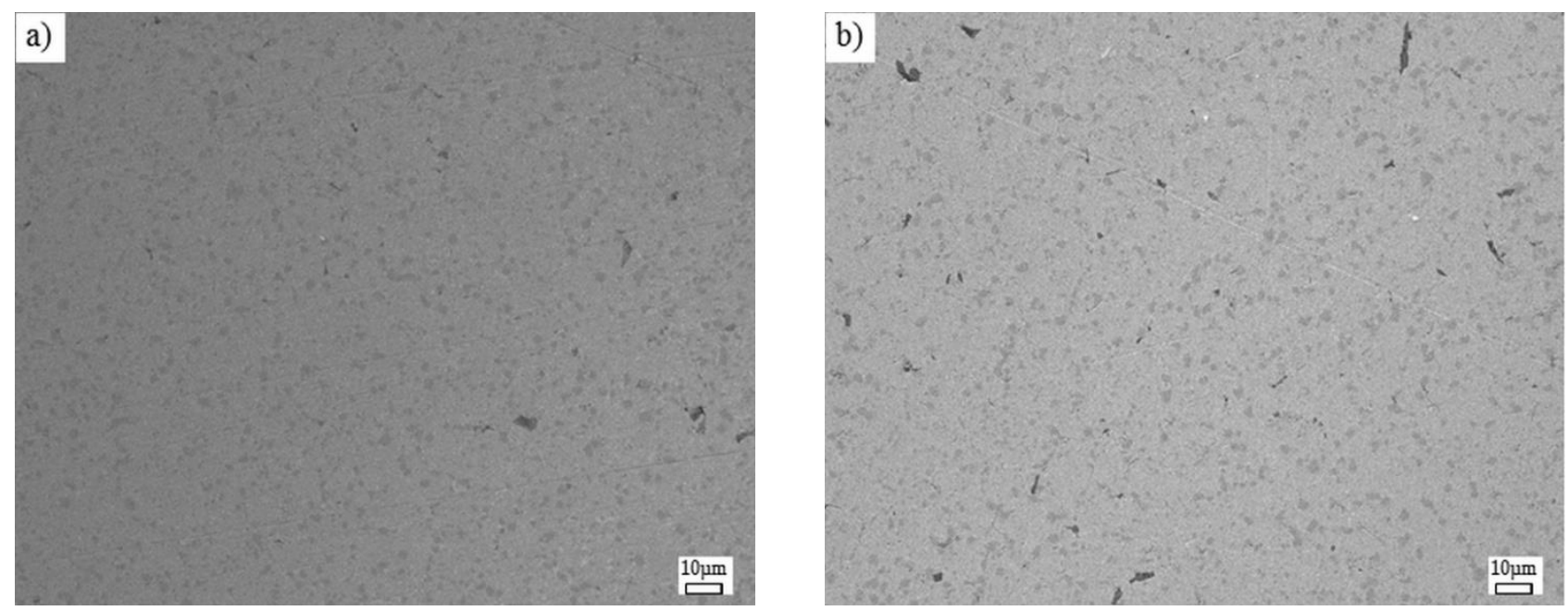

Fig. 4.6 SEM micrographs of as sintered (a) specimen A (b) specimen B.

Furthermore, longer cyclic oxidation tests were performed and Fig. 4.7(a-g) and (h-i) revealed the surface microstructure, EDX elemental mapping and line scan along with wt.\% of specimen A and B after 160 thermal cycles. As can be observed in Fig. 4.7(a) and (h) the microstructure for both specimens were formed with interwoven dark and grey spots with micropores, where the dark spot was growing into the grey matrix. To investigate the element distribution across the grey matrix and dark spots, EDX elemental mapping for specimen A and line scan for both specimens were performed after 160 thermal cycles. It was shown for specimen A as in Fig. 4.7(b-f), that all the starting elements were distributed all over the grey matrix and dark spots. However, the distribution of nickel is more dominant on the grey spots and chromium on the dark spot. The EDX element scan depicted in Fig. 4.7(g), indicated specifically that on the dark spot the elemental counts for $\mathrm{Cr}, \mathrm{Al}$ and $\mathrm{O}$ were higher compared to the $\mathrm{Ni}$ concentration indicating the combination of $\mathrm{Cr}$-rich secondary phase and $\gamma^{\prime}-\mathrm{Ni}_{3} \mathrm{Al}$ precipitates $[14,103,135$ 136]. Primary recrystallization of the $\gamma$ 'phase was judged to have happened dynamically during pre-heating of powders or immediately following sintering. 
Moreover, the grey portion belongs to the $\gamma$-phase matrix. The dark region usually contains carbides (Cr-rich), which is formed by the presence of carbon probably from mill contamination during ball milling [16] in combination with micro-pores. Yttrium, which was considered as a trace element in wt.\% among the starting elements was found nicely distributed in the EDX mapping and along the line scan plotted in Fig 4.7(e) and (g), respectively. Similar observation is also seen for specimen B as indicated in Fig 4.7(h-i).
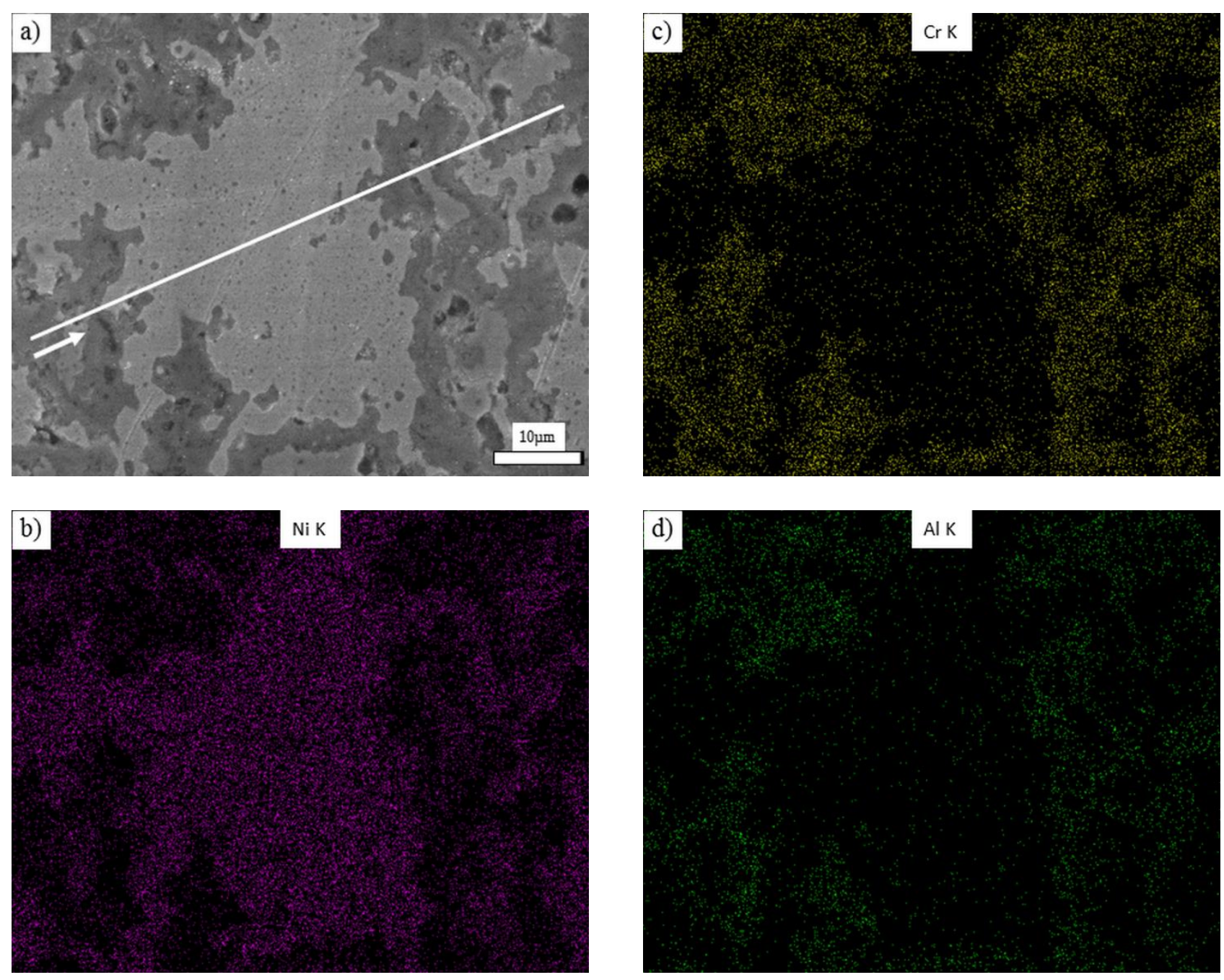


\section{e)}

YL

g)
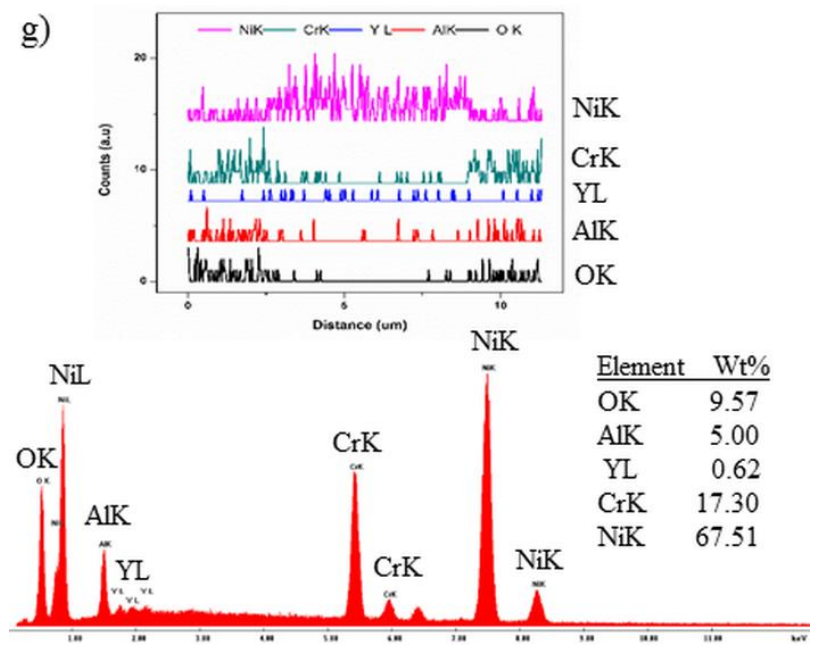

h)

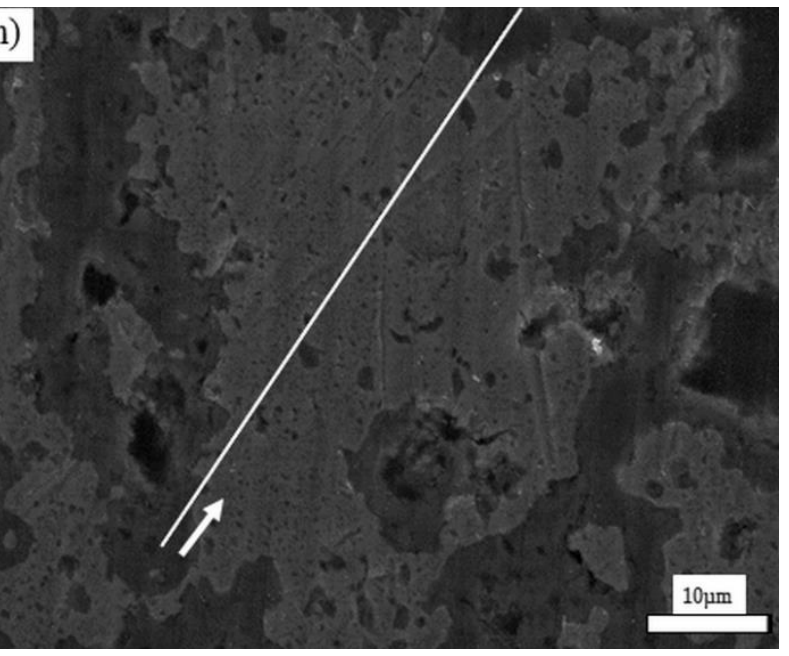

i)
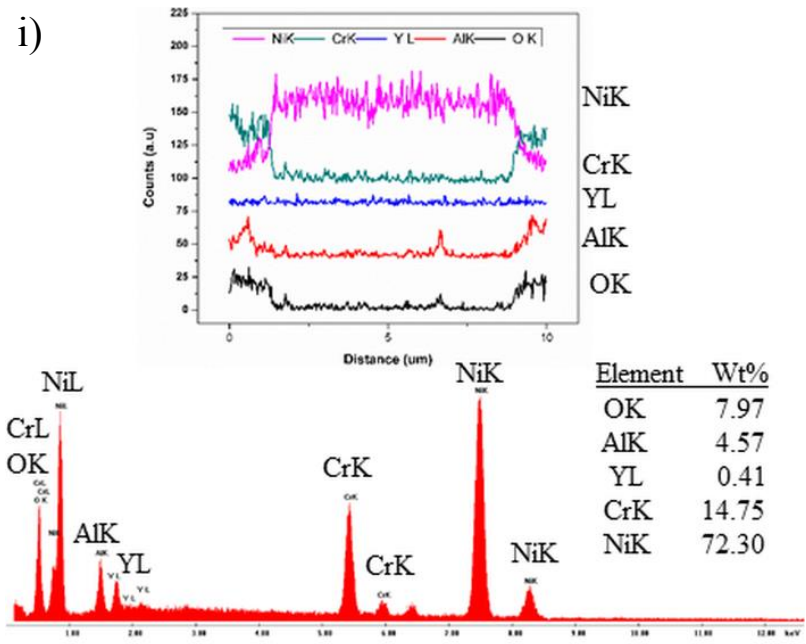

Fig. 4.7 SEM micrographs after 160 cycles of specimen A (a-g), and specimen B (h-i) along with EDX spectrum, line scans and wt.\%. 


\subsubsection{Cross-Sectional Analysis of Thermal Cycled ODS Alloys}

More detailed phenomenon can be observed on the metallographic cross-sections of ODS alloys. This includes the microstructure and element distribution of the metallographic matrix, metal-oxide scale interface, and oxide scales. In order to investigate the metallographic crosssection of thermal cycle exposed ODS alloy coupons, specimen B were polished after 40 cycles as indicated in Fig. 4.8(a-c). Fig. 4.8(a) indicated the metallographic cross-sectional matrix microstructure with grey and dark spots, a similar observation as specimens polished parallel to the oxide scale discussed in the previous section. Oxide scale formation is observed in Fig. 4.8(b). The damage on the oxide scale is from specimen preparation. As depicted in Fig. 4.8(c), the EDX element spectrum and wt.\% indicated that all elements are present in the matrix and near oxide scale. However, near the oxide scale the element $Y$ presence is higher than that of the matrix, with a clear EDX spectrum. This could be the result of Y depletion from within the oxide scale to the surface of oxide scale [25] or Y segregation near oxide scale/grain boundary [102, 135-137] in Nibased ODS superalloy.
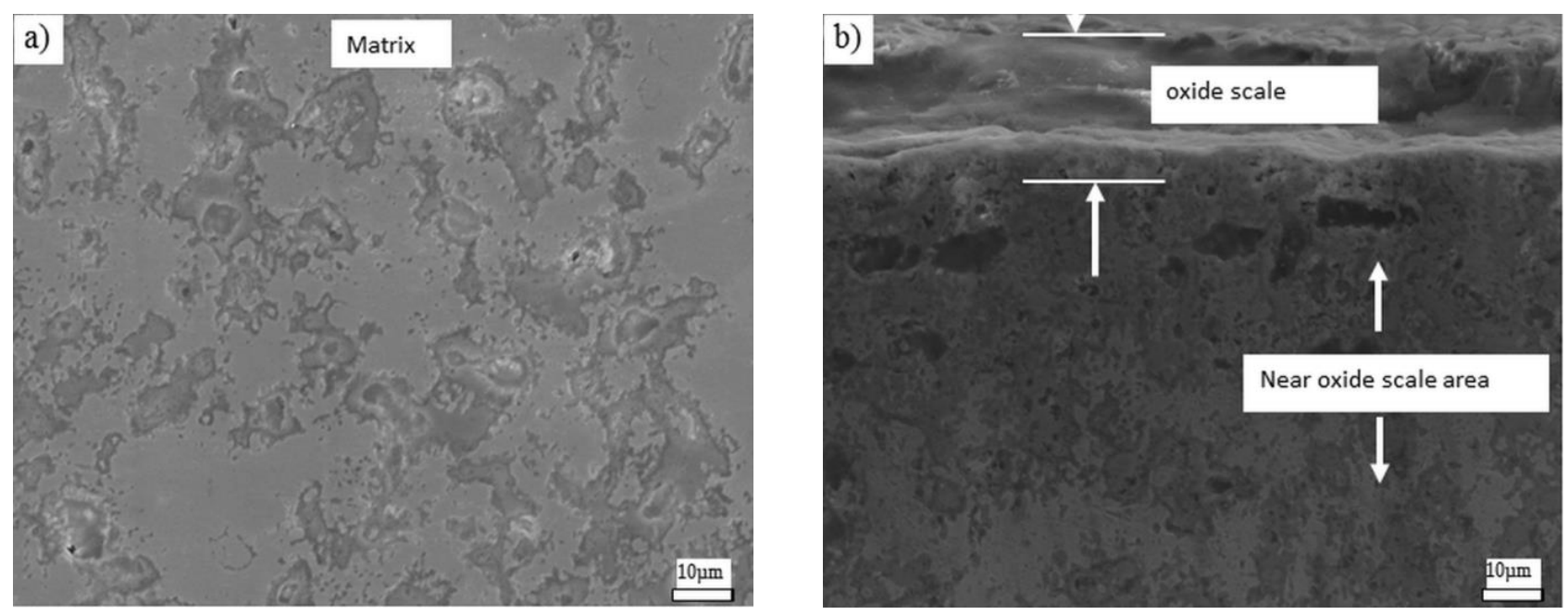

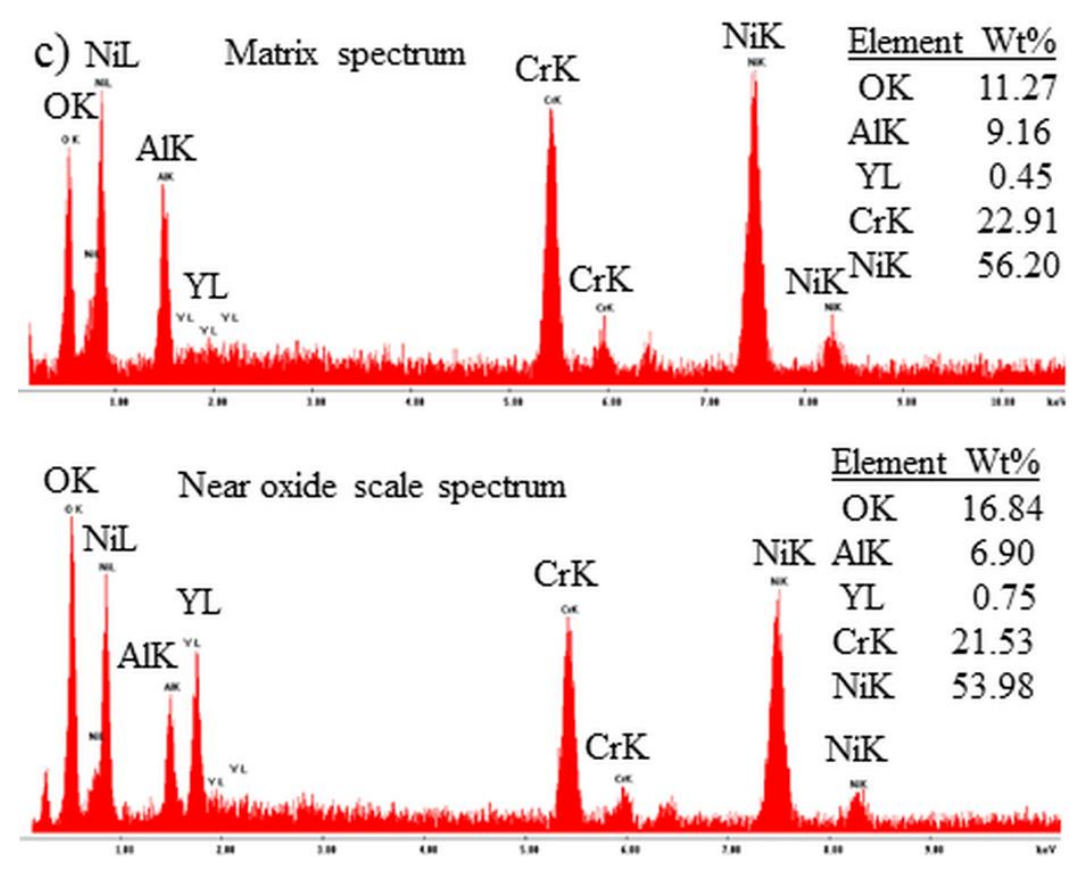

Fig. 4.8 SEM metallographic cross-section micrographs of specimen B after 40 cycles (a) matrix, (b) near oxide scale, (c) EDX spectrum of (a) and (b) with wt.\%.

Furthermore, Fig. 4.9(a-d) shows the SEM metallographic cross-section micrographs with EDX spectrum of specimen A after 120 thermal cycles. The oxide scale visibly indicated two distinct scales as depicted in Fig. 4.9(b). The outer part of the oxide scale is dominated by Ni-rich transient oxide scale [14] and the one below this transient Ni-rich oxide scale is an oxide scale dominated by aluminum and chromium as shown in the EDX elemental maps, depicted in Fig. 4.9(c). It should be noted that $\mathrm{Y}$ is found to be distributed uniformly in the oxide scale, Fig. 4.9(c). This uniform Y distribution in the oxide scale, especially on the grain boundaries [101, 134] contributes to the selective oxidation of alumina and chromia forming ODS alloys. In this study, the presence of Ni-rich oxide scale was not unexpected because of the lower Al content in the ODS alloys and the porous nature of the specimens. A similar Ni-rich oxide scales were found on $\mathrm{Ni}$ based ODS alloys $[102,136]$. As seen in the micrograph, the Ni-rich oxide scale is dominated by micro-pores, but it is nicely adhered to the below $\mathrm{Al}$ and $\mathrm{Cr}$-rich oxide scale without any oxide 
scale debonding. The EDX element spectrum and wt.\% indicated that all elements are present in the matrix and near oxide scale, depicted in Fig. 4.9(d).
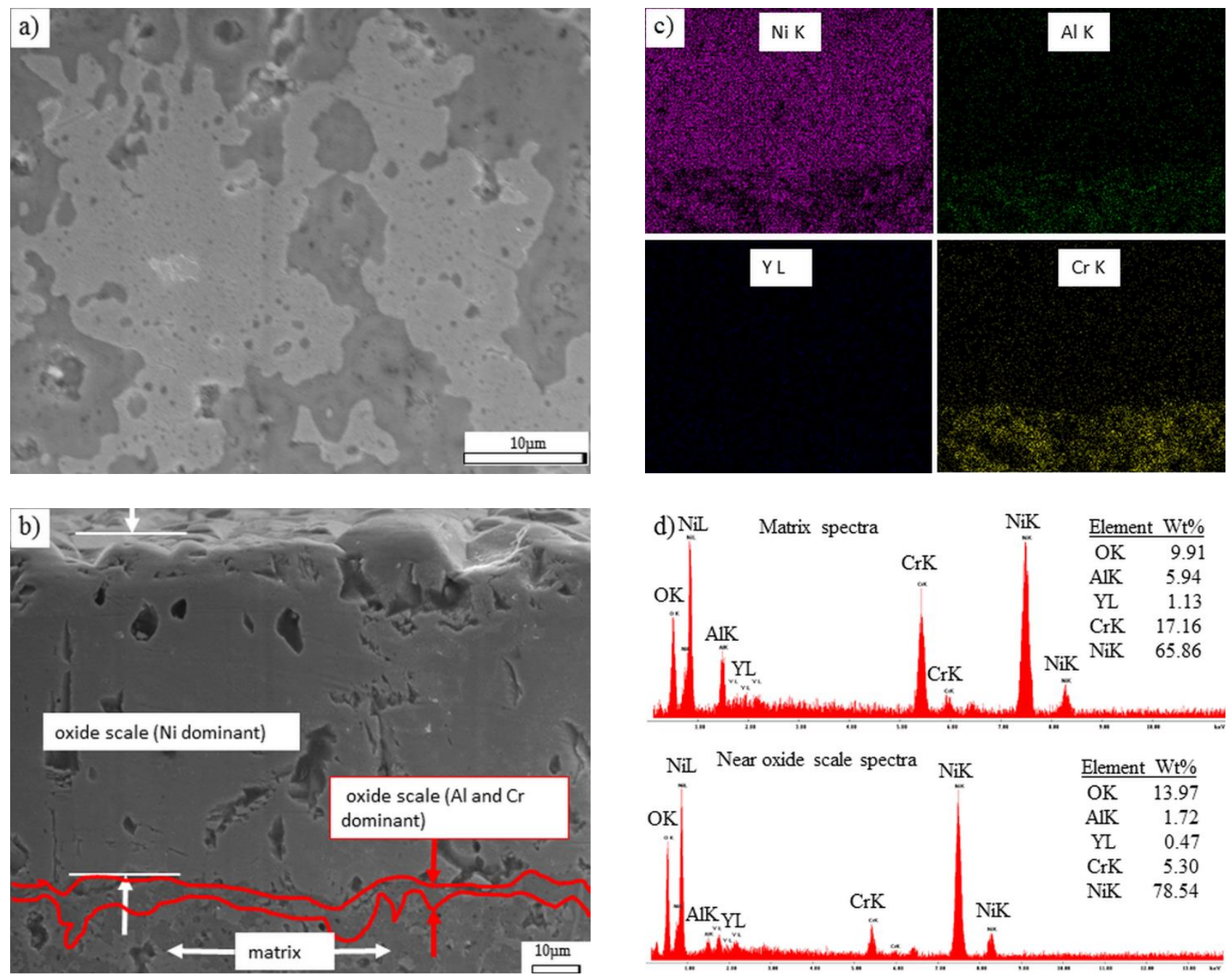

Fig. 4.9 SEM metallographic cross-section micrographs of specimen A after 120 cycles (a) matrix,

(b) near oxide scale, (c) EDX maps of (b), and (d) EDX spectrum of (a) and (b) with wt.\%.

Additionally, specimen B was studied for further analysis on the oxide scale and matrix microstructure with elemental distribution after 120 cycles depicted in Fig. 4.10(a-e). Fig. 4.10(a) and (b) shows the SEM metallographic matrix microstructure and EDX element spectrum and line scan with the element wt.\%, respectively. The dark spots are characterized by higher element counts of $\mathrm{Cr}, \mathrm{Al}, \mathrm{Y}$ and $\mathrm{O}$, while the grey matrix being dominated by Ni shown by the EDX line 
scan, Fig. 4.10(b). The oxide scale indicated in Fig. 4.10(c), shows crack which runs through the scale down to the metal-oxide scale interface, which could have been caused by the outer $\mathrm{Ni}$-rich oxide scale cracking during thermal cyclic cooling, or minor oxide surface crack could be worsened during specimen preparation. However, if this is a through the oxide thickness cracking, it indicated that the outer $\mathrm{Ni}$-rich oxide scale has very good adherence to the inner $\mathrm{Al}$ and $\mathrm{Cr}$-rich oxide scale without any spallation occurred during thermal cyclic exposure.

The inset picture shown in Fig. 4.10(d) along with its EDX spectrum, line scan and wt.\% of Fig. 4.10(e), indicated that the outer scale is indeed the Ni-rich transient oxide while the inner scale is $\mathrm{Al}$ and $\mathrm{Cr}$-rich oxides. A closer look on the EDX line scan shows that the inner oxide scale between the outer Ni-rich transient oxide scale (NiO) $[14,25,102,136-137]$ and the matrix is $\alpha$ $\mathrm{Al}_{2} \mathrm{O}_{3}[14,102]$. This Ni-rich oxide scale could also contain $\mathrm{Ni}(\mathrm{Cr}, \mathrm{Al})_{2} \mathrm{O}_{4}$ spinel-type structure [136-137] as there are some $\mathrm{Cr}$ counts observed in the EDX spectrum. Moreover, voids are visible on outer Ni-rich oxide scale. Cr-rich oxide is also evidently present between the outer Ni-rich oxide scale and $\alpha-\mathrm{Al}_{2} \mathrm{O}_{3}$, which could have been the result of fast $\mathrm{Cr}$-rich oxide scale growth at the beginning of oxidation [14]. This could also indicate that there is no any outer Ni-rich oxide scale spallation and regrowth discussed by Pint et al. [102] formed on ODS Ni3 $\mathrm{Al}$ during thermal cyclic oxidation. In general, this could lead to the formation of a total of three layers with different chemical compositions for the oxide scale. Starting from the metal, the oxide scales consisted of Al-rich layer, mixed layer, and Ni-rich outer layer. The existence of the outermost layer of $\mathrm{NiO}$ was common to the Ni-based alloys [137]. The intermediate layer contained main elements of $\mathrm{Cr}$ and $\mathrm{O}$ with trace elements of $\mathrm{Ni}$ and $\mathrm{Al}$. The mixed oxides could possibly consist of mainly $\mathrm{Cr}_{2} \mathrm{O}_{3}$ and $\mathrm{Ni}(\mathrm{Cr}, \mathrm{Al})_{2} \mathrm{O}_{4}$ spinel. The innermost layer was $\alpha-\mathrm{Al}_{2} \mathrm{O}_{3}$-rich layer. 


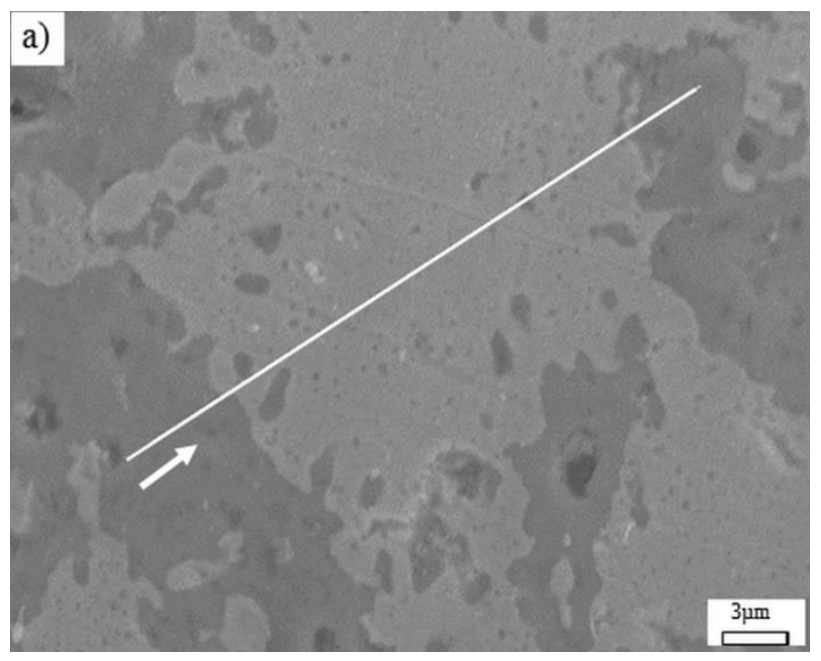

b)

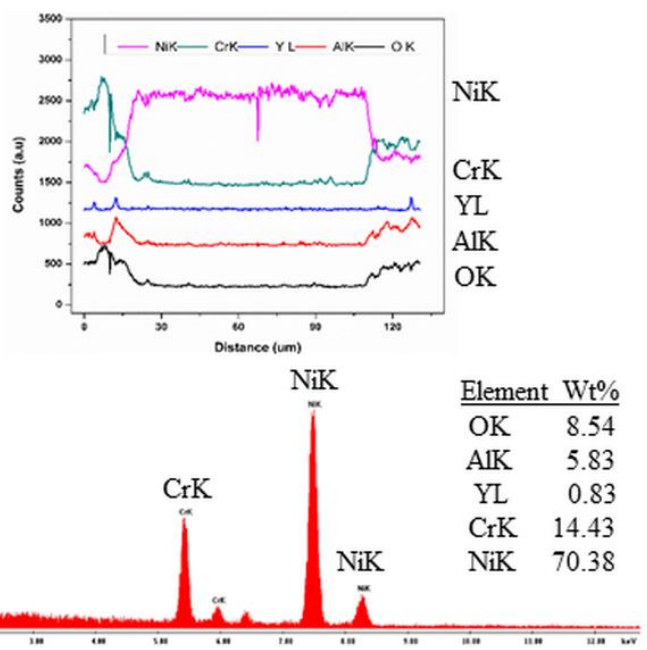

c)

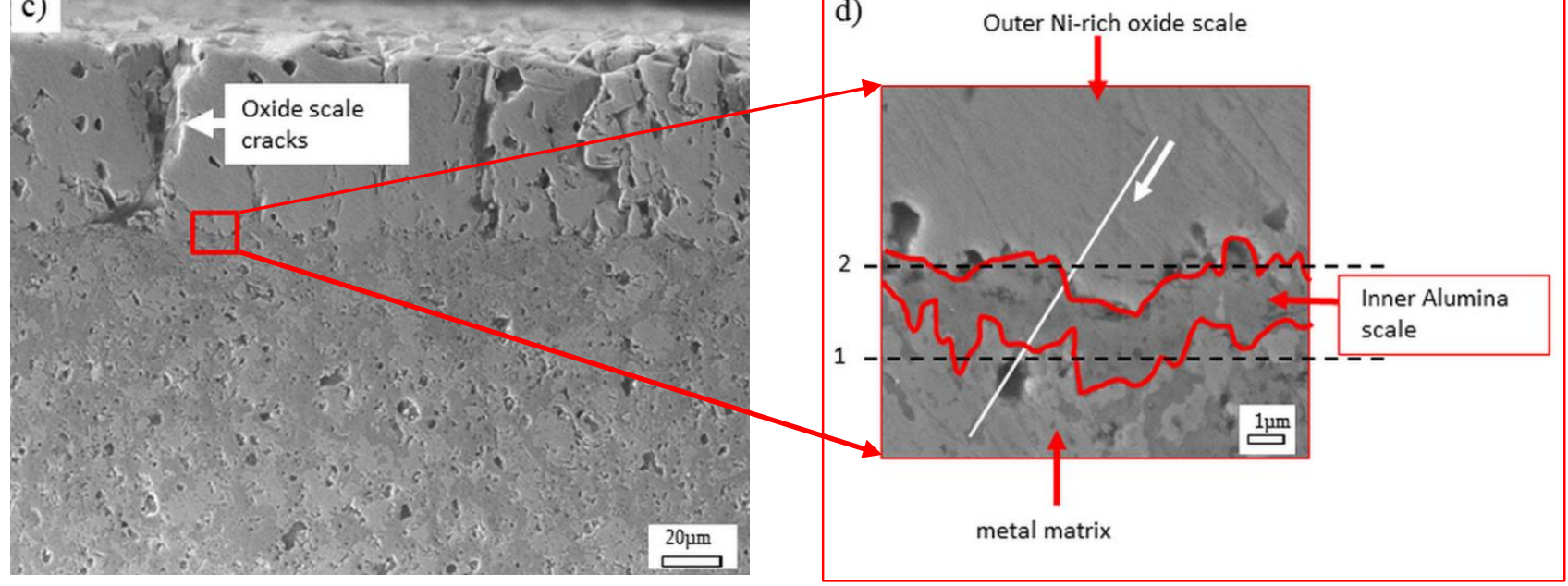

e)
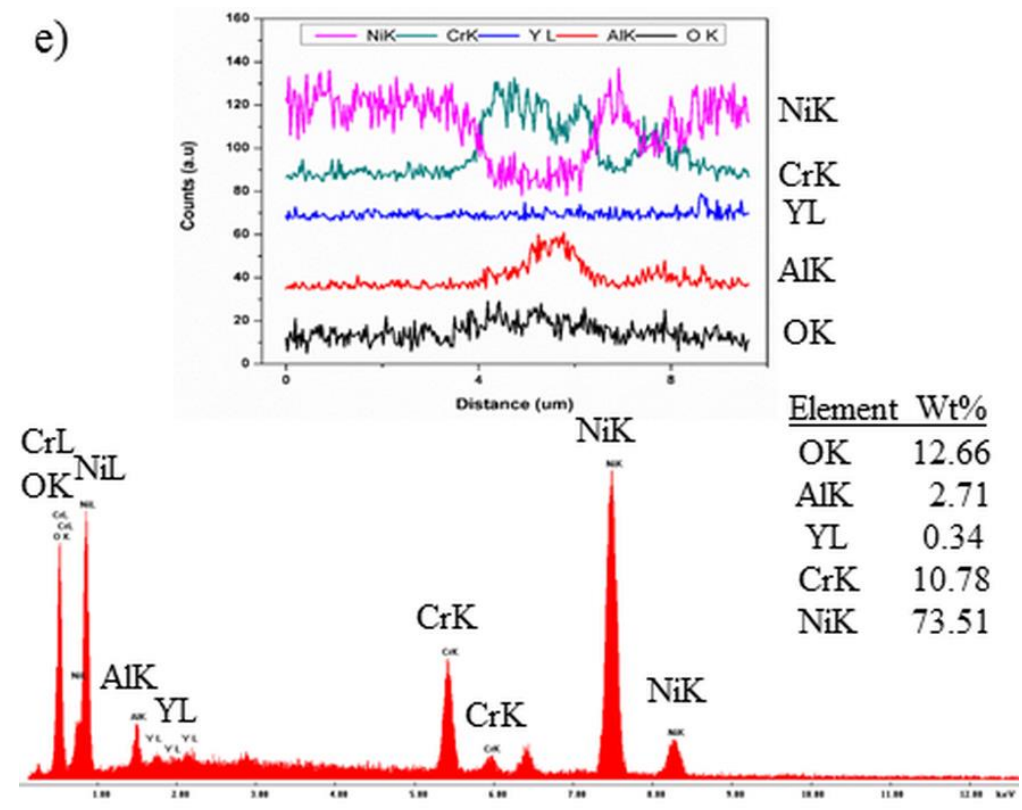
Fig. 4.10 SEM cross-section micrographs of specimen B after 120 cycles (a) matrix, (b) matrix EDX spectrum and its line scan with wt.\%, (c) near oxide scale, (d) near oxide scale inset picture, and (e) its EDX spectra and line scan with wt.\%.

Furthermore, metallographic cross-section study was taken on specimen A after longer thermal cycles of 360, depicted in Fig. 4.11(a-d). A similar distribution of elements in the matrix and oxide scale are observed, but the thickness of the transient Ni-rich oxide scale (about $60 \mu \mathrm{m}$ ) is higher than the 120 cycles of oxidation (about $40 \mu \mathrm{m}$ ). This confirmed that no outer Ni-rich transient oxide scale spallation has happened up to this stage of oxidation. Similarly, after 600 cycles of oxidation the outer Ni-rich oxide scale remains intact to ODS structure as indicated above the solid arrows in Fig. 4.11(e). This time the thickness is about $100 \mu \mathrm{m}$ with micro-pores (voids) indicated by dashed arrows all over the microstructure. The mechanism that led to the good adhesion of this scale could be related to the porous nature of the ODS alloy coupons and the MCB plus ball milling process unique to this study. That means this technique has the capacity of uniformly distributing yttria in the powder which is key to the high temperature strength of ODS alloys.

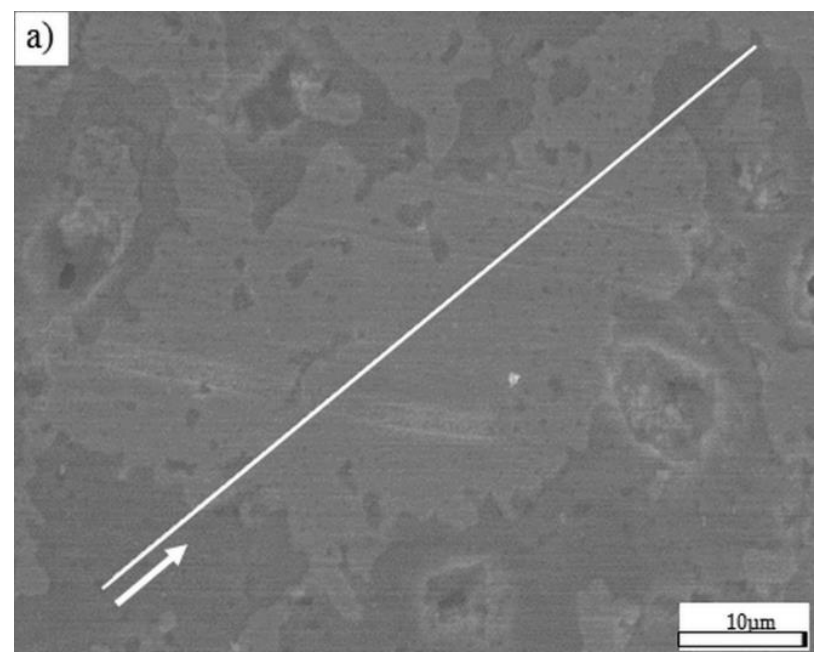

b)
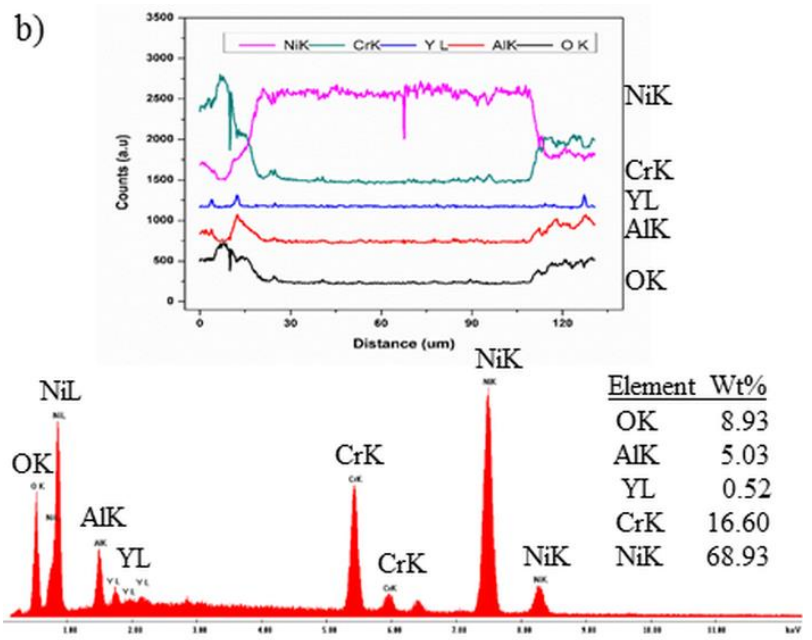

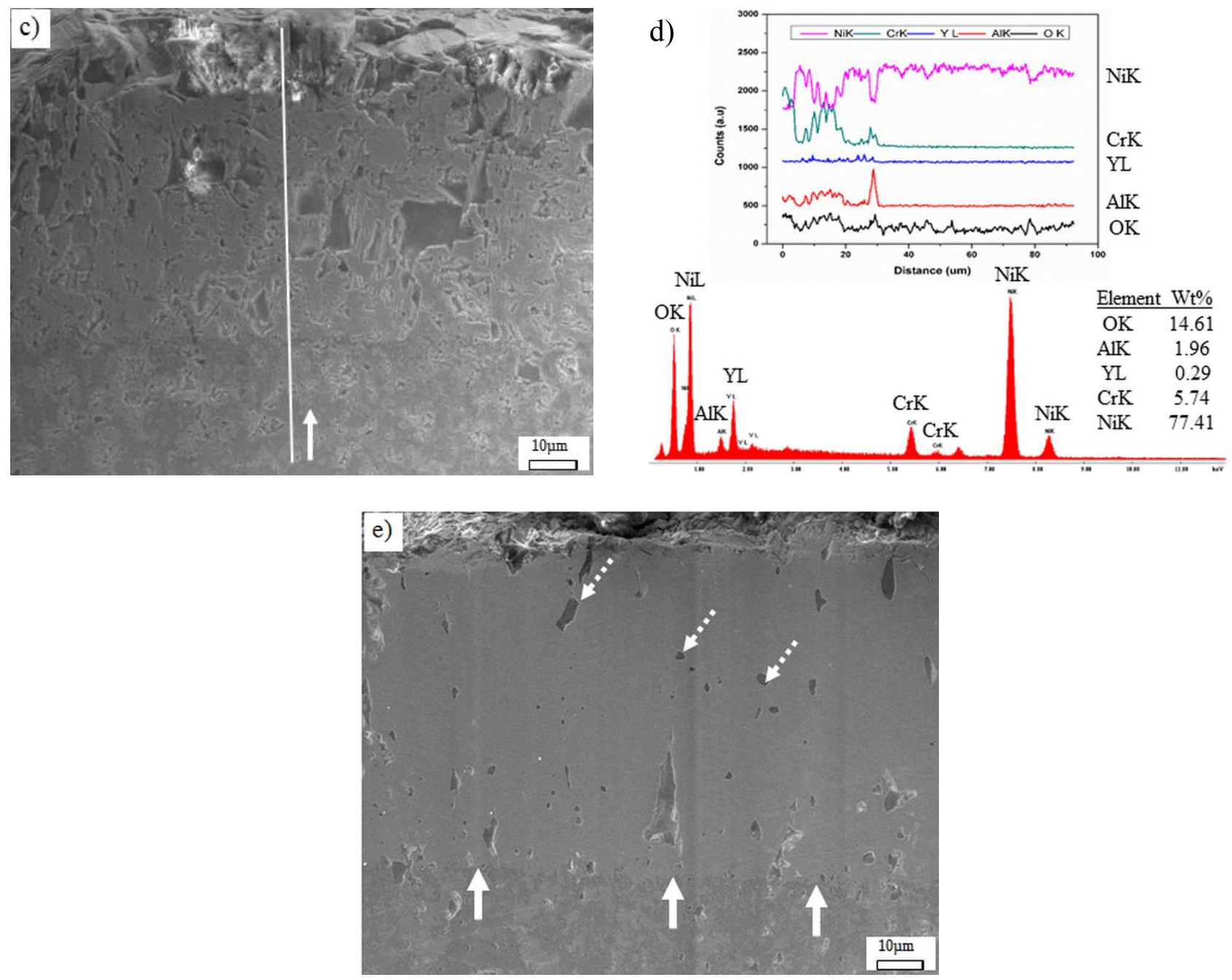

Fig. 4.11 SEM cross-section micrographs of specimen A (a-b) matrix with EDX spectrum, line scan and wt.\%, (c-d) near oxide scale with EDX spectrum, line scan and wt.\% after 360 cycles, and (e) near oxide scale after 600 cycles.

\subsubsection{Oxide Scale Analysis of Thermal Cycled ODS Alloy}

The as sintered specimen $\mathrm{B}$ is covered with rough surface containing all the starting elements, shown in Fig. 4.12(a-b), with a significant Al content. However, it is difficult to refer oxide scale formation at this stage because the sintering is performed in a flowing argon gas environment. The ridge surfaces could be the products of sintering and it should be noted that the 
thermal cyclic oxidation is performed on the as sintered surfaces without performing any surface polishing.

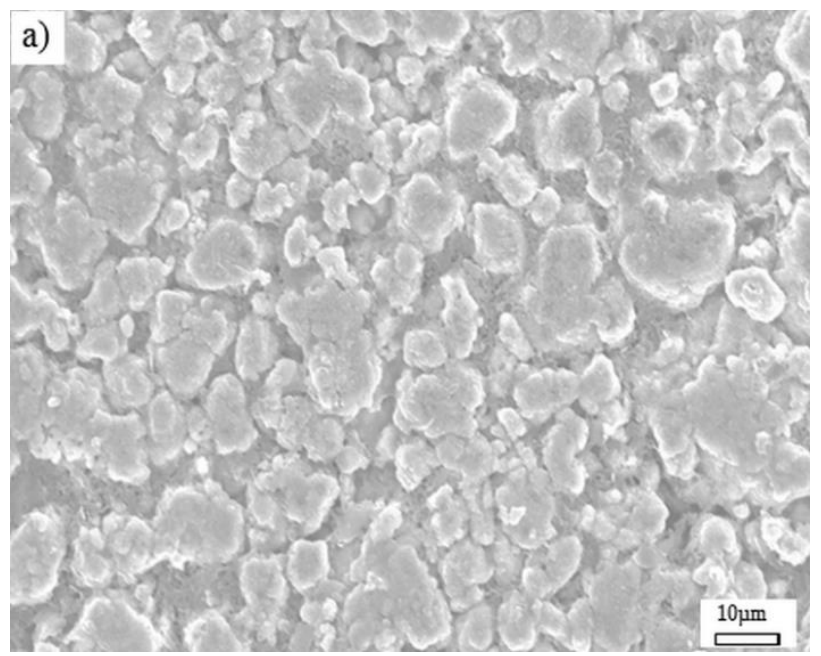

b)

\begin{tabular}{cr} 
Element & $\mathrm{Wt} \%$ \\
\hline OK & 16.03 \\
AlK & 38.03 \\
YL & 0.84 \\
CrK & 12.33 \\
NiK & 32.77
\end{tabular}

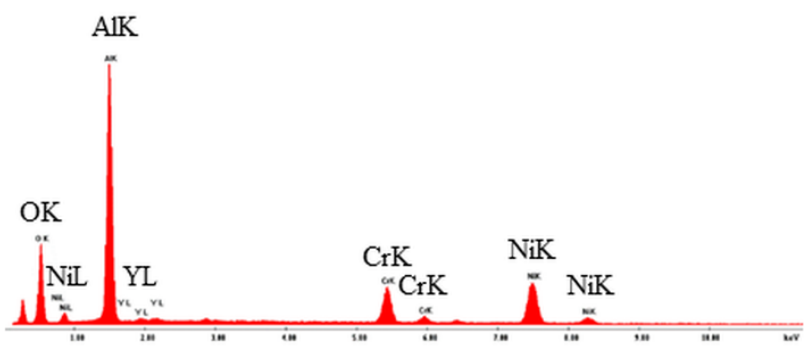

Fig. 4.12 As sintered specimen B outer surface SEM micrograph (a), EDX spectrum with wt.\% (b).

After 80 thermal cycles of exposure at $1100{ }^{\circ} \mathrm{C}$ the surface of the oxide scale was observed visually to contain two portions: (1) oxide scale surface with greenish color similar to the as sintered surface and (2) oxide scale with dark color, which appeared to grow replacing the greenish surfaces. SEM microstructure analysis was performed on both sections (1) and (2) indicated in Fig. 4.13(a) and (c) with the respective EDX spectrum and wt.\% shown in Fig. 4.13(b) and (d), respectively. The growth of new oxide scale could have taken place at the alloy-scale interface [105], which causes the formation of ridges or intrusions of oxide indicated as in Fig 4.13(a), giving rise to roughened interface between the alloy and oxide scales as seen in the cross-sectional micrographs of the previous section, such as Fig. 4.10(d). The greenish portion of the oxide scale contains high $\mathrm{Cr}$ and $\mathrm{Al}$ contents formed on each ridge (no. 1 and 2 in Fig. 4.13(a) with EDX line scan and wt.\% in Fig. 4.13(b)). According to the EDX line scan, the ridge near no. 1 is dominated by $\mathrm{Cr}$ and near no. 2 by Al. It could be possible that these nodules are composed of Y-containing 
oxides $[14,101]$ on top of a primary oxide scale formed as chromia and alumina. This could be true due to the significant number of $\mathrm{Y}$ content on the scale indicated by the wt.\%., Fig. 4.13(b). A detailed analysis of the oxidation of Ni-based ODS superalloy by Angerman et al. [14], indicated the presence of $\alpha-\mathrm{Al}_{2} \mathrm{O}_{3}$ both on the metallographic cross-section and oxide surface at lower oxidation time of $5 \mathrm{hrs}$.

The dark portion of the scale which is mostly covered by Ni-rich oxide scale as in Fig. 4.13(c) appeared to grow with the expense of the greenish outer scale and could have replaced and covered it underneath. This is because there is no ground for oxide scale spallation as the weight gain is never reduced, which will be discussed later. Oxide scale formed during transient oxidation has a tendency to remain at the oxide scale and it has been claimed that the presence of yttria as an important factor for the improved adherence of oxide scales on ODS alloys [5, 11, 26, 75, 101]. However, $\mathrm{Cr}_{2} \mathrm{O}_{3}$ could be oxidized in to volatile $\mathrm{CrO}_{3}$ [14]. It can be noted that the presence of some small oxide scale crack observed at this stage of oxidation and the presence of $\mathrm{Al}$ and $\mathrm{Cr}$ is very small to be detected by EDX analysis on the surface indicated in Fig. 4.13(d) by wt.\%.
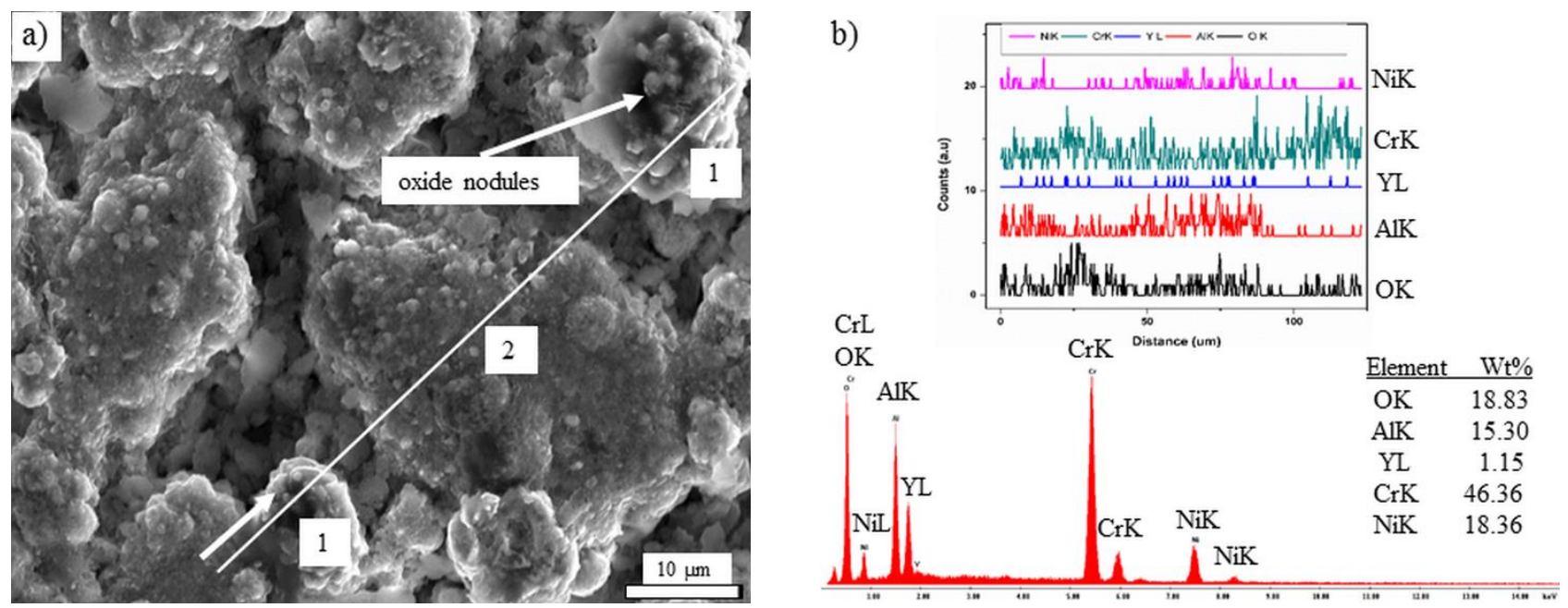


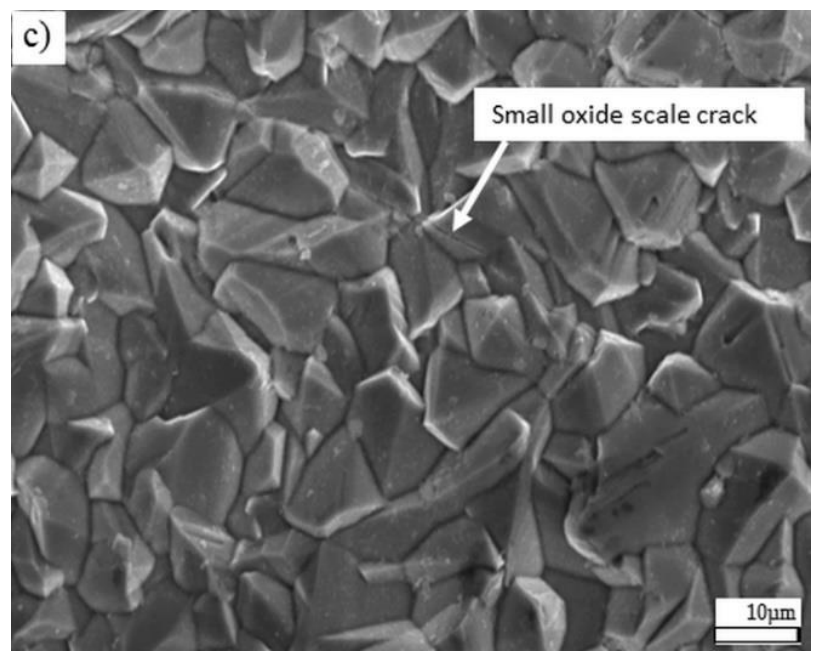

d)

\begin{tabular}{cr} 
Element & $\mathrm{W} t \%$ \\
\hline $\mathrm{OK}$ & 11.14 \\
$\mathrm{YL}$ & 0.27 \\
$\mathrm{CrK}$ & 0.72 \\
$\mathrm{NiK}$ & 87.87
\end{tabular}

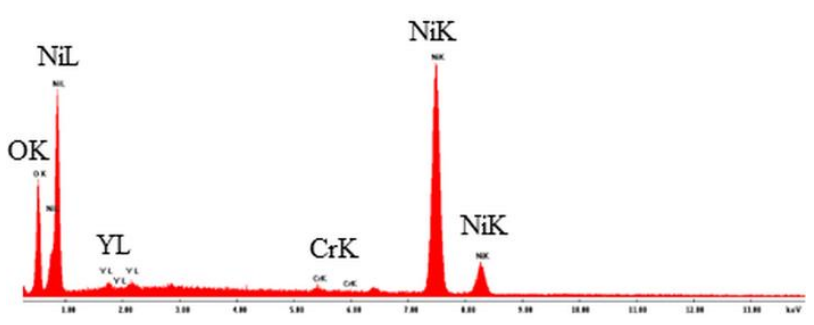

Fig. 4.13 Oxide scale SEM micrographs of specimen A after 80 cycles (a-b) grey portion and (cd) dark portion with EDX spectrum, line scan and wt.\%, respectively.

Several ideas had been proposed relating the mechanisms of oxide scale formation on ODS alloys reviewed by Prescott et al. [105] on the basis of observations of scale morphologies. The growth of new oxide scale by some is considered to take place at the alloy-scale interface or at scale-gas interface causing the formation of ridges/intrusions or ridges/protrusions of oxide, extending inward at the alloy-scale interface or extending outward at the scale-gas interface, respectively. The inward protrusion suggests that the oxidation takes place by inward oxygen diffusion, whereas the outward extension is caused by cation diffusion. Sometimes the ridges could be found extending both ways, indicating the counter diffusion of oxygen and cation. Based on the cross-section micrographs in the previous section and the outer oxide scale ridge/oxide nodule formation in this section, the oxidation mechanism in this study could be governed by cation diffusion at least for Ni-rich transient oxide formation.

At longer 440 cycles of oxidation specimen A and B were analyzed by SEM as shown in Fig. 4.14(a) and (b) with their EDX spectrum and wt.\% indicated in Fig. 4.14(c), respectively. It should be noted that the presence of alloying elements other than $\mathrm{Ni}$ and $\mathrm{O}$ are very trace on the 
oxide scale. The Ni-rich oxide scale consisted of complex differently oriented sandwiched splats on both specimens that strongly adhered to the underneath alumina scale discussed in the previous section (Fig. 4.10(c) and 4.11(c)). As discussed on the metallographic cross-section, the composition of the outer oxide scale was dominated by oxides of $\mathrm{Ni}(\mathrm{NiO})$ as confirmed by XRD analysis observed on the oxide surface shown in Fig. 4.14(d) after 600 thermal cycles. A similar observation of small amounts of iron on alumina forming Fe-based superalloy MA 956 and dominant amount of $\mathrm{NiO}$ scale on chromia forming Ni-based superalloy MA 754 [28], ODS-Ni 3 Al [102], and uncoated Ni-based superalloy [136, 138] were reported. Moreover, the XRD analysis performed on the oxide surfaces indicated the presence of $\mathrm{Cr}_{2} \mathrm{O}_{3}$ and $\alpha-\mathrm{Al}_{2} \mathrm{O}_{3}$. This could probably be the result of X-ray penetration through the outer $\mathrm{NiO}$ surface and characterizes the underneath chromia and alumina scales [42].
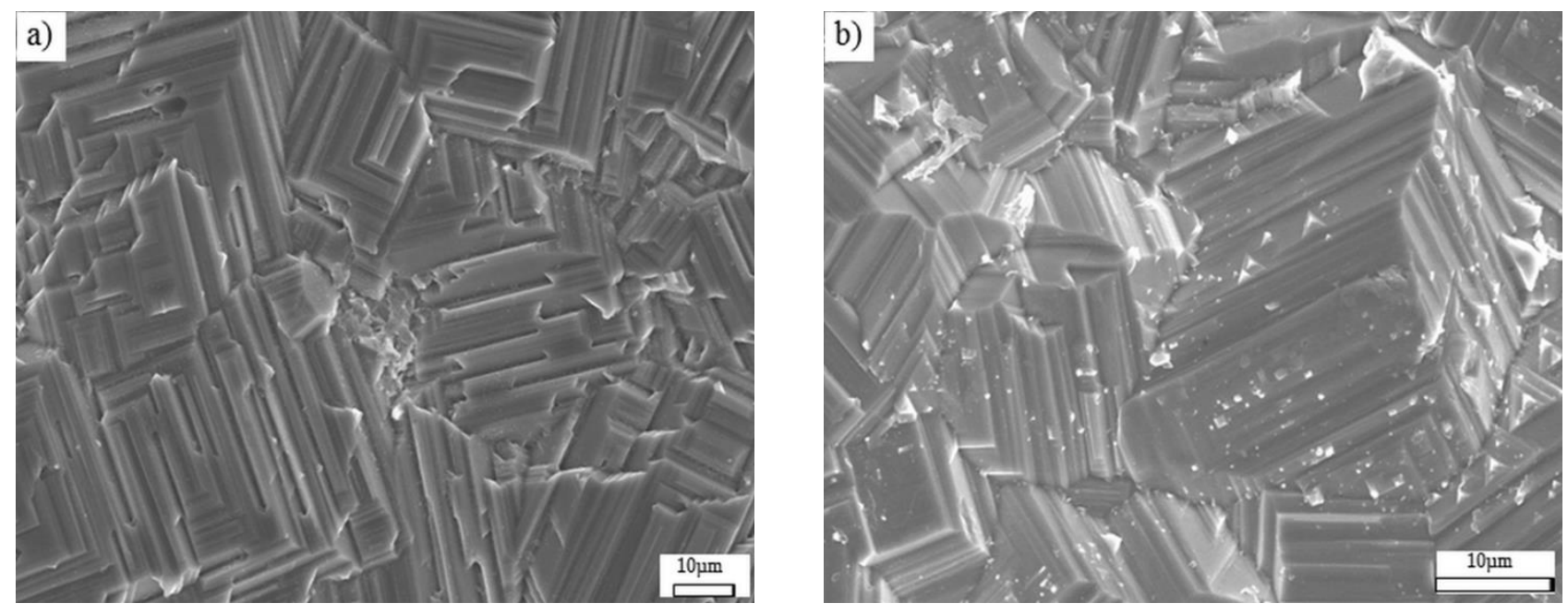

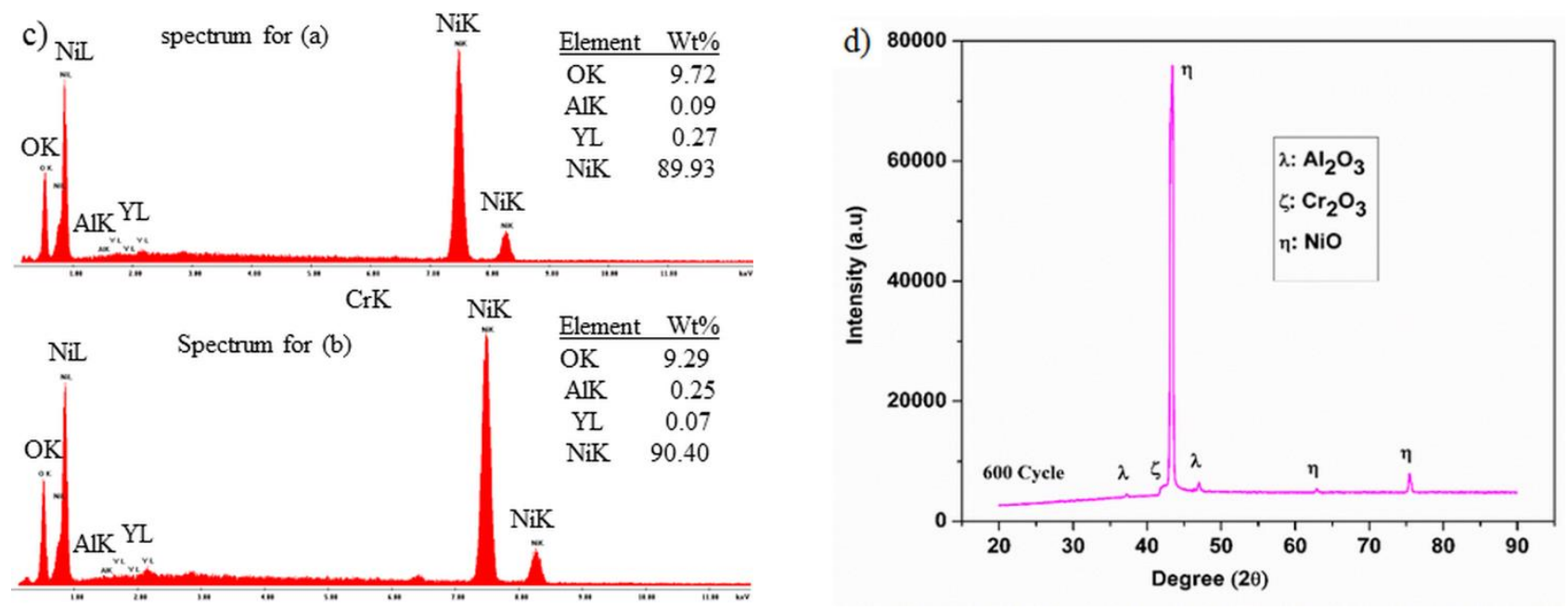

Fig. 4.14 Oxide scale SEM micrographs after 440 cycles (a) specimen A, (b) specimen B with their EDX spectrum and wt.\% (c), and (d) XRD spectrum of specimen A after 600 cycles.

Based on the observation of cross-sectional micrographs and oxide scale surfaces, the oxide scale formation throughout the cyclic oxidation could be presented in the following simple schematic, Fig. 4.15. As discussed above below 100 thermal cycles, Al and Cr-rich oxide scales together with Y-rich oxide nodules were observed initially and subsequently Ni-rich oxide scale grows covering them underneath, Fig. 4.15(a-b). The Ni-rich oxide scale started to fully cover the surface at about 100 thermal cycles. At an intermediate, up to 500 thermal cycles, Fig. 4.15(c), the oxide scale has a wave shape with uniform alumina scale. The adherent outer $\mathrm{NiO}$ at longer thermal cycles showed surface cracks which grows down to the alumina scale leaving the alumina scale to have a non-uniform thickness. These cracks may simply be thermal (cooling) stresses [102] observed on ODS $\mathrm{Ni}_{3} \mathrm{Al}$ and compressive stresses [104] on FeAl ODS alloys. Ni-rich oxide scale spallation and subsequent regrowth [102] is not unfamiliar on Ni-based ODS alloys. However, its adherence to the underneath alumina scale without any spallation observed even up to longer thermal cycles, above 700 cycles is a unique and an interesting finding of this study. 


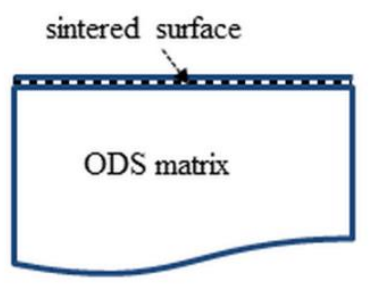

a) As sintered specimen

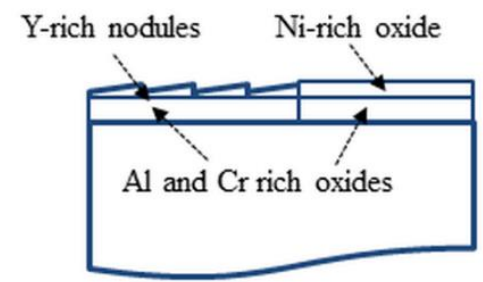

b) Below 100 cycles

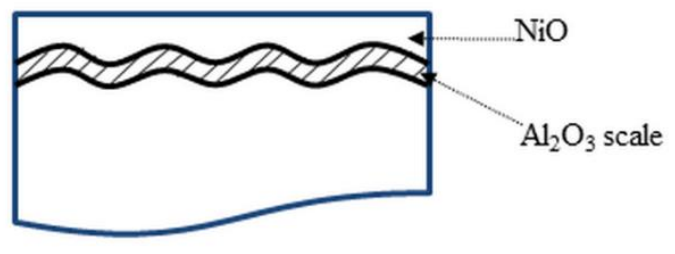

c) Intermediate cycles

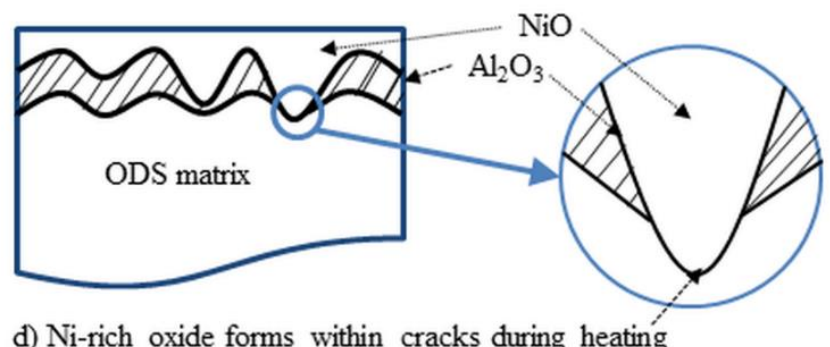

d) Ni-rich oxide forms within cracks during heating

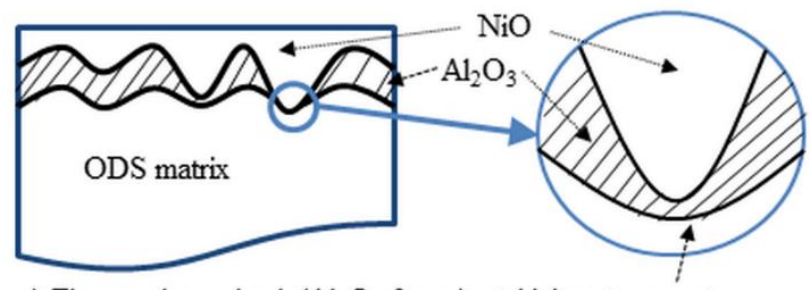

e) The cracks re-heal $\left(\mathrm{Al}_{2} \mathrm{O}_{3}\right.$ forms) at higher temperature

Fig. 4.15 Schematic illustrations: The outer Ni-rich oxide cracks together with alumina scale at longer oxidation cycles above, 500 cycles (d-e) but remains adherent. Upon insertion and heating Ni-rich oxide is able to form in the cracks before alumina re-heals at higher temperature.

While there is some degree of speculation as to why $\mathrm{NiO}$ did not spall away, it has been observed that the alumina scale undulation and some level of through-scale cracks at longer thermal cycles. This could happen when the specimen is cooled to room temperature and the fast Ni-rich oxide grows through the cracks immediately after the specimen is inserted and heated, Fig. 
4.15(d). When the temperature increased and reach to a certain value the cracked alumina scale is believed to re-heal and close the cracks, Fig. 4.15(e). In the present study, however, there is no outer $\mathrm{NiO}$ scale spallation and regrowth reported by Pint et al. [102] on ODS $\mathrm{Ni}_{3} \mathrm{Al}$ during thermal cyclic exposure.

The possible importance to future high temperature alloy development is why this $\mathrm{NiO}$ adherence phenomenon is unique to MCB plus ball milling process. The most likely is (1) the uniform distribution of reactive yttria throughout the alloying powders imparted by MCB plus ball milling process and the associated room temperature uniaxial pressing to form the ODS alloy with porosity, and (2) the presence of oxide nodules (Y-rich) together with $\mathrm{Al}$ and $\mathrm{Cr}$-oxide at the beginning of oxidation, which could act as oxide keying or pegging of $\mathrm{NiO}$ scale to the underneath stable alumina scale.

The formation of this adherent outer $\mathrm{NiO}$ scale on top of the stable $\alpha-\mathrm{Al}_{2} \mathrm{O}_{3}$ scale and its effect on the oxidation mechanisms of high temperature ODS alloys were neither determined in this study nor by other groups [14, 25-26, 102], it is unclear and further investigation is needed. However, due to the fast growth of $\mathrm{NiO}$ compared to $\alpha-\mathrm{Al}_{2} \mathrm{O}_{3}$ [55] there is a possibility of reduced $\mathrm{O}$ anions diffusion down to the interfaces of $\mathrm{NiO} / \alpha-\mathrm{Al}_{2} \mathrm{O}_{3}$ due to its interaction with $\mathrm{Ni}$ cations to form $\mathrm{NiO}$. This could enhance the stable and flawless formation of $\alpha-\mathrm{Al}_{2} \mathrm{O}_{3}$ through longer thermal cyclic exposure. Moreover, the strong adhesion of $\mathrm{NiO}$ on this alloy system could be additional benefit as high temperature corrosion resistance for ODS alloy coating sytems [139], if its purity can be controlled.

To address why the Ni-rich oxide scale still remains adhered without spallation up to these longer thermal cycles, finite element analysis (FEA) is done. Some research works conducted on the mechanisms of spallation of oxide scales on ODS alloys suggested that oxide scale spallation 
is by either surface cracks [102] or biaxial compression leading to bending [104] occurred during cooling due to the difference in thermal expansion coefficient between the scale and the underlying matrix with an assumption of good oxide adherence and smooth interface. However, based on Fig. 4.10(d) the outer Ni-rich oxide scale and the underlying alumina scale has sinusoidal rather than smooth interface.

Finite element analysis (FEA) is performed to see the difference in residual stress distribution between this sinusoidal and smooth interface geometry and relate on the spallation mechanism. To accomplish this, sinusoidal interface, Fig. 4.16 and simple smooth interface, Fig. 4.17 were implemented for both the $\mathrm{NiO} /$ alumina as well as the alumina/ODS matrix interface. The sinusoidal interface was modeled in such a way that an equal amplitude of $5 \mu \mathrm{m}$ and a wave length of $100 \mu \mathrm{m}$ for both interfaces. Enhancing resolution of the resultant stress distribution, minimum element sizes of $2.5 \mu \mathrm{m}$ were implemented within the alumina and increased to a value of $10 \mu \mathrm{m}$ when entering to the $\mathrm{NiO}$ and ODS matrix. Plane182 axisymmetric element is employed with thermal dependent elastic isotropic material behavior, table 6. Some of the material properties are taken as an average values.

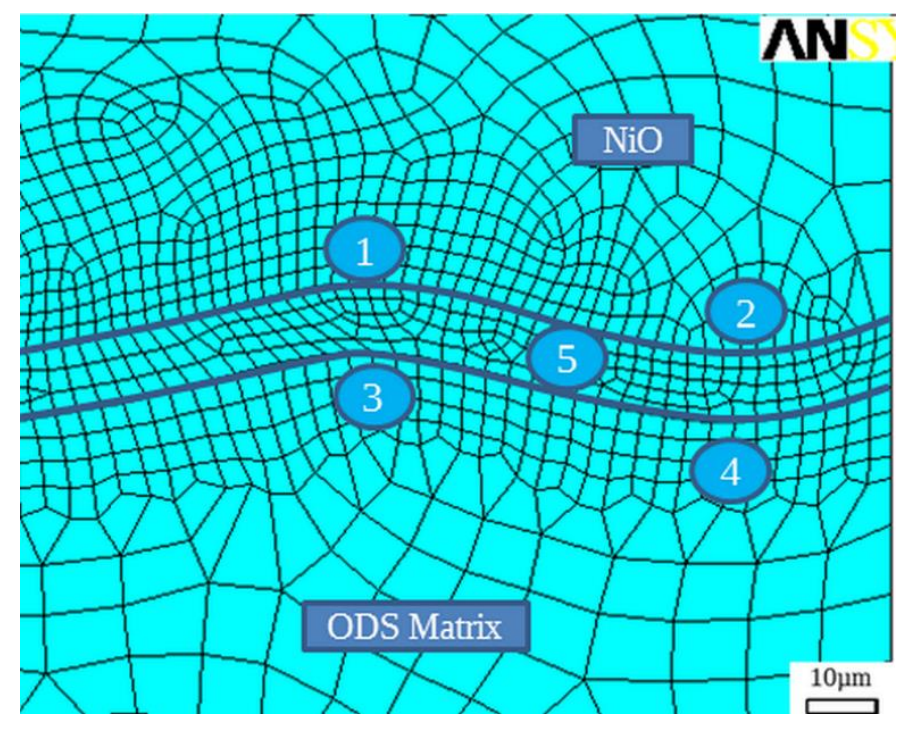

Fig. 4.16 Modeling parameters for sinusoidal interface and FEA mesh 
Table 6 Material properties of oxides and ODS matrix [140-142]

\begin{tabular}{|c|c|c|c|c|c|c|c|c|c|c|c|c|}
\hline \multirow[t]{2}{*}{$\begin{array}{l}\text { Temp. } \\
\left({ }^{\circ} \mathrm{C}\right)\end{array}$} & \multicolumn{3}{|c|}{$\begin{array}{l}\text { Young's } \\
\text { Modulus (GPa) }\end{array}$} & \multicolumn{3}{|c|}{$\begin{array}{l}\text { Coefficients of } \\
\text { Thermal Expansion }\end{array}$} & \multicolumn{3}{|c|}{$\begin{array}{l}\text { Thermal } \\
\text { Conductivity }\left(\mathrm{W} / \mathrm{m}{ }^{\circ} \mathrm{C}\right)\end{array}$} & \multicolumn{3}{|c|}{$\begin{array}{l}\text { Specific heat } \\
\left(\mathrm{J} / \mathrm{kg}{ }^{\circ} \mathrm{C}\right)\end{array}$} \\
\hline & $\mathrm{NiO}$ & $\begin{array}{l}\alpha- \\
\mathrm{Al}_{2} \mathrm{O}_{3}\end{array}$ & ODS & $\mathrm{NiO}$ & $\begin{array}{l}\alpha- \\
\mathrm{Al}_{2} \mathrm{O}_{3}\end{array}$ & ODS & $\mathrm{NiO}$ & $\begin{array}{l}\alpha- \\
\mathrm{Al}_{2} \mathrm{O}_{3}\end{array}$ & ODS & $\mathrm{NiO}$ & $\begin{array}{l}\alpha- \\
\mathrm{Al}_{2} \mathrm{O}_{3}\end{array}$ & ODS \\
\hline 30 & 220 & 300 & 203 & 14.5 & 7.2 & 12 & 15 & 0.9 & 14.3 & 600 & 800 & 440 \\
\hline 200 & 220 & 300 & 194 & 14.5 & 7.5 & 13.1 & 17 & 1.0 & 17.7 & 600 & 800 & 488 \\
\hline 600 & 220 & 300 & 170 & 14.5 & 8.6 & 15.1 & 20 & 1.2 & 25 & 600 & 800 & 595 \\
\hline 800 & 220 & 300 & 150 & 14.5 & 9.2 & 16.1 & 22 & 1.3 & 28.9 & 600 & 800 & 647 \\
\hline 900 & 220 & 300 & 140 & 14.5 & 9.4 & 16.6 & 25 & 1.4 & 30.8 & 600 & 800 & 672 \\
\hline 1000 & 220 & 300 & 130 & 14.5 & 9.7 & 17 & 30 & 1.5 & 32.6 & 600 & 800 & 695 \\
\hline 1100 & 220 & 300 & 120 & 14.5 & 10 & 20.2 & 35 & 1.7 & 34.2 & 600 & 800 & 720 \\
\hline $\begin{array}{l}\text { Poisson's } \\
\text { Ratio }\end{array}$ & 0.3 & 0.21 & 0.3 & & & & & & & & & \\
\hline $\begin{array}{l}\text { Density } \\
\left(\mathrm{kg} / \mathrm{m}^{3}\right)\end{array}$ & 6670 & 3690 & 8550 & & & & & & & & & \\
\hline $\begin{array}{l}\text { Thickness } \\
(\mu \mathrm{m})\end{array}$ & 10 & 100 & 2000 & & & & & & & & & \\
\hline
\end{tabular}

The axisymmetric geometry is modeled in ANSYSTM v14.0 containing all layers with thicknesses of each being $100 \mu \mathrm{m}, 10 \mu \mathrm{m}$ and $2000 \mu \mathrm{m}$ for the NiO, alumina, and ODS matrix, respectively. A film coefficient of $100 \mathrm{~W} / \mathrm{m} \mathrm{K}$ at a bulk temperature of $30{ }^{\circ} \mathrm{C}$ was applied to the outer surfaces of the model after an initial temperature of $1100^{\circ} \mathrm{C}$ was given and transient analysis was performed for 600 seconds to store temperature results for the structural analysis part.

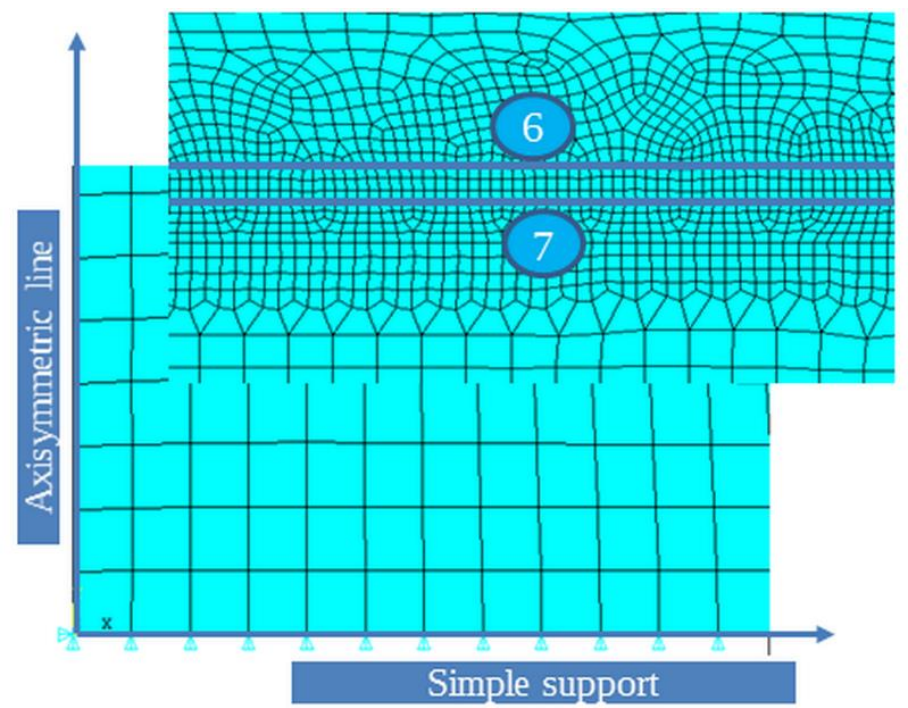

Fig. 4.17 Modeling parameters of smooth interface and boundary conditions for structural analysis. 
After the transient analysis was performed and results stored at each time step structural analysis was performed by calling the temperature effect from the transient analysis. To avoid singularity and obtain a semi-infinite domain for the structural analysis fixed boundary is used with nodes at the bottom origin of the axisymmetric model and simple support along the $\mathrm{x}$-axis, Fig. 4.17. The temperature distribution in the model after the transient analysis is depicted in Fig. 4.18, showing the temperature gradient reaching steady state condition.

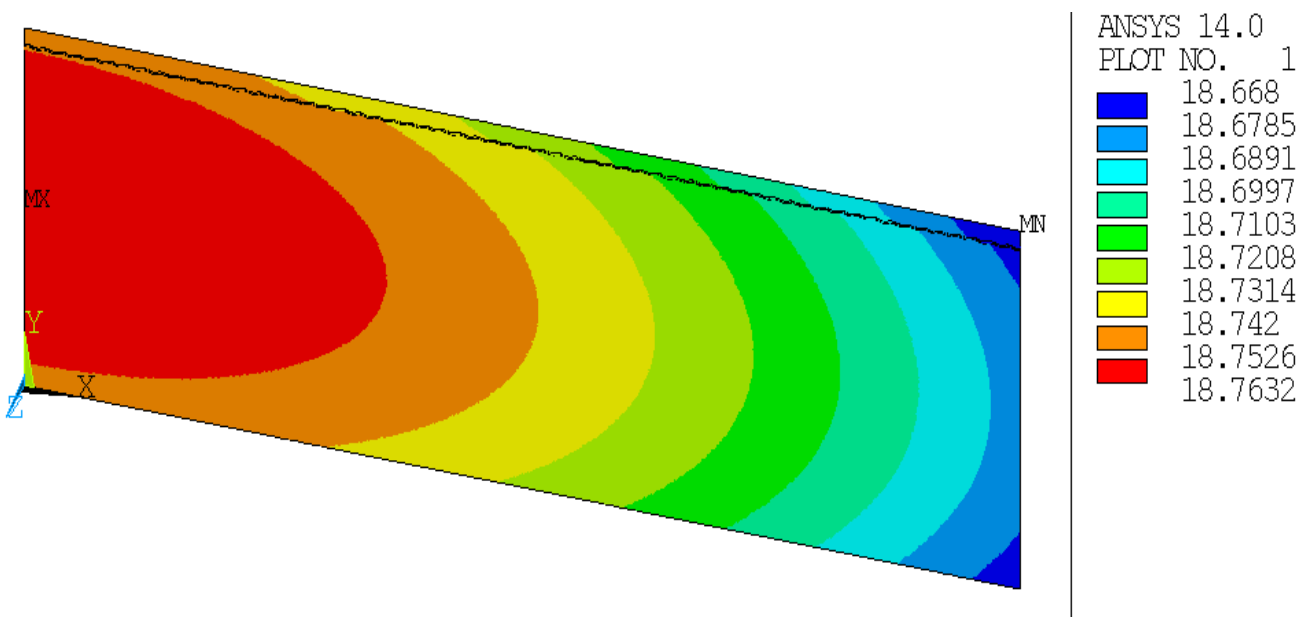

Fig. 4.18 Temperature distribution after transient analysis and model coordinate system.

To investigate the failure mechanisms of the oxide scales in both smooth and sinusoidal interfaces, different location were investigated numbered in Fig. 4.16 and Fig. 4.17. Of the five locations in the sinusoidal interface, four reside at the apex and base of the NiO/alumina (locations 1 and 2) and alumina/ODS matrix (locations 3 and 4) interfaces, in addition to one at the alumina wave's midline (location 5). Similarly location 6 and 7 are investigated at the NiO/alumina and alumina/ODS matrix interface for the smooth interfaces. Although in-plane residual stress states have been reviewed, their overall magnitude was found to be well below that needed to cause compressive or tensile failure. Furthermore, recent studies in TBC systems indicated that it is not 
the in-plane but rather that out-of-plane tensile stresses that are directly responsible for microcracking and spallation failure [143]. However, in-plane bi-axial compressive stress and shear stress [104] were found to cause bending failure of the scale in ODS FeAl alloy and wrinkles [144] caused by oxidation induced compressive stress in aluminum containing alloys at high temperature. Due to this, out-of-plane tensile and compressive stresses at interface locations $1,2,3$ and 4, as well as shear stress at node 5 for sinusoidal interfaces and interface locations 6 and 7 for smooth interfaces are presented below for both $\mathrm{NiO}$ and alumina scales.

The out-of-plane stresses developed in the $\mathrm{NiO}$ and alumina scale at the NiO/alumina interfaces, Fig. 4.19(a-b) for the case of smooth interface (location 6) are found to be tensile and compressive, respectively throughout the length of the model. The alumina scale at alumina/ODS matrix interfaces (location 7) is also found to be in compression, Fig. 4.19(b). For the sinusoidal interface in the $\mathrm{NiO}$ scale, the residual stress is in tension, Fig. 4.19(c). However, the residual stress distribution for the sinusoidal interface in the alumina scale is different at different locations. At the top and bottom apex (locations 1 and 4) the residual state of stress is compressive, while at locations 2 and 3 it is in tension, Fig. 4.19(d). These contrasting states of stress at nodes 1 and 2, 3 and 4 act to prevent localized cracking that may develop at either locations from propagating beyond by closing it. As a result, this could be the reason why NiO scale did not spall in this study, while NiO scale spallation and regrowth [102] and oxide scale spallation observed [104], as the interface was mentioned to be smooth. Moreover, in this study the $\mathrm{NiO}$ scale for both interfaces was predominantly subjected to tensile stresses throughout the length of the model, Fig. 19(b and d). These tensile stresses developed in the $\mathrm{NiO}$ scale could exacerbate $\mathrm{NiO}$ spallation for smooth interface as there is no contrasting states of stresses at NiO/alumina interface compared to the sinusoidal interface. However for the sinusoidal interface, compressive stresses produced at 
location 1 are not favorable to micro-crack development and those tensile stresses developing at location 2 typically do not propagate along the $\mathrm{NiO}$ /alumina interface and do not result in $\mathrm{NiO}$ large scale spallation failure either.
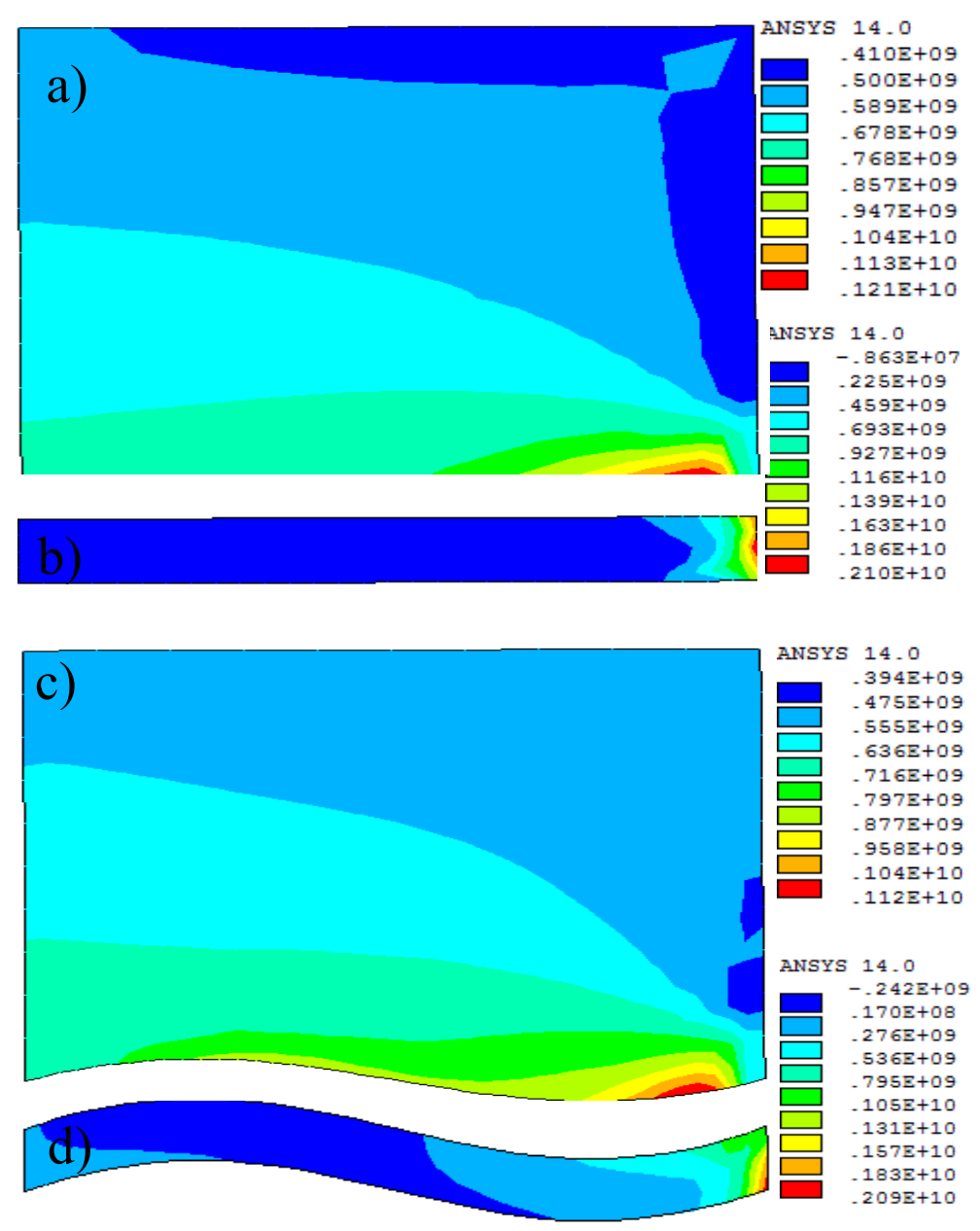

Fig. 4.19 Residual stress distributions in the $\mathrm{NiO}$ (a and c) and alumina scale (b and d) for both smooth and sinusoidal interfaces, respectively.

The shear stress distribution in the alumina scale is depicted as in Fig. 4.20. The shear stress in the smooth interfaces Fig. 4.20(a) appeared to be less localized, except at the extreme outer edges where edge effect could be dominant. For the sinusoidal interfaces, Fig. 4.20(b) the shear stress distribution appeared to be localized at location 5. Cracks developing at location 5, unlike that of locations 1,2,3, and 4 are not easily explained by considering only the out-of-plane residual 
stresses. The out-of-plane residual stress acting in this region is in a compressive state of stress throughout the model. However, if there is a crack in this region the cause of cracking could be become evident upon considering the systems maximum shear stress due to its high magnitude and localized nature.

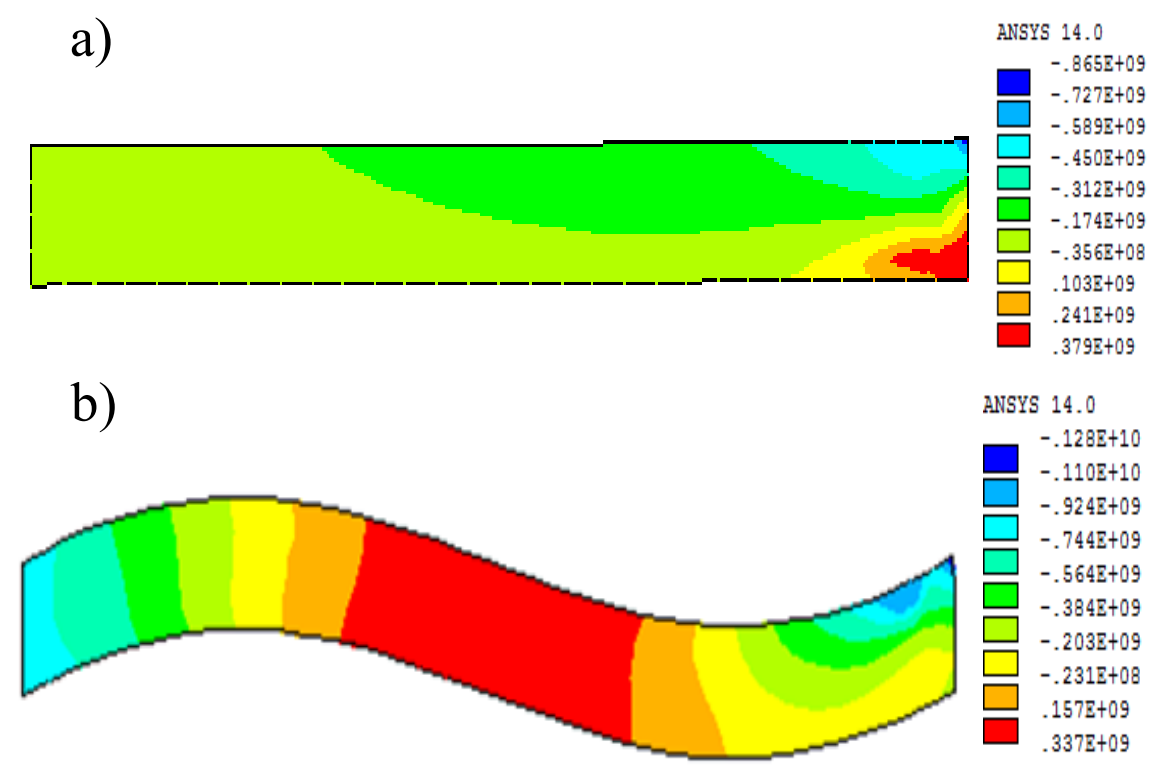

Fig. 4.20 Shear stress distributions in an alumina scale for both smooth and sinusoidal interfaces.

In addition to sinusoidal interfaces of the oxide scale, oxide nodules grown at the beginning of oxidation could played the role of pining the outer $\mathrm{NiO}$ scale to the underlying alumina scale. Moreover, the higher wt. \% of the Ni in the alloy and its transport through the porous ODS matrix could have played the role for the strong adherence of this scale to such a longer thermal cycles.

\subsubsection{Elastic Modulus Determination Based on Microindentation}

To understand more about the oxidation behavior, weight gain analysis was performed on specimens C and D as seen in Fig. 4.21(a), which indicated an increase in the weight gain during the oxidation process. There were two regimes observed in the process, an initial rapid weight gain followed by slow and smooth increment. Almost $50 \%$ of the total weight gain was obtained in the first 150 thermal cycles in both specimens. The fast weight gain at the beginning of the cycles 
could be related to the fast growth of oxides due to the presence of micro-pores. When comparison was done on both specimens with similar dimensions, specimen $\mathrm{C}$ sintered for $60 \mathrm{~min}$ showed a lower weight gain than D sintered for $120 \mathrm{~min}$. This could be the result of grain size difference between the two specimens as oxygen anion diffusion is mainly through grain boundary transport $[23,75,106]$ and grain size could increase with increasing sintering time or increasing sintering temperature [20, 123] for both Ni-based and Fe-based ODS alloys. Additionally, the longer sintering time in specimen D could increase yttrium depletion [25] and hence increase oxidation of specimen D. This is because, one purpose of yttrium presence in ODS alloys is to suppress the cations diffusion paths so that only selective oxidation is formed by the inward grain boundary diffusion of oxygen [28]. However, it could be difficult to identify the differences in the oxidation mechanisms of the two specimens based on such a small amount of sintering time variation. Notably, the trend of the weight gain curves obtained in this work was in agreement with reported in $[25,28,145]$.
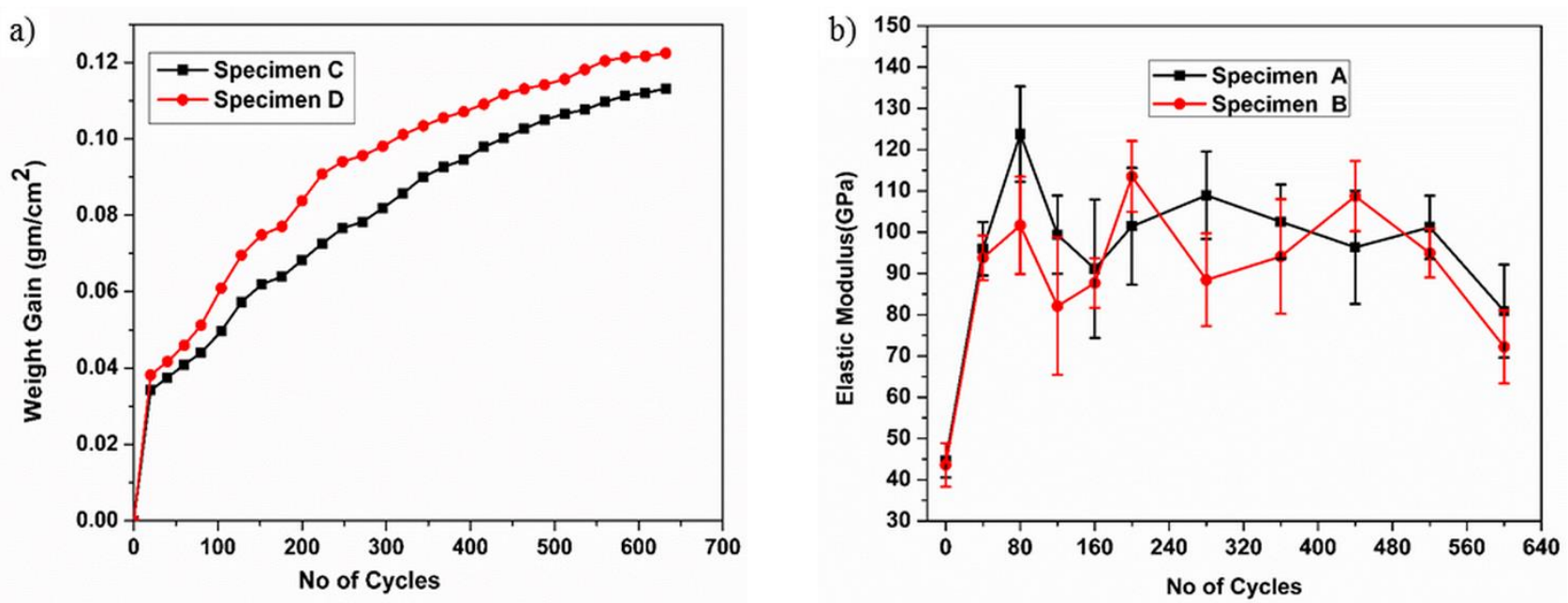

Fig. 4.21 Cyclic oxidation at $1100{ }^{\circ} \mathrm{C}$ in air: (a) weight gain, (b) microindentation stiffness response.

The performance of oxide scales developed on specimens A and B were investigated by microindentation technique having a capability of performing nondestructive testing. It was 
coupled with a multiple-partial unloading procedure during indentation process, resulting in a loaddepth sensing indentation system capable of determining elastic modulus of metallic alloys with flat, tubular, or curved architectures [117]. Test results showed consistent and correct elastic modulus values when performing indentation tests on standard alloys such as steel, aluminum, bronze, and single crystal superalloys having a precision with coefficient of variation less than $4.5 \%$.

Fig. 4.21(b) showed the variation in elastic modulus (E) of the specimens A and B. The results indicated three distinctive regimes in $\mathrm{E}$ values with the number of thermal cycles for both specimens. In the first regime an increase of $\mathrm{E}$ was observed for both specimens up to 100 thermal cycles and the longest and second regime with stable maximum values for about 400 thermal cycles, while the third regime where $\mathrm{E}$ was reducing after 500 cycles. Based on the microstructures of the ODS alloys in the as-sintered and after some thermal cycles it was observed precipitation strengthening by $\gamma^{\prime}-\mathrm{Ni}_{3} \mathrm{Al}$ formation. Additionally, particle size increase with thermal cyclic exposure could reduce the porosity due to sintering of ODS alloys and could be the reason for E to increase at the first regime. The stiffness response is constantly higher at the second regime for longer thermal cycles, indicating that the oxide scale has very good adherence to the ODS matrix in addition to the precipitation of the $\gamma^{\prime}$-phase $[101,135]$. However, the stiffness response starts to drop at latter stages beyond 500 thermal cycles of oxidation. This reduction could have an indication of oxide scale failure. However, the interface between oxide scale and ODS matrix were strongly adhered up to longer thermal cycles (600 cycles, Fig. 4.11(e)), albeit oxide scale surface rumpling was visually observed at mid-section of the specimens at this stage of oxidation which could happen due to compressive stresses developed [104] during repeated heating and cooling. Furthermore, yttrium presence on oxide scales at the beginning of oxidation in this study as oxide 
nodules, Fig. 13(a) indicated its depletion within the oxide scale to the top of the oxide layer [25] and the predominant growth of $\mathrm{NiO}$ as an outer oxide scale $[74,102,146]$ including this work, indicated the minimization of constituent elements from the ODS matrix with thermal cyclic exposure. Moreover, the increase growth of outer Ni-rich oxide scale on top of the alumina scale and minor oxide scale cracks with thermal cyclic exposure and residual stresses [147] due to thermal expansion mismatch during cooling could weaken the oxide-metal interfaces that potentially cause gentle rumpling and could be the reasons behind the stiffness response reduction. Yield strength which is proportional to $\mathrm{E}$ was reported to decrease with an increase in grain size [123] for nickel-based ODS alloy. Thus, particle coarsening of the matrix with thermal cyclic oxidation could also affect the strength of the oxide scale to which it adhered. Moreover, the differences in stiffness between specimen A with higher $\mathrm{E}$ and specimen B with lower E could be related to the differences in particle size of the matrix caused by the $60 \mathrm{~min}$ and $120 \mathrm{~min}$ sintering. Microhardness of Fe-based ODS alloys was also found to decrease with increase in heat treatment time at the same temperature $[20,148]$.

\subsection{Heat Transfer Analysis of ODS Alloy Coating with Micro-Channel Cooling System using}

\section{FEA}

\subsubsection{Geometry and Models}

Due to the need to increase the efficiency of modern power plants, land-based gas turbines are designed to operate at high temperature, as well as under harsh environments $[1,3,91]$. Table 7 lists the thermal load induced by high turbine inlet temperature (TIT), which will lead to immense challenge in maintaining material integrity of turbine components [149]. Future coal-based power generation systems would face new technical challenges in protecting turbine hot sections, particularly for intermediate pressure turbine (IPT) of the oxyfuel system when TIT reaches over 
$1750{ }^{\circ} \mathrm{C}[150]$ requiring efforts of developing high temperature substrate material, thermal barrier coatings (TBCs) with aerothermal cooling systems.

Table 7 Projected advanced turbine operating parameters [151]

\begin{tabular}{|c|c|c|}
\hline \hline & $\begin{array}{c}\text { Hydrogen Turbine } \\
2015\end{array}$ & $\begin{array}{c}\text { Oxy-Fuel Turbine } \\
2015\end{array}$ \\
\hline Turbine inlet temp., ${ }^{\circ} \mathrm{F}\left({ }^{\circ} \mathrm{C}\right)$ & $\sim 2600(1425)$ & $\sim 3200(1760)$ \\
\hline Turbine inlet pressure, $\mathrm{MPa}$ & $\sim 2.07$ & $\sim 4.3$ \\
\hline Combustor exhaust composition, & $\mathrm{CO}_{2}(1.4)$ & $\mathrm{CO}_{2}(25-10)$ \\
vol \% & $\mathrm{H}_{2} \mathrm{O}(17.3)$ & $\mathrm{H}_{2} \mathrm{O}(75-90)$ \\
& $\mathrm{N}_{2}(72.2)$ & $\mathrm{N} 2, \mathrm{Ar}, \mathrm{O}_{2}(1.7)$ \\
& $\mathrm{Ar}(0.9)$ & \\
& $\mathrm{O}_{2}(8.2)$ & \\
\hline
\end{tabular}

If the heat transfer on external surface of a turbine is determined, the temperature of metal substrate of the blade can also be determined [149] for a given internal cooling condition. For a numerical characterization of the external thermal loads over a turbine foil to be possible a solution of transport equations for mass, momentum and energy is required over the flow around the airfoil [150]. The main focus of this section is to study the performance of ODS alloy coating thermal protection capability by implementing micro-channel cooling systems and compare the results with typical TBC system configuration for a hydrogen-fired turbines TIT conditions, Table 7. Steady state thermal analysis is performed using the commercial finite element package ANSYS. Fig. 4.22 gives a schematic of the multilayer thermal protection system for the metal substrate (base material). Exterior to the base material are the bond coat and the ceramic outer layer (TBC system, Fig. 4.22(a)) and ODS alloy layer with micro-channel cooling system (ODS alloy, Fig. 4.22(b)). Table 8 and 9 list the properties of YSZ-based TBC and ODS alloy, respectively. In this simulation single crystal nickel-based superalloy CMSX-4 is used as a substrate material. 

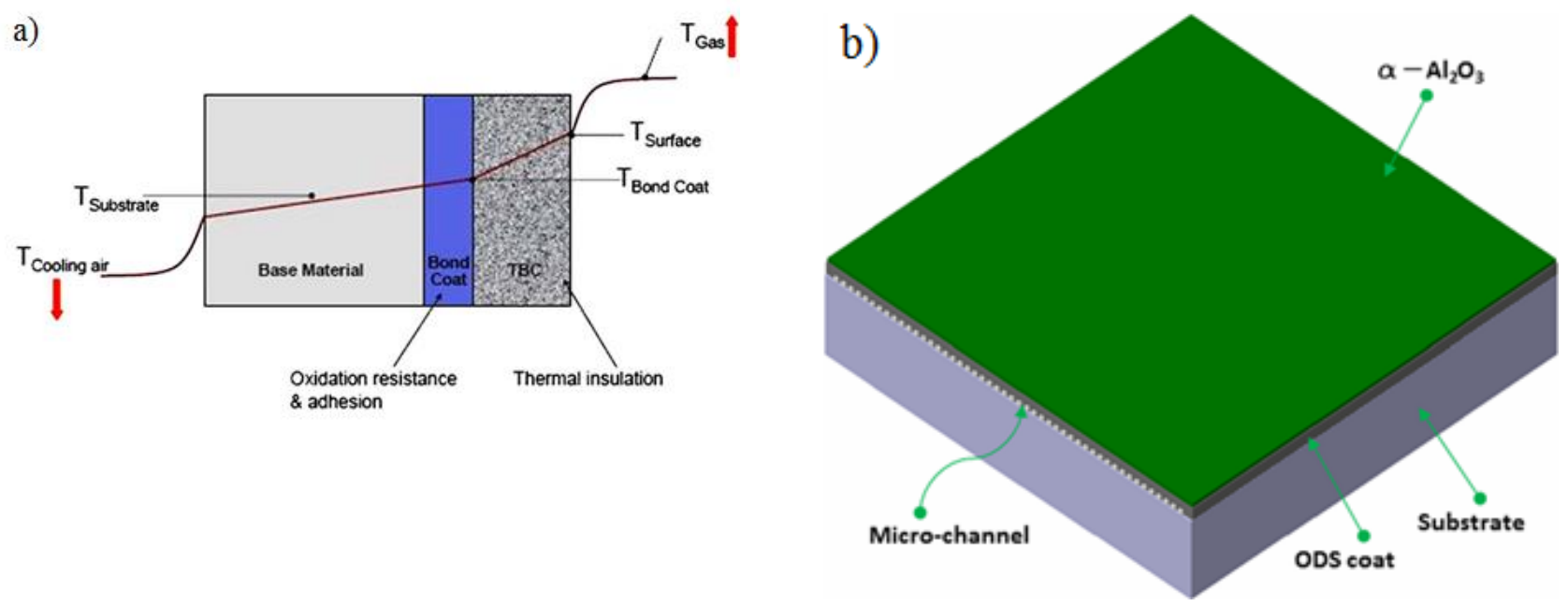

Fig. 4.22 Schematic of multilayer thermal and oxidation protection system: (a) TBC [145], (b) ODS alloy coating with micro-channel cooling.

Substrate temperature distribution with constant local surface heat transfer coefficient $\left(\mathrm{h}_{\mathrm{g}}\right)$ over external gas-side surfaces, obtained [149] using the commercial CFD code Fluent, and over all internal heat transfer coefficient $\left(\mathrm{h}_{\mathrm{c}}\right)$ over cooling passage walls of the model are imposed. This obviously is an approximation, as external gas-side heat transfer coefficient obtained from CFD analysis varies depending on the suction and pressure side contours and the internal heat transfer coefficient depends strongly on the actual surface enhancement and how the coolant flows inside the airfoil. Based on CFD analysis [149-150] for hydrogen-fired turbine and TBC systems of Table 8 at mid-span, the external heat transfer coefficient $\left(h_{g}\right)$ extreme values ranges from 2500 to 8500 $\mathrm{W} / \mathrm{m}^{2} \mathrm{~K}$ on both suction and pressure side, while internal heat transfer coefficient typically varies between $1000 \mathrm{~W} / \mathrm{m}^{2} \mathrm{~K}$ and $5000 \mathrm{~W} / \mathrm{m}^{2} \mathrm{~K}$, whereas the coolant inlet temperature ranges between $800 \mathrm{~K}\left(\sim 530{ }^{\circ} \mathrm{C}\right)$ and $1000 \mathrm{~K}\left(\sim 730{ }^{\circ} \mathrm{C}\right)$. The $\left(\mathrm{h}_{\mathrm{g}}\right)$ with values of $6000 \mathrm{~W} / \mathrm{m}^{2} \mathrm{~K}$ and gas-side temperature $\left(\mathrm{T}_{\mathrm{g}}\right)$ of $1700 \mathrm{~K}\left(\sim 1430{ }^{\circ} \mathrm{C}\right)$ and $\left(\mathrm{h}_{\mathrm{c}}\right)$ with values of $1000 \mathrm{~W} / \mathrm{m}^{2} \mathrm{~K}$ and coolant inlet temperature $\left(\mathrm{T}_{\mathrm{c}}\right)$ of $800 \mathrm{~K}\left(\sim 530^{\circ} \mathrm{C}\right)$ is used for both TBC and ODS alloy coating system in this study. 
Table 8 Thermal barrier coating properties [150]

\begin{tabular}{lll}
\hline Type & Thermal conductivity $(\mathrm{W} / \mathrm{m} \mathrm{K})$ & Thickness $(\mu \mathrm{m})$ \\
\hline TBC top coat & 0.9 & 250 \\
Thermal grown oxide & 0.9 & 10 \\
Bond coat & 1.7 & 100 \\
\hline
\end{tabular}

Table 9 ODS alloy coating system properties [150-152]

\begin{tabular}{lll}
\hline Type & Thermal conductivity (W/m K) & Thickness \\
\hline$\alpha-\mathrm{Al}_{2} \mathrm{O}_{3}$ & 0.9 & $10 \mu \mathrm{m}$ \\
ODS coat & 30 & $1 \mathrm{~mm}$ \\
CMSX-4 substrate & 35 & $3 \mathrm{~mm}$ \\
\hline
\end{tabular}

The boundary conditions are in such a way that on the TBC system, $\mathrm{h}_{\mathrm{g}}$ and $\mathrm{T}_{\mathrm{g}}$ are applied on the external surface at the top coat side and $h_{c}$ and $T_{c}$ is applied on the substrate side, Fig. 4.23 (a), while for ODS alloy coating system with micro-channel cooling system an additional $\mathrm{h}_{\mathrm{c}}$ and $\mathrm{T}_{\mathrm{c}}$ is applied inside the micro-channels. The model is meshed with SOLID87, 3-D 10-Node tetrahedral thermal solid element [153].

\subsubsection{Temperature Distribution in the Model and Substrate}

Fig. 4.23 illustrates the nodal temperature contour plots of TBC-coated substrate (b), ODS alloy coated substrate with micro-channel cooling system located at the edge of ODS alloy (c), and ODS alloy coated substrate with micro-channel cooling system located within ODS alloy (d). The plots indicated the maximum and minimum temperature distribution in the model, with the maximum temperature distribution observed on the TBC model and the minimum on the ODS alloy coated substrate with edge micro-channel cooling system. This temperature distribution 
should be within the creep dictated operating limit of substrate materials, such as, Rene/ N5 and CMSX-4, which is $1050{ }^{\circ} \mathrm{C}(1320 \mathrm{~K})-1150{ }^{\circ} \mathrm{C}(1420 \mathrm{~K})$.
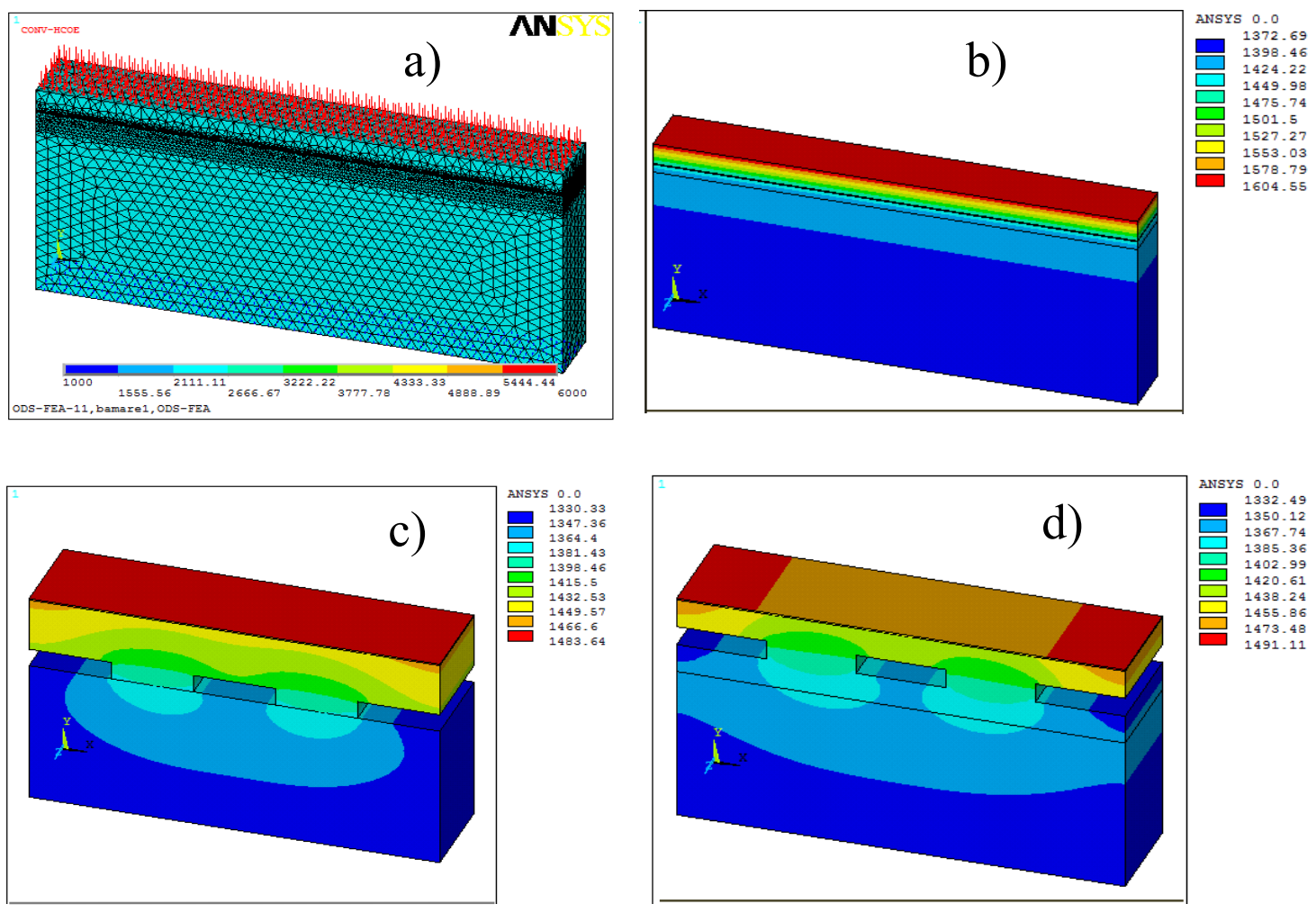

Fig. 4.23 Heat transfer analysis comparison of TBC systems and ODS alloy coating with microchannel cooling system: (a) model boundary condition, nodal temperature distribution (b) TBC systems, (c) micro-channel cooling located at the edge of ODS alloy, and (d) micro-channel cooling located within ODS alloy.

Fig. 4.24 illustrates the nodal temperature contour plots of the substrate for TBC system (a), ODS alloy coating without micro-channel cooling (b), ODS alloy coating with micro-channel cooling system located at the edge of ODS alloy (c), and ODS alloy coating with micro-channel cooling system located within ODS alloy (d) with a maximum substrate temperature $1405 \mathrm{~K}, 1543$ $\mathrm{K}, 1381 \mathrm{~K}$, and $1373 \mathrm{~K}$ respectively. The substrate of both ODS alloy coating with micro-channel cooling system received the smallest maximum temperature distribution. 


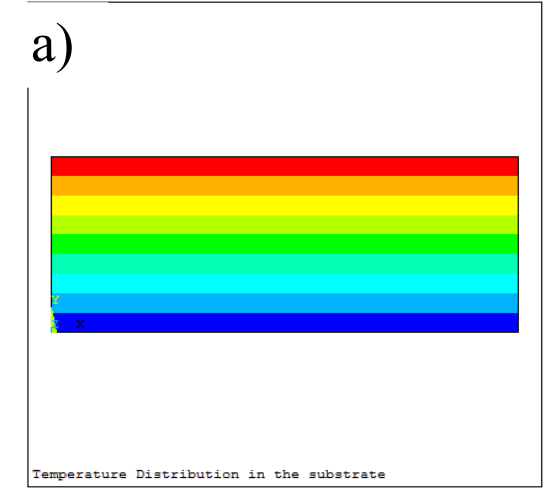

c)

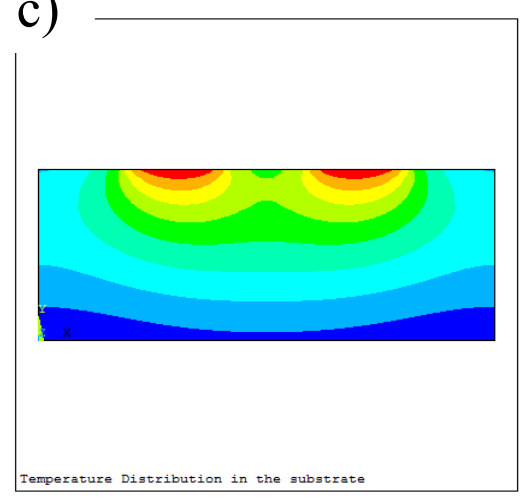

b)

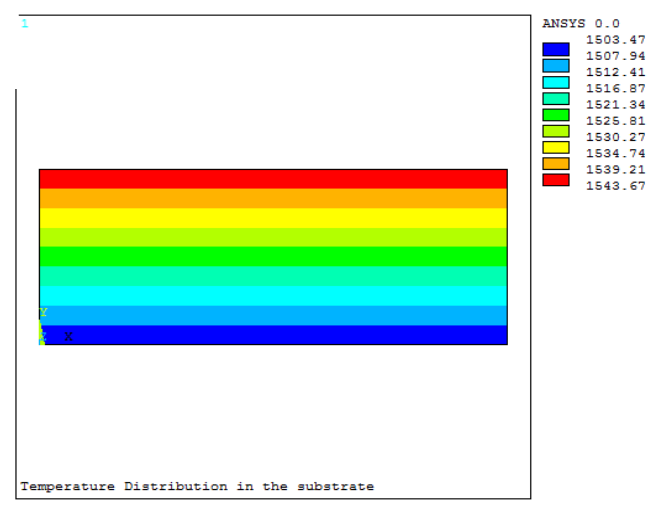

d)

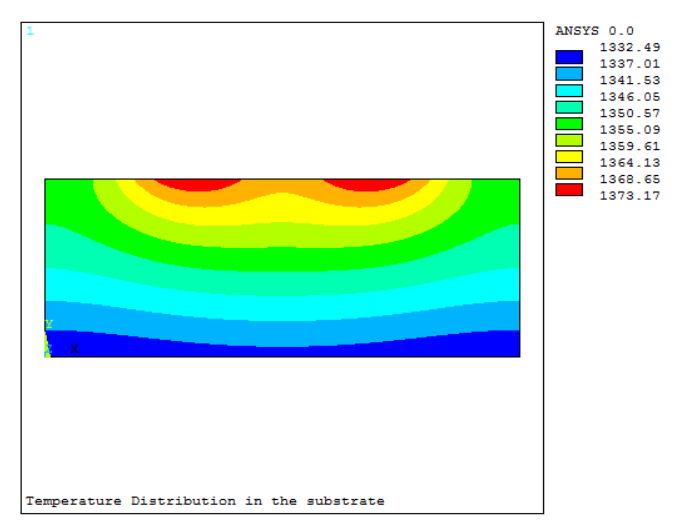

Fig. 4.24 Heat transfer analysis comparison of nodal temperature distribution in the substrate for TBC systems and ODS alloy coating with and without micro-channel cooling system: (a) TBC systems, (b) ODS alloy coating without micro-channel cooling (c) micro-channel cooling located at the edge of ODS alloy, and (d) micro-channel cooling located within ODS alloy.

Furthermore, the temperature distribution across the top surface of the substrate along the length and across the thickness of the model is plotted as show in Fig. 4.25(a) and (b), respectively. The effect of micro-channel cooling system has an insightful impact on the substrate temperature distribution. The ODS alloys model with micro-channel cooling system exhibited a reduced substrate temperature distribution regardless of the higher thermal conductivity compared with lower TBC thermal conductivity. Fig. 4.25 (a) shows an approximate of $30{ }^{\circ} \mathrm{C}$ difference between the TBC systems and ODS alloy coating with micro-channel cooling system. With the current simulation, the maximum substrate temperature for ODS alloy coating with micro-channel cooling 
system is approximately $1381 \mathrm{~K}\left(1108^{\circ} \mathrm{C}\right)$ for micro-channel cooling system located at the edge of ODS alloy, which is even lower for micro-channel cooling system located within ODS alloy, $1373 \mathrm{~K}\left(1100{ }^{\circ} \mathrm{C}\right)$. This value is within the dedicated operating limit of substrate materials and it is below the substrate temperature distribution of TBC systems, which is $1405 \mathrm{~K}\left(1132{ }^{\circ} \mathrm{C}\right)$. However, ODS alloy coating without micro-channel cooling system has higher substrate temperature distribution $1543 \mathrm{~K}\left(1270{ }^{\circ} \mathrm{C}\right)$, far above the substrate temperature limit.
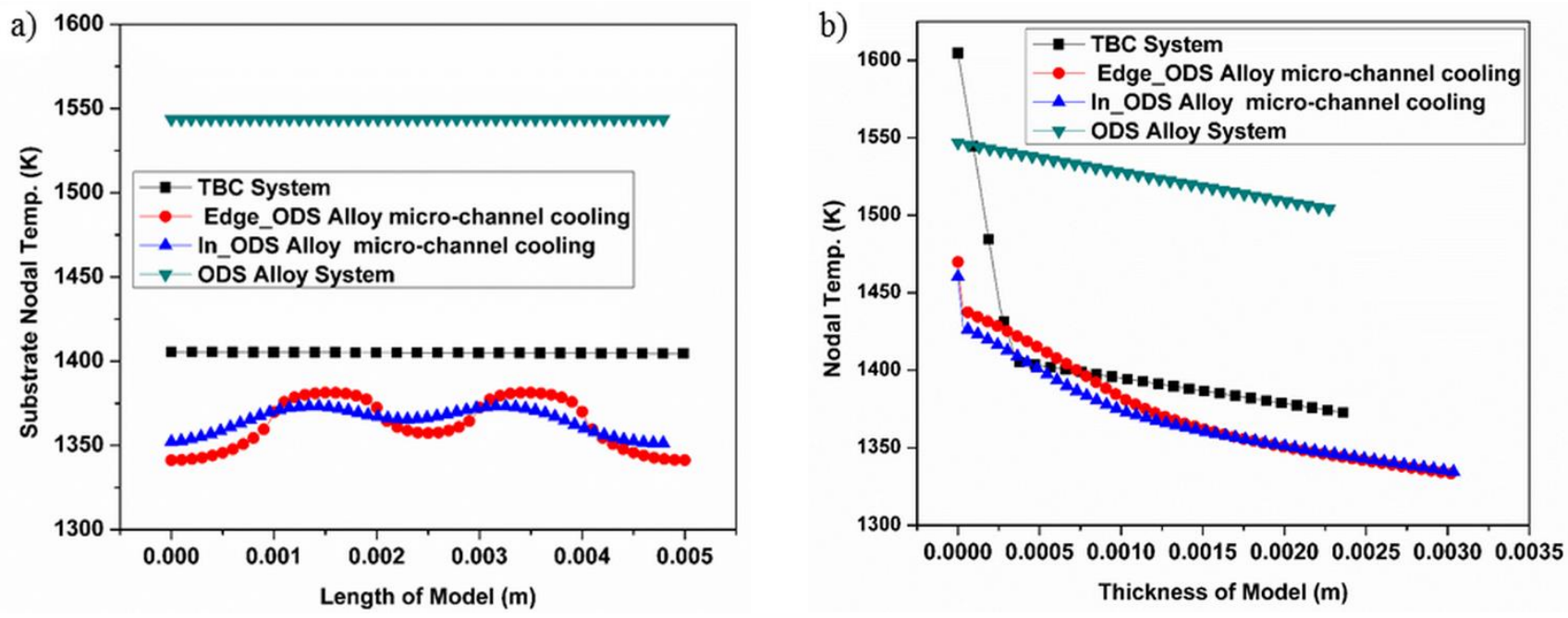

Fig. 4.25 Nodal temperature distribution plot: (a) along the substrate top, (b) across the model thickness.

Moreover, the temperature distribution across the thickness of the model, Fig. 4.25(b) indicated that the ODS alloy coating with micro-channel cooling system leads to a lower temperature differential from the outermost surface to the innermost wall. Specifically, for ODS alloy coating with micro-channel cooling system within ODS alloy, it is about $160{ }^{\circ} \mathrm{C}$, but for $\mathrm{TBC}$ system it is about $230{ }^{\circ} \mathrm{C}$. This greater temperature drop across the TBC system would induce additional thermal stress within the TBC layer, leading to TBC degradation [120].

Additional efforts were also addressed to establish the basis for enhanced stiffness response with extended high temperature cyclic testing of MCB plus ball milled ODS alloy systems in 
comparison to current/previously developed HVOF ODS alloy coating [154] and thermal barrier coating (TBC) systems [120] as a possible means of implementing these MCB plus ball milled ODS alloys as a structural high temperature coating on turbine blades by implementing microchannel cooling system beneath or within the coating [155]. In a similar test condition of this study, TBC systems [120] showed spallation failure after 400 thermal cycles, whereas oxide scales on MCB plus ball milled ODS alloy specimens were very adherent to the metal matrix without any spallation up to longer thermal cycles, more than 700 cycles. 


\section{CONCLUSIONS}

In this research work a combined mechano-chemical bonding (MCB) technique plus ball milling was used to homogenize nano-sized oxide in ODS powders and produce uniformly distributed ODS alloys. Initially, the powder samples were prepared by the MCB process and characterized using SEM, TEM, HRTEM and XRD. The results suggested that:

- the MCB processing enabled the hosting particles such as $\mathrm{Ni}$ and $\mathrm{Cr}$ particles to be coated with a nano-sized thin film containing elemental particles of $\mathrm{Y}_{2} \mathrm{O}_{3}$

- during MCB processing, the soft aluminum particles were subjected to deformation and fragmentation and randomly bonded onto the hosting particles or existed as discrete particles in the mixture

- small particle size of hosting powders such as $\mathrm{Cr}$ and $\mathrm{Ni}$ would improve the homogeneity of alloying powder mixture and help building up a smooth thin film around the hosting particles

- $\mathrm{MCB}$ process could transform crystalline nano-sized $\mathrm{Y}_{2} \mathrm{O}_{3}$ particles to an amorphous thin film bonded on the surfaces of host particles, causing the disappearance of $\mathrm{Y}_{2} \mathrm{O}_{3}$ peak in the XRD spectrum

The MCB processed powders were further processed by using ball milling to improve the distribution of discrete elements, such as aluminum to get uniform distributions through the alloys. Based on the MCB plus ball milling process it was observed that particle size to change through ball milling time. An optimum ball milling time of 40-60 hrs was deduced from the ball milling experiments in which this MCB plus ball milling technique has the capacity of reducing the typical ball milling time by about 10-30 hrs. Furthermore, the ODS powders processed by MCB plus ball milling were compacted by uniaxial pressing. The specimens were studied for microstructure, 
stiffness response of oxide scale, and phase evolution subjected to thermal cyclic exposure at 1100 ${ }^{\circ} \mathrm{C}$. The following observation were noted:

- the microstructures were found to be strengthened by $\gamma^{\prime}$-precipitates throughout the oxidation process

- a rapid increase in weight gain was observed at the beginning of the cycle and slow increase to the final cycles

- the elastic modulus showed three distinctive regimes with a maximum average value of about $100 \mathrm{GPa}$

- the increase in elastic modulus was found to be related to the precipitation strengthening by $\gamma^{\prime}-\mathrm{Ni}_{3} \mathrm{Al}$ formation and porosity reduction

- the reduction in stiffness response was related to oxide scale rumpling due to thermal expansion mismatch and minimization of constituent elements from the matrix through thermal cycle

- the oxide layer was found to be dominated by an outer $\mathrm{NiO}$ and an underneath $\alpha-\mathrm{Al}_{2} \mathrm{O}_{3}$ Moreover, the finite element analysis (FEA) performed to see the effectiveness of implementing ODS alloy coating with micro-channel cooling system was found to significantly influence on lowering the temperature profile along the substrate length and across the model thickness. Additionally, the temperature drop across the model thickness is lowered by implementing ODS alloy coating with micro-channel cooling system compared to the higher temperature drop by TBC systems. This lower temperature drop across the thickness of the model lowers the thermal stress within ODS alloy coating. 


\section{RECOMMENDATIONS FOR FURTHER WORK}

This work showed an explanatory and first time research done on MCB plus ball milled ODS alloys on their processing and thermal cyclic testing to investigate the mechanical and microstructure properties at high temperature in an air environment. One of the next work that can be performed on this ODS alloy system is investigating their performance in a thermo-chemical environment for understanding their combined corrosive and oxidation behaviors.

Moreover, in this work it was investigated the possibility of applying ODS alloy as a coating by implementing micro-channel cooling system using finite element methods (FEA). This is done in order to demonstrate the application of ODS alloy coatings without the use of TBC system to protect the underlying superalloy substrate in harsh high temperature environment. Thus, the second recommended and future work will be depositing this ODS alloy systems on typical superalloy substrate by implementing micro-channel cooling system within or beneath the ODS alloy system and investigate their adhesion behaviors along with high temperature oxidation and corrosion tests. The following outline could be a recommended method for achieving this goal, Fig. 6.1.

- superalloy substrate will be coated by patterned photoresist deposited by the principle of photolithography with the patterned size equivalent to the micro-channel cooling size

- ODS powder will be coated on the photoresist patterned superalloy substrate by using appropriate coating mechanism such as cold spray coating

- the ODS alloy coating on the substrate will be heat treated (sintered) at $1300-1350{ }^{\circ} \mathrm{C}$ in a tube furnace with reducing environment to prevent oxidation of the coating during the sintering process and this step will be expected to remove the photoresist layer, opening the micro-channel cooling system 
- the sintered ODS alloy coating with the micro-channel cooling system will be subjected to high temperature oxidation and corrosion testing at $1100{ }^{\circ} \mathrm{C}$

- mechanical and microstructure property evaluation of the ODS alloy coating with microchannel cooling system during and after thermal exposure will be performed
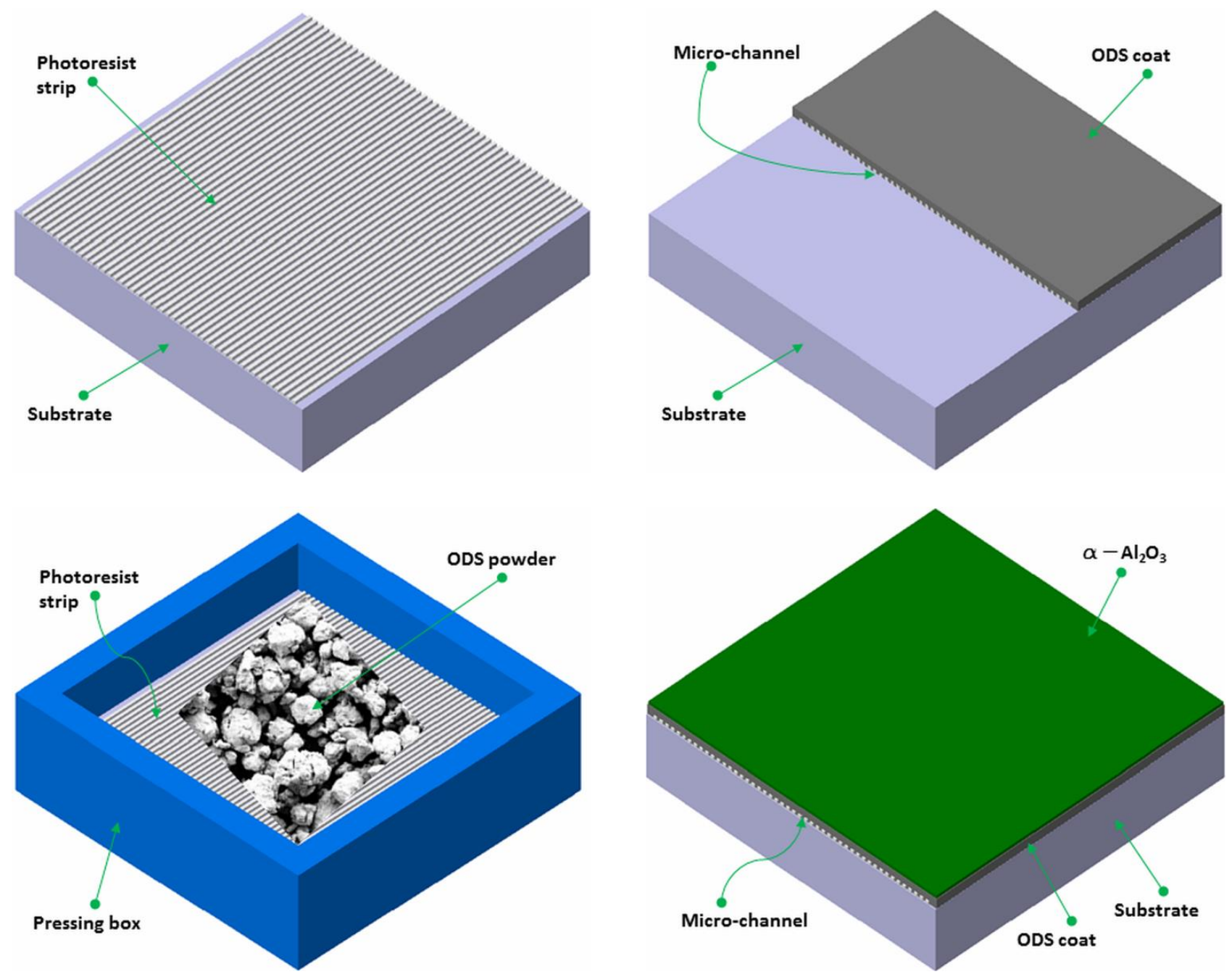

Fig 6.1 Schematic of implementing micro-channel cooling system using ODS alloy coating. 


\section{REFERENCES}

[1] Song, Peng. Influence of material and testing parameters on the lifetime of TBC systems with MCrAlY and NiPtAl bondcoats. Vol. 137. Forschungszentrum Jülich, 2012.

[2] Bischoff, Jeremy, and Arthur T. Motta. "Oxidation behavior of ferritic-martensitic and ODS steels in supercritical water." Journal of Nuclear Materials 424, no. 1 (2012): 261-276.

[3] Park, L. J., H. J. Ryu, S. H. Hong, and Y. G. Kim. "Microstructure and mechanical behavior of mechanically alloyed ODS Ni-base superalloy for aerospace gas turbine application." Advanced Performance Materials 5, no. 4 (1998): 279-290.

[4] Ukai, Shigeharu, and Masayuki Fujiwara. "Perspective of ODS alloys application in nuclear environments." Journal of Nuclear Materials 307 (2002): 749-757.

[5] Schäublin, R., A. Ramar, N. Baluc, V. De Castro, M. A. Monge, T. Leguey, N. Schmid, and C. Bonjour. "Microstructural development under irradiation in European ODS ferritic/martensitic steels." Journal of nuclear materials 351, no. 1 (2006): 247-260.

[6] Merceron, G., Régine Molins, Jean Loup Strudel, I. Alliat, and L. Menneron. "Long term oxidation of FeCrAl ODS alloys at high temperature." In Materials science forum, vol. 369, pp. 269-276. 2001.

[7] Glasgow, T. K., and G. J. Santoro. "Oxidation and hot corrosion of coated and bare oxide dispersion strengthened superalloy MA-755E." Oxidation of Metals 15, no. 3-4 (1981): 251-276.

[8] Wasilkowska, A., M. Bartsch, U. Messerschmidt, R. Herzog, and A. Czyrska-Filemonowicz. "Creep mechanisms of ferritic oxide dispersion strengthened alloys." Journal of materials processing technology 133, no. 1 (2003): 218-224.

[9] Ngala, W. O., and H. J. Maier. "Creep-fatigue interaction of the ODS superalloy PM 1000." Materials Science and Engineering: A 510 (2009): 429-433.

[10] Nagode, A., L. Kosec, B. Ule, and G. Kosec. "Review of creep resistant alloys for power plant applications." Metalurgija 50, no. 1 (2011): 45-48. 
[11] Türker, M. "The long-term oxidation behavior of ferritic ODS alloys at $1100-1200^{\circ} \mathrm{C}$ in air and nitrogen-2\% oxygen." Corrosion science 41, no. 10 (1999): 1921-1935.

[12] Scholz, R., and A. M. Morissey. "Determination of Creep Damage in the ODS Superalloy MA6000." Key Engineering Materials 99 (1995): 135-142.

[13] Iino, Y. "Effects of high-temperature air and vacuum exposure on tensile properties and fracture of ODS alloy MA6000." Materials Science and Engineering: A 234 (1997): 802-805.

[14] Angermann, H-H., K. Nishi, Y. Aono, M. Inagaki, and H. Kodama. "Evolution of oxides on Nibase ODS superalloys." Oxidation of metals 48, no. 1-2 (1997): 1-39.

[15] Aluru, Sreenivasa. "Microstructure-Mechanical Property Relationships in Transient Liquid Phase Bonded Nickel-Based Superalloys and Iron-based ODS Alloys." (2006).

[16] Klueh, R. L., J. P. Shingledecker, R. W. Swindeman, and D. T. Hoelzer. "Oxide dispersionstrengthened steels: A comparison of some commercial and experimental alloys." Journal of Nuclear Materials 341, no. 2 (2005): 103-114.

[17] Zhang, Lin, Xuanhui Qu, Xinbo He, Rafi-ud Din, Hengsan Liu, Mingli Qin, and Hongmin Zhu. "Microstructural Characterization of Co-Based ODS Alloys." Journal of Materials Engineering and Performance 21, no. 11 (2012): 2487-2494.

[18] Koch, C. C. "Materials synthesis by mechanical alloying." Annual review of materials science 19, no. 1 (1989): 121-143.

[19] Gilman, P. S., and J. S. Benjamin. "Mechanical alloying." Annual Review of Materials Science 13, no. 1 (1983): 279-300.

[20] Chen, C-L., and Y-M. Dong. "Effect of mechanical alloying and consolidation process on microstructure and hardness of nanostructured Fe-Cr-Al ODS alloys." Materials Science and Engineering: A 528, no. 29 (2011): 8374-8380. 
[21] Phasha, Maje, Kasonde Maweja, and Cornelius Babst. "Mechanical alloying by ball milling of Ti and Mg elemental powders: Operation condition considerations." Journal of Alloys and Compounds 492, no. 1 (2010): 201-207.

[22] Moyer, Kenneth H. An Improved Manufacturing Process for the Production of Higher Purity Superalloy Powders. Ft. Belvoir: Defense Technical Information Center, 1969.

[23] He, X. D., Y. Xin, M. W. Li, and Y. Sun. "Microstructure and mechanical properties of ODS Nibased superalloy foil produced by EB-PVD." Journal of Alloys and Compounds 467, no. 1 (2009): $347-350$.

[24] He, Ye-dong, Hong-mei Pang, Hui-bin Qi, De-ren Wang, Zheng-wei Li, and Wei Gao. "Microcrystalline Fe-Cr-Ni-Al- $\mathrm{Y}_{2} \mathrm{O}_{3}$ ODS alloy coatings produced by high frequency electric-spark deposition." Materials Science and Engineering: A 334, no. 1 (2002): 179-186.

[25] Weinbruch, S., A. Anastassiadis, H. M. Ortner, H. P. Martinz, and P. Wilhartitz. "On the mechanism of high-temperature oxidation of ODS superalloys: significance of yttrium depletion within the oxide scales." Oxidation of metals 51, no. 1-2 (1999): 111-128.

[26] Guttmann, V., José Luis González-Carrasco, and H. Fattori. "Oxidation behavior of ODS alloy MA 6000." Oxidation of metals 51, no. 1-2 (1999): 159-180.

[27] Maréchal, Laurent, Bernard Lesage, Anne-Marie Huntz, and Régine Molins. "Analytical study of the evolution of alumina scales formed on an ODS alloy." Materials at high temperatures 20, no. 3 (2003): 295-301.

[28] Quadakkers, W. J. "Growth mechanisms of oxide scales on ODS alloys in the temperature range 1000-1100 ${ }^{\circ}$ C." Materials and Corrosion 41, no. 12 (1990): 659-668.

[29] Schulz, Uwe, Christoph Leyens, Klaus Fritscher, Manfred Peters, Bilge Saruhan-Brings, Odile Lavigne, Jean-Marc Dorvaux, Martine Poulain, Remy Mévrel, and Michaël Caliez. "Some recent 
trends in research and technology of advanced thermal barrier coatings." Aerospace Science and Technology 7, no. 1 (2003): 73-80.

[30] Vecchione, N., K. Wasmer, D. S. Balint, and K. Nikbin. "Characterization of EB-PVD yttriumstabilised zirconia by nanoindentation." Surface and Coatings Technology 203, no. 13 (2009): 1743-1747.

[31] Padture, Nitin P., Maurice Gell, and Eric H. Jordan. "Thermal barrier coatings for gas-turbine engine applications." Science 296, no. 5566 (2002): 280-284.

[32] Chen, L. B. "Yttria-stabilized zirconia thermal barrier coatings-a review." Surface Review and Letters 13, no. 05 (2006): 535-544.

[33] Miller, Robert A. "Thermal barrier coatings for aircraft engines: history and directions." Journal of Thermal Spray Technology 6, no. 1 (1997): 35-42.

[34] Vaßen, Robert, Maria Ophelia Jarligo, Tanja Steinke, Daniel Emil Mack, and Detlev Stöver. "Overview on advanced thermal barrier coatings." Surface and Coatings Technology 205, no. 4 (2010): 938-942.

[35] Karger, M., R. Vaßen, and D. Stöver. "Atmospheric plasma sprayed thermal barrier coatings with high segmentation crack densities: Spraying process, microstructure and thermal cycling behavior." Surface and Coatings Technology 206, no. 1 (2011): 16-23.

[36] Chen, Dianying, Maurice Gell, Eric H. Jordan, Eric Cao, and Xinqing Ma. "Thermal stability of air plasma spray and solution precursor plasma spray thermal barrier coatings." Journal of the American Ceramic Society 90, no. 10 (2007): 3160-3166.

[37] Guo, Hongbo, Huibin $\mathrm{Xu}$, Xiaofang $\mathrm{Bi}$, and Shengkai Gong. "Preparation of $\mathrm{Al}_{2} \mathrm{O}_{3} \mathrm{YSZ}$ composite coating by EB-PVD." Materials Science and Engineering: A 325, no. 1 (2002): 389-393. 
[38] Wei, Qiuli, Hongbo Guo, Shengkai Gong, and Huibin Xu. "Novel microstructure of EB-PVD double ceramic layered thermal barrier coatings." Thin Solid Films 516, no. 16 (2008): 5736-5739.

[39] Toscano Alvarez, Juan Pablo. "Influence of composition and processing on the oxidation behavior of MCrAlY-coatings for TBC applications." PhD dissertation, Universitätsbibliothek, 2008.

[40] Di Ferdinando, Martina, Alessio Fossati, Alessandro Lavacchi, Ugo Bardi, Francesca Borgioli, Claudia Borri, Carlo Giolli, and Andrea Scrivani. "Isothermal oxidation resistance comparison between air plasma sprayed, vacuum plasma sprayed and high velocity oxygen fuel sprayed CoNiCrAlY bond coats." Surface and Coatings Technology 204, no. 15 (2010): 2499-2503.

[41] Mayoral, M. C., J. M. Andrés, M. T. Bona, V. Higuera, and F. J. Belzunce. "Aluminium depletion in NiCrAlY bond coatings by hot corrosion as a function of projection system." Surface and Coatings Technology 202, no. 9 (2008): 1816-1824.

[42] Hesnawi, A., Hefei Li, Zhaohui Zhou, Shengkai Gong, and Huibin Xu. "Isothermal oxidation behaviour of EB-PVD MCrAlY bond coat." Vacuum 81, no. 8 (2007): 947-952.

[43] Choi, Hanshin, Byounghyun Yoon, Hyungjun Kim, and Changhee Lee. "Isothermal oxidation of air plasma spray NiCrAlY bond coatings." Surface and Coatings Technology 150, no. 2 (2002): 297-308.

[44] Nijdam, T. J., and W. G. Sloof. "Microstructural evolution of a MCrAlY coating upon isothermal annealing." Materials Characterization 59, no. 12 (2008): 1697-1704.

[45] Baufeld, Bernd, and M. Schmücker. "Microstructural evolution of a NiCoCrAlY coating on an IN100 substrate." Surface and Coatings Technology 199, no. 1 (2005): 49-56.

[46] Vialas, Nadia, and Daniel Monceau. "Effect of Pt and Al content on the long-term, high temperature oxidation behavior and interdiffusion of a Pt-modified aluminide coating deposited on Ni-base superalloys." Surface and Coatings Technology 201, no. 7 (2006): 3846-3851. 
[47] Shirvani, K., S. Firouzi, and A. Rashidghamat. "Microstructures and cyclic oxidation behaviour of Pt-free and low-Pt NiAl coatings on the Ni-base superalloy Rene-80." Corrosion Science 55 (2012): 378-384.

[48] J.A. Haynes, B.A. Pint, Y. Zhang, I.G. Wright, "Comparison of the oxidation behavior of $\beta$ and $\gamma$ $\gamma^{\prime}$ NiPtAl coatings." Surface and Coatings Technology 204, no. 6-7 (2009):816-819

[49] J.A. Haynes, B.A. Pint, Y. Zhang, I.G. Wright, "Comparison of the cyclic oxidation behavior of $\beta$-NiAl, $\beta$-NiPtAl and $\gamma-\gamma^{\prime}$ NiPtAl coatings on various superalloys." Surface and Coatings Technology 202, no. 4-7 (2007):730-734

[50] Nicholls, J. R. "Designing oxidation-resistant coatings." JoM 52, no. 1 (2000): 28-35.

[51] Haynes, J. Allen, M. K. Ferber, and W. D. Porter. "Thermal cycling behavior of plasma-sprayed thermal barrier coatings with various MCrAlX bond coats." Journal of Thermal Spray Technology 9, no. 1 (2000): 38-48.

[52] Subanovic, M., P. Song, E. Wessel, R. Vassen, D. Naumenko, L. Singheiser, and W. J. Quadakkers. "Effect of exposure conditions on the oxidation of MCrAlY-bondcoats and lifetime of thermal barrier coatings." Surface and Coatings Technology 204, no. 6 (2009): 820-823.

[53] Tang, Feng, Leonardo Ajdelsztajn, George E. Kim, Virgil Provenzano, and Julie M. Schoenung. "Effects of surface oxidation during HVOF processing on the primary stage oxidation of a CoNiCrAlY coating." Surface and Coatings Technology 185, no. 2 (2004): 228-233.

[54] Heidloff, Andrew James, "Development of Pt-modified $\gamma-\mathrm{Ni}+\gamma^{\prime}-\mathrm{Ni}_{3} \mathrm{Al}$-based alloys for hightemperature applications" Graduate Theses and Dissertations, Paper 10855 (2009).

[55] Pollock, Tresa M., and Sammy Tin. "Nickel-based superalloys for advanced turbine engines: chemistry, microstructure and properties." Journal of propulsion and power 22, no. 2 (2006): 361374. 
[56] Harada, Hiroshi. "High temperature materials for gas turbines: the present and future." In International Gas Turbine Congress. 2003.

[57] Elzey, D. M., and E. Arzt. "Oxide Dispersion Strengthened Superalloys: The Role of Grain Structure and Dispersion during High Temperature Low Cycle Fatigue." The Metallurgical Society (1988).

[58] Heeg, Bauke, Vladimir K. Tolpygo, and David R. Clarke. "Damage Evolution in Thermal Barrier Coatings with Thermal Cycling." Journal of the American Ceramic Society 94, no. s1 (2011): s112-s119.

[59] Singh, Jitendra P., Balakrishnan G. Nair, Daniel P. Renusch, Manish P. Sutaria, and Marcus H. Grimsditch. "Damage evolution and stress analysis in zirconia thermal barrier coatings during cyclic and isothermal oxidation." Journal of the American Ceramic Society 84, no. 10 (2001): 2385-2393.

[60] A.C. Karaoglanli, E. Altuncu, I. Ozdemir, A. Turk, F. Ustel. "Structure and durability evaluation of $\mathrm{YSZ}+\mathrm{Al}_{2} \mathrm{O}_{3}$ composite TBCs with APS and $\mathrm{HVOF}$ bond coats under thermal cycling conditions." Surface and Coatings Technology 205 (2011): S369-S373.

[61] Rabiei, A., and A. G. Evans. "Failure mechanisms associated with the thermally grown oxide in plasma-sprayed thermal barrier coatings." Acta materialia 48, no. 15 (2000): 3963-3976.

[62] Sohn, Y. H., J. H. Kim, E. H. Jordan, and M. Gell. "Thermal cycling of EB-PVD/MCrAlY thermal barrier coatings: I. Microstructural development and spallation mechanisms." Surface and Coatings Technology 146 (2001): 70-78.

[63] Quadakkers, W. J., V. Shemet, D. Sebold, R. Anton, E. Wessel, and L. Singheiser. "Oxidation characteristics of a platinized MCrAlY bond coat for TBC systems during cyclic oxidation at 1000 ${ }^{\circ} \mathrm{C} . "$ Surface and Coatings Technology 199, no. 1 (2005): 77-82. 
[64] Ali, M. S., Shenhua Song, and Ping Xiao. "Degradation of thermal barrier coatings due to thermal cycling up to $1150^{\circ} \mathrm{C} . "$ Journal of materials science 37, no. 10 (2002): 2097-2102.

[65] Verhiest, Katelijne, A. Almazouzi, N. De Wispelaere, Roumen Petrov, and Serge Claessens. "Development of oxides dispersion strengthened steels for high temperature nuclear reactor applications." Journal of Nuclear Materials 385, no. 2 (2009): 308-311.

[66] Capdevila, Carlos, and Harry KDH Bhadeshia. "Manufacturing and microstructural evolution of mechanuically alloyed oxide dispersion strengthened superalloys." Advanced Engineering Materials 3, no. 9 (2001): 647-656.

[67] Kimura, A., R. Kasada, N. Iwata, H. Kishimoto, C. H. Zhang, J. Isselin, P. Dou et al. "Development of Al added high-Cr ODS steels for fuel cladding of next generation nuclear systems." Journal of Nuclear Materials 417, no. 1 (2011): 176-179.

[68] Bailey, P. G. "Manufacture and engine test of advanced oxide dispersion strengthened alloy turbine vanes." (1977).

[69] Wright, I. G., N. S. Bornstein, E. G. Dyadko, and S. N. Dryepondt. "Enabling the practical application of oxide dispersion-strengthened ferritic steels." In Proc. 20th Annual Conference on Fossil Energy Materials, Knoxville, Tennessee, 24th-26th April. 2006.

[70] Baker, I., B. Iliescu, J. Li, and H. J. Frost. "Experiments and simulations of directionally annealed ODS MA 754." Materials Science and Engineering: A 492, no. 1 (2008): 353-363.

[71] Sugino, Yoshito, Shigeharu Ukai, Shigenari Hayashi, Qingxin Tang, and Bin Leng. "Directional recrystallization of ODS alloys by means of zone annealing." Journal of Nuclear Materials 417, no. 1 (2011): 171-175.

[72] Miller, M. K., D. T. Hoelzer, E. A. Kenik, and K. F. Russell. "Stability of ferritic MA/ODS alloys at high temperatures." Intermetallics 13, no. 3 (2005): 387-392. 
[73] Wright, Ian G., and Bruce A. Pint. Overview of ODS alloy development. Oak Ridge National Laboratory (ORNL), 2005.

[74] Meyer, John. "Advanced gas atomization production of oxide dispersion strengthened (ODS) Nibase superalloys through process and solidification control." (2013).

[75] He, Y., Z. Huang, H. Qi, D. Wang, Z. Li, and W. Gao. "Oxidation behavior of micro-crystalline Ni-20Cr- $\mathrm{Y}_{2} \mathrm{O}_{3}$ ODS alloy coatings." Materials Letters 45, no. 2 (2000): 79-85.

[76] Xu, Yingli, Zhangjian Zhou, Ming Li, and Pei He. "Fabrication and characterization of ODS austenitic steels." Journal of Nuclear Materials 417, no. 1 (2011): 283-285.

[77] Dai, Lei, Yongchang Liu, and Zhizhong Dong. "Size and structure evolution of yttria in ODS ferritic alloy powder during mechanical milling and subsequent annealing." Powder Technology 217 (2012): 281-287.

[78] Kamal, Subhash, R. Jayaganthan, and S. Prakash. "High temperature cyclic oxidation and hot corrosion behaviours of superalloys at $900{ }^{\circ} \mathrm{C} . "$ Bulletin of Materials Science 33, no. 3 (2010): 299-306.

[79] Zhang, Lin, Xuanhui Qu, Xinbo He, Din Rafi-Ud, Mingli Qin, and Hongmin Zhu. "Hot deformation behavior of Co-base ODS alloys." Journal of Alloys and Compounds 512, no. 1 (2012): 39-46.

[80] Zhang, Lin, Shigeharu Ukai, Takeshi Hoshino, Shigenari Hayashi, and Xuanhui Qu. " $\mathrm{Y}_{2} \mathrm{O}_{3}$ evolution and dispersion refinement in Co-base ODS alloys." Acta Materialia 57, no. 12 (2009): $3671-3682$.

[81] Du Pasquier, Aurelien, C. C. Huang, and Timothy Spitler. "Nano $\mathrm{Li}_{4} \mathrm{Ti}_{5} \mathrm{O}_{12}-\mathrm{LiMn}_{2} \mathrm{O}_{4}$ batteries with high power capability and improved cycle-life." Journal of Power Sources 186, no. 2 (2009): 508-514. 
[82] Welham, Nicholas J., Paul E. Willis, and Tony Kerr. "Mechanochemical formation of metalceramic composites." Journal of the American Ceramic Society 83, no. 1 (2000): 33-40.

[83] Naito, Makio, Hiroya Abe, Akira Kondo, Toyokazu Yokoyama, and C. C. Huang. "Smart powder processing for advanced materials." KONA Powder and Particle Journal 27 (2009): 130-141.

[84] Alvin, M. A. "Materials and Component Development for Advanced Turbine Systems." In ASME Turbo Expo 2009: Power for Land, Sea, and Air, pp. 737-746. American Society of Mechanical Engineers, 2009.

[85] Ma, Longzhou, Bruce S-J. Kang, Mary A. Alvin, and C. C. Huang, "Characterization of OxideDispersion-Strengthened (ODS) Alloy Powders Processed by Mechano-Chemical-Bonding (MCB) and Balling Milling (BM)." KONA Powder Part J. 31 (2014):146-155.

[86] Odette, G. R., M. J. Alinger, and B. D. Wirth. "Recent developments in irradiation-resistant steels." Annu. Rev. Mater. Res. 38 (2008): 471-503.

[87] Put, Aurelie Vande, Sebastien Vande Dryepondt, and Bruce A. Pint. "Cyclic oxidation behavior of ODS FeCrAl alloys at high temperature in $\mathrm{H}_{2} \mathrm{O}$ and $\mathrm{CO}_{2}$ rich atmospheres." CORROSION 2011 (2011).

[88] Heilmaier, M., and F. E. H. Müller. "The role of grain structure in the creep and fatigue of Nibased superalloy PM 1000." JOM 51, no. 4 (1999): 23-27.

[89] Zinkle, Steven J. "Advanced materials for fusion technology." Fusion engineering and design 74, no. 1 (2005): 31-40.

[90] Yvon, P., and F. Carré. "Structural materials challenges for advanced reactor systems." Journal of Nuclear Materials 385, no. 2 (2009): 217-222. 
[91] El-Genk, Mohamed S., and Jean-Michel Tournier. "A review of refractory metal alloys and mechanically alloyed-oxide dispersion strengthened steels for space nuclear power systems." Journal of Nuclear materials 340, no. 1 (2005): 93-112.

[92] Oksiuta, Z., P. Olier, Y. De Carlan, and N. Baluc. "Development and characterisation of a new ODS ferritic steel for fusion reactor application." Journal of Nuclear Materials 393, no. 1 (2009): 114-119.

[93] Ukai, Shigeharu, and Masayuki Fujiwara. "Perspective of ODS alloys application in nuclear environments." Journal of Nuclear Materials 307 (2002): 749-757.

[94] Lindau, R., A. Möslang, M. Rieth, M. Klimiankou, E. Materna-Morris, A. Alamo, A-AF Tavassoli et al. "Present development status of EUROFER and ODS-EUROFER for application in blanket concepts." Fusion Engineering and Design 75 (2005): 989-996.

[95] Klimiankou, M., R. Lindau, and A. Möslang. "HRTEM study of yttrium oxide particles in ODS steels for fusion reactor application." Journal of crystal growth 249, no. 1 (2003): 381-387.

[96] Steckmeyer, A., Vargas Hideroa Rodrigo, J. M. Gentzbittel, V. Rabeau, and B. Fournier. "Tensile anisotropy and creep properties of a Fe-14CrWTi ODS ferritic steel." Journal of Nuclear Materials 426, no. 1 (2012): 182-188.

[97] Genes, D. S., R. J. Lobsinge, and W. F. Brown. "Fabrication Technological Development of the Oxide Dispersion Strengthened Alloy MA957 I for Fast Reactor Applications." (2000).

[98] Rowcliffe, Arthur F., Louis K. Mansur, David T. Hoelzer, and Randy K. Nanstad. "Perspectives on radiation effects in nickel-base alloys for applications in advanced reactors." Journal of Nuclear Materials 392, no. 2 (2009): 341-352.

[99] Ngala, W. O., and H. J. Maier. "Creep-fatigue interaction of the ODS superalloy PM 1000." Materials Science and Engineering: A 510 (2009): 429-433. 
[100] Neikov, Oleg D., Stanislav Naboychenko, Irina B. Mourachova, Victor G. Gopienko, Irina V. Frishberg, and Dina V. Lotsko. Handbook of non-ferrous metal powders: technologies and applications. Elsevier, 2009.

[101] Quadakkers, W. J. "Oxidation of ODS alloys." Le Journal de Physique IV 3, no. C9 (1993): C9177.

[102] Pint, B. A., A. J. Garratt-Reed, and L. W. Hobbs. "Analytical electron-microscopy study of the breakdown of $\alpha-\mathrm{A} 12 \mathrm{O} 3$ scales formed on oxide dispersion-strengthened alloys." Oxidation of metals 56, no. 1-2 (2001): 119-145.

[103] Tawancy, H. M., N. M. Abbas, A. I. Al-Mana, and T. N. Rhys-Jones. "Thermal stability of advanced Ni-base superalloys." Journal of materials science 29, no. 9 (1994): 2445-2458.

[104] Montealegre, M. A., José Luis González-Carrasco, M. A. Morris-Munoz, Jesús Chao, and David G. Morris. "The high temperature oxidation behaviour of an ODS FeAl alloy." Intermetallics 8, no. 4 (2000): 439-446.

[105] Prescott, R., and M. J. Graham. "The formation of aluminum oxide scales on high-temperature alloys." Oxidation of Metals 38, no. 3-4 (1992): 233-254.

[106] Zhu, Chao, Xiaoyu Wu, Yuan Wu, and Gongying Liang. "The Effect of Initial Oxidation on LongTerm Oxidation of NiCoCrAlY Alloy." Engineering 2, no. 08 (2010): 602.

[107] Estrin, Yuri, Martin Heilmaier, and Gemma Drew. "Creep properties of an oxide dispersion strengthened nickel-base alloy: the effect of grain orientation and grain aspect ratio." Materials Science and Engineering: A 272, no. 1 (1999): 163-173.

[108] Heilmaier, M., H. J. Maier, A. Jung, M. Nganbe, F. E. H. Müller, and H-J. Christ. "Cyclic stressstrain response of the ODS nickel-base, superalloy PM 1000 under variable amplitude loading at high temperatures." Materials Science and Engineering: A 281, no. 1 (2000): 37-44. 
[109] Kovan, Volkan, Joachim Hammer, Ronny Mai, and Mehmet Yüksel. "Thermal-mechanical fatigue behaviour and life prediction of oxide dispersion strengthened nickel-based superalloy PM1000." Materials Characterization 59, no. 11 (2008): 1600-1606.

[110] Tortorelli, P. F., S. R. J. Saunders, G. Shafirstein, and D. J. Hall. "Use of the mechanical properties microprobe for characteristics of oxide scales." Materials at high temperatures 12, no. 2-3 (1994): 95-101.

[111] González-Carrasco, José Luis, G. Ciapetti, M. A. Montealegre, S. Pagani, Jesús Chao, and N. Baldini. "Evaluation of mechanical properties and biological response of an alumina-forming Nifree ferritic alloy." Biomaterials 26, no. 18 (2005): 3861-3871.

[112] Yang, B., and H. Vehoff. "Dependence of nanohardness upon indentation size and grain size-a local examination of the interaction between dislocations and grain boundaries." Acta materialia 55, no. 3 (2007): 849-856.

[113] Liu, C., C. Yu, N. Hashimoto, S. Ohnuki, M. Ando, K. Shiba, and S. Jitsukawa. "Micro-structure and micro-hardness of ODS steels after ion irradiation." Journal of Nuclear Materials 417, no. 1 (2011): 270-273.

[114] Sniezewski, Julien, Vanessa Vidal, Philippe Lours, and Yannick Le Maoult. "Thermal barrier coatings adherence and spallation: Interfacial indentation resistance and cyclic oxidation behaviour under thermal gradient." Surface and Coatings Technology 204, no. 6 (2009): 807-811.

[115] Choi, W. B., L. Prchlik, S. Sampath, and A. Gouldstone. "Indentation of Metallic and Cermet Thermal Spray Coatings." Journal of thermal spray technology 18, no. 1 (2009): 58-64.

[116] Menčík, Jaroslav. "Determination of mechanical properties by instrumented indentation." Meccanica 42, no. 1 (2007): 19-29. 
[117] Feng, C., J. M. Tannenbaum, B. S. Kang, and M. A. Alvin. "A load-based multiple-partial unloading micro-indentation technique for mechanical property evaluation." Society for Experimental Mechanics 2009 50, no. NETL-TPR-2246 (2009).

[118] Feng, Chuanyu, and Bruce S. Kang. "A transparent indenter measurement method for mechanical property evaluation." Experimental mechanics 46, no. 1 (2006): 91-103.

[119] Kasada, Ryuta, Yoshiyuki Takayama, Kiyohiro Yabuuchi, and Akihiko Kimura. "A new approach to evaluate irradiation hardening of ion-irradiated ferritic alloys by nano-indentation techniques." Fusion Engineering and Design 86, no. 9 (2011): 2658-2661.

[120] Tannenbaum, Jared Michael. Progression in Non-Destructive Spallation Prediction and Elevated Temperature Mechanical Property Evaluation of Thermal Barrier Coating Systems by Use of a Spherical Micro-Indentation Method. West Virginia University, 2011.

[121] Lin, Xiu, Mingwei Li, Yesheng Zhong, Yijie Zhao, Yue Sun, Shuyuan Zhao, and Xiaodong He. "Microstructure and hardness of nanocrystalline ferritic ODS alloy foil with high oxide content fabricated by EBPVD." Applied Surface Science 284 (2013): 679-682.

[122] Pang, Hongmei, Huibin Qi, Yedong He, Deren Wang, and Zhengwei Li. "High-frequency electropulse deposition of microcrystallized MGH754 ODS alloy coatings." Science in China Series B: Chemistry 43, no. 5 (2000): 540-546.

[123] Chen, Song, Shoujiang Qu, Jun Liang, and Jiecai Han. "Effects of heat treatment on mechanical properties of ODS nickel-based superalloy sheets prepared by EB-PVD." Rare Metals 30, no. 1 (2011): 76-80.

[124] Liu, Xiu-Bo, Ge-Yan Fu, Shuang Liu, Shi-Hong Shi, Xiang-Ming He, and Ming-Di Wang. "High temperature wear and corrosion resistance of Co-free Ni-based alloy coatings on nuclear valve sealing surfaces." Nuclear Engineering and Design 241, no. 12 (2011): 4924-4928. 
[125] Kang, B., K. Ogawa, L. Ma, M. A. Alvin, N. Wu, and G. Smith. "Materials and component development for advanced turbine systems-ODS alloy development." In $23 \mathrm{rd}$ annual conference on fossil energy materials Pittsburgh, pp. 12-14. 2009.

[126] P. S. Gilman, and J. S. Benjamin. "Mechanical Alloying." Ann. Rev. Mater. Sci. 13, (1983): 279300.

[127] M.S.A. Karunaratne, C.M.F. Rae, and R.C. Reed, "On the Microstructural Instability of an Experimental Nickel-Based Single-Crystal Superalloy." Met. Trans. A, 32A, (2001): 2409-2421.

[128] Nicholas J. Welham, Paul E. Willis, and Tony Kerr. "Mechanochemical Formation of MetalCeramic Composites." J. Am. Ceram. Soc.83, (2000): 33-40.

[129] J.G. Nam and J.S. Lee. "Mechano-ChemicalSynthesis of Nanosized Stainless Steel Powder." Nano Structured Materials12, (1999): 475-478.

[130] Kang, Bruce S., Minking K. Chyu, Mary Anne Alvin, and Brian M. Gleeson. "Method of producing an oxide dispersion strengthened coating and micro-channels." U.S. Patent 8,609,187, issued December 17, 2013.

[131] Gu, Lijian, Binglin Zou, Xizhi Fan, Shuibing Zeng, Xiaolong Chen, Ying Wang, and Xueqiang Cao. "Oxidation behavior of plasma sprayed $\mathrm{Al} @ \mathrm{NiCr}$ with cyclic thermal treatment at different temperatures." Corrosion Science 55 (2012): 164-171.

[132] Frazier, William E. "Metal Additive Manufacturing: A Review." Journal of Materials Engineering and Performance 23, no. 6 (2014): 1917-1928.

[133] Vilaro, Thomas, Christophe Colin, and Jean-Dominique Bartout. "As-fabricated and heat-treated microstructures of the Ti-6Al-4V alloy processed by selective laser melting." Metallurgical and Materials Transactions A 42, no. 10 (2011): 3190-3199. 
[134] Przybylski, Kazimierz, A. J. Garratt-Reed, B. A. Pint, E. P. Katz, and G. J. Yurek. "Segregation of $\mathrm{Y}$ to grain boundaries in the $\mathrm{Al} 2 \mathrm{O} 3$ scale formed on an ODS alloy." Journal of the Electrochemical Society 134, no. 12 (1987): 3207-3208.

[135] Hotzler, Russel. "Recrystallization characteristics of oxide dispersion strengthened nickel-base alloys." superalloys 1980, proceedings of the forth international symposium on superalloys: 21 to 25 september 1980, seven springs Mountain Resort, Champion.

[136] Unocic, Kinga A., Chad M. Parish, and Bruce A. Pint. "Characterization of the alumina scale formed on coated and uncoated doped superalloys." Surface and Coatings Technology 206, no. 7 (2011): 1522-1528.

[137] Swadźba, R., L. Swadźba, J. Wiedermann, M. Hetmańczyk, and B. Witala. "Characterization of Alumina Scales Grown on a 2nd Generation Single Crystal Ni Superalloy during Isothermal Oxidation at 1050, 1100 and $1150^{\circ}$ C." Oxidation of Metals 82, no. 3-4 (2014): 195-208.

[138] Wu, Y., X. W. Li, G. M. Song, Y. M. Wang, and T. Narita. "Improvement of the Oxidation Resistance of the Single-Crystal Ni-Based TMS-82+ Superalloy by Ni-Al Coatings with/without the Diffusion Barrier." Oxidation of metals 74, no. 5-6 (2010): 287-303.

[139] Aprigliano, Louis F. "Nickel oxide, ceramic insulated, high temperature coating." U.S. Patent 4,639,399, issued January 27, 1987.

[140] Lewis, F. B., and N. H. Saunders. "The thermal conductivity of $\mathrm{NiO}$ and $\mathrm{CoO}$ at the Neel temperature." Journal of Physics C: Solid State Physics 6, no. 15 (1973): 2525.

[141] www.accuratus.com, 94\% Alumina Material Properties

[142] http://www.specialmetals.com/documents/Inconel\%20alloy\%20MA754.pdf 
[143] Evans, Anthony Glyn, D. R. Mumm, J. W. Hutchinson, G. H. Meier, and F. S. Pettit. "Mechanisms controlling the durability of thermal barrier coatings." Progress in materials science 46, no. 5 (2001): 505-553.

[144] Suo, Z. "Wrinkling of the oxide scale on an aluminum-containing alloy at high temperatures." Journal of the Mechanics and Physics of Solids 43, no. 6 (1995): 829-846.

[145] Pint, Bruce A. "Optimization of Reactive-Element Additions to Improve Oxidation Performance of Alumina-Forming Alloys." Journal of the American Ceramic Society 86, no. 4 (2003): 686-95.

[146] Georgia Obigodi-Ndjeng, High temperature oxidation and electrochemical investigations on nickel-base alloys, Doctoral Thesis, 2011.

[147] Liu, Chun, Anne-Marie Huntz, and Jean-Lou Lebrun. "Origin and development of residual stresses in the Ni-NiO system: in-situ studies at high temperature by X-ray diffraction." Materials Science and Engineering: A 160, no. 1 (1993): 113-126.

[148] Rieken, Joel, Iver Anderson, and Matthew Kramer. Innovative Powder Processing of Oxide Dispersion Strengthened ODS Ferritic Stainless Steels. No. IS-M 963. Ames Laboratory (AMES), Ames, IA (United States), 2011.

[149] Chyu, Minking K., Danny W. Mazzotta, Sean C. Siw, Ventzislav G. Karaivanov, William S. Slaughter, and Mary Anne Alvin. "Aerothermal challenges in syngas, hydrogen-fired, and oxyfuel turbines-part I: Gas-side heat transfer." Journal of Thermal Science and Engineering Applications 1, no. 1 (2009): 011002.

[150] Chyu, Minking K., Sean C. Siw, Ventzislav G. Karaivanov, William S. Slaughter, and Mary Anne Alvin. "Aerothermal challenges in syngas, hydrogen-fired, and oxyfuel turbines-part II: Effects of internal heat transfer." Journal of Thermal Science and Engineering Applications 1, no. 1 (2009): 011003. 
[151] Karaivanov, Ventzislav G., Sean Siw, Minking K. Chyu, William S. Slaughter, and Mary Anne Alvin. "Substrate Damage Modeling for Advanced Turbine System Airfoils." In ASME Turbo Expo 2009: Power for Land, Sea, and Air, pp. 309-317. American Society of Mechanical Engineers, 2009.

[152] Haynes, J. A., B. A. Pint, W. D. Porter, and I. G. Wright. "Comparison of thermal expansion and oxidation behavior of various high-temperature coating materials and superalloys." Materials at high temperatures 21, no. 2 (2004): 87-94.

[153] ANSYS User's Manual, Swanson Analysis Systems Inc., Vols. I, II, III, and IV, Revisions 5.0

[154] Alvin, M. A., J. Klinger, B. McMordie, M. Chyu, S. Siw, N. Miller, B. V. K. Reddy et al. "NETL Research Efforts on Development and Integration of Advanced Material Systems and Airfoil Cooling Configurations for Future Land-Based Gas Turbine Engines." In ASME Turbo Expo 2014: Turbine Technical Conference and Exposition, pp. V006T22A006-V006T22A006. American Society of Mechanical Engineers, 2014.

[155] Kang, Bruce S., Minking K. Chyu, Mary Anne Alvin, and Brian M. Gleeson. "Method of producing an oxide dispersion strengthened coating and micro-channels." U.S. Patent 8,609,187, issued December 17, 2013.

[156] Belachew N. Amare, Bruce S.-J. Kang, and Mary Anne Alvin. "Thermal Cyclic Oxidation of Nickel based ODS alloy."American Ceramic Society's Ceramic Transactions (CT), $\mathbf{x x x}(\mathrm{xxxx})$ $\mathrm{XXX}-\mathrm{XxX}$ 